\title{
Fluid Performance in Coal Reservoirs: A Comprehensive Review
}

\author{
Changjing Gao $\mathbb{D},,^{1,2}$ Dameng Liu $\mathbb{D},,^{1,2}$ Zhentao Li $\mathbb{D},,^{1,2}$ Yidong Cai $\mathbb{D}^{1,2}$ and Yufeng Fang $^{3}$ \\ ${ }^{1}$ School of Energy Resources, China University of Geosciences, Beijing 100083, China \\ ${ }^{2}$ Coal Reservoir Laboratory of National Engineering Research Center of CBM Development \& Utilization, China University \\ of Geosciences, Beijing 100083, China \\ ${ }^{3}$ The Tenth Oil Production Plant of PetroChina Changqing Oilfield Branch Company, Qingyang, 745100 Gansu, China
}

Correspondence should be addressed to Dameng Liu; dmliu@cugb.edu.cn

Received 30 December 2020; Revised 3 March 2021; Accepted 10 March 2021; Published 2 April 2021

Academic Editor: Giovanni Mongelli

Copyright $@ 2021$ Changjing Gao et al. This is an open access article distributed under the Creative Commons Attribution License, which permits unrestricted use, distribution, and reproduction in any medium, provided the original work is properly cited.

\begin{abstract}
The fluids in coal reservoirs mainly consist of different gases and liquids, which show different physical properties, occurrence behaviors, and transport characteristics in the pore-fracture system of coal. In this study, the basic characteristics of fluids in coal reservoirs are firstly reviewed, consisting of coalbed methane (CBM) components and physical properties of CBM/coalbed water. The complex pore-fracture system mainly provides the enrichment space and flow path for fluids, which have been qualitatively and quantitatively characterized by various methods in recent years. Subsequently, this study has summarized CBM adsorption/desorption behaviors and models, the CBM diffusion-seepage process and models, and gas-water two-phase flow characteristics of coal reservoirs. Reviewed studies also include the effects of internal factors (such as coal metamorphism, petrographic constituents, macroscopic types, and pore structure) and external factors (such as pressure, temperature, and moisture content) on CBM adsorption/desorption and diffusion behaviors, and the relationship between three main effects (effective stress, gas slippage effect, and coal matrix shrinkage effect) and the CBM seepage process. Moreover, we also discuss in depth the implication of fluid occurrence and transport characteristics in coal reservoirs for CBM production. This review is aimed at proposing some potential research directions in future studies, which mainly includes the control mechanism of the microscopic dynamics of fluids on CBM enrichment/storage; enhancing CBM desorption/seepage rate; and the synergistic effect of multiple spaces, multilevel flow fields, and multiphase flow in coal reservoirs. From this review, we have a deeper understanding of the occurrence and transport characteristics of fluids in pore-fracture structures of coal and the implication of fluid performance for CBM production. The findings of this study can help towards a better understanding of gas-water production principles in coal reservoirs and enhancing CBM recovery.
\end{abstract}

\section{Introduction}

Coal is one of the most widely available energy sources with a huge world consumption, which is formed from the remains of ancient organisms through deep burial and coalification under the conditions of incredible heat and pressure (Figure 1(a)) [1-3]. It is estimated that the global methane reserves in coal seams can be up to $269 \times 10^{12} \mathrm{~m}^{3}$, which constrains production safety in coal mines and contributes significantly to greenhouse gas emissions [4]. From the last century, United States, Canada, and Australia have carried out extensive exploration and commercial exploitation of the CBM resource in multiple coal-bearing basins, such as San Juan Basin, Black Warrior Basin, Bowen Basin, and Surat Basin [5-9]. Due to the complex geological conditions of coal-bearing basins and primitive CBM development technology, the CBM commercial exploitation process is comparatively slow in China even though the total CBM amount is proven as high as $36.81 \times 10^{12} \mathrm{~m}^{3}[10,11]$. Since 2002, a breakthrough of CBM development has been made in the medium-high-rank coal reservoirs, and several large-scale CBM fields have been built in the southern Qinshui Basin and eastern margin of Ordos Basin, China [12-15]. The efficient development and utilization of CBM are of great 


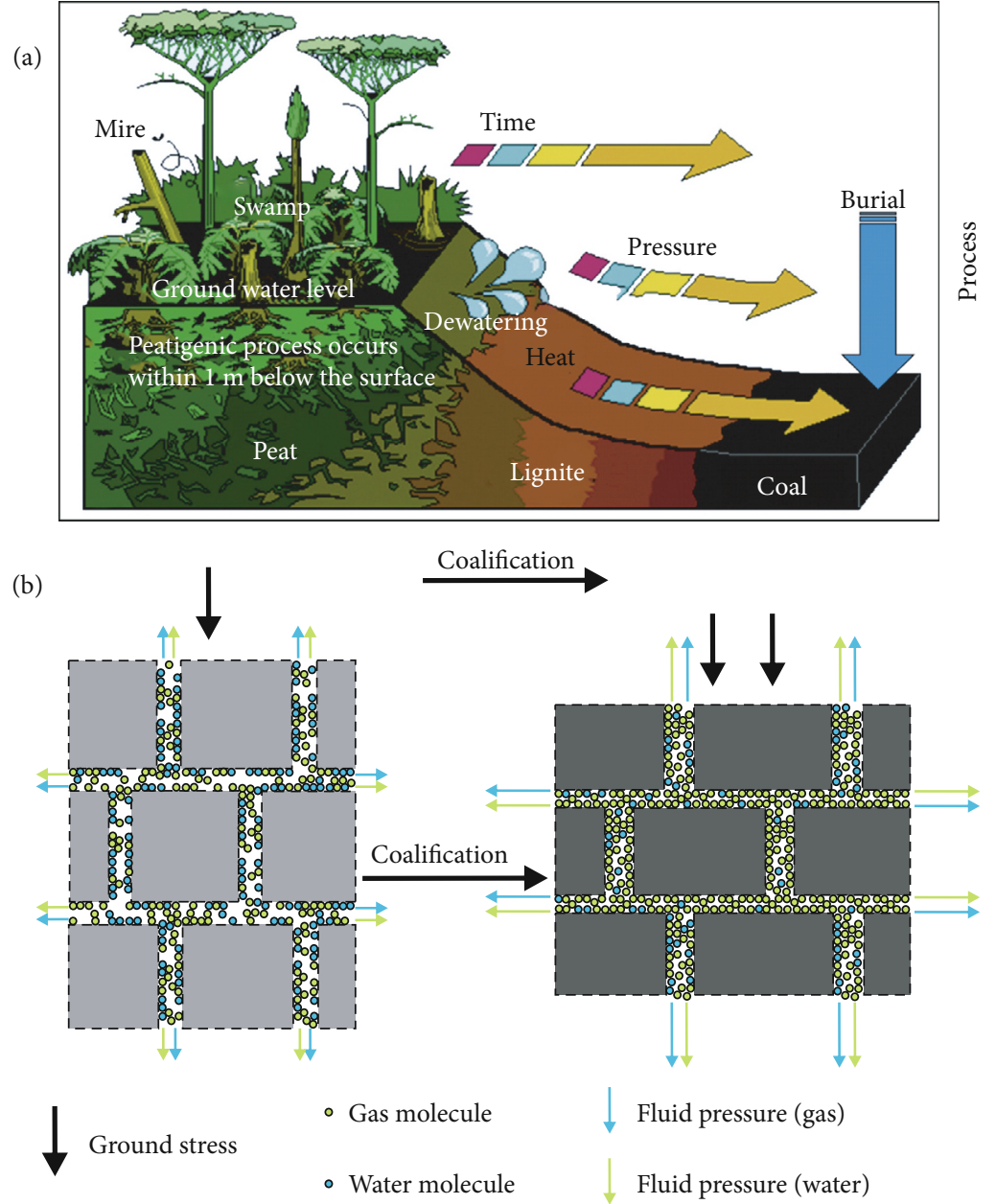

Figure 1: The diagram of the coalification process and fluid performance in coal reservoirs (modified from Greb et al. [1]).

significance to reverse the situation of coal mine safety production, improve the energy structure, and alleviate the natural gas supply shortfall.

During the process of coalification, complex physical and chemical changes occur in coal-forming materials, which demonstrates the decrease of volatile fraction and water content, the increase of calorific value and fixed carbon content, and also the generation of fluids accompanied with methane as main components in coals (Figure 1(b)) $[16,17]$. CBM mostly exists in the pore surface as the adsorbed state in a coal matrix and in the cleat/fracture system as the free state, whereas ground water is generally replenished into the coal seam and mainly migrates through the cleat/fracture system under reservoir pressure [18]. The pore structure of coals is characterized as a dual pore system consisting of micropores $(<10 \mathrm{~nm})$ and mesopores $\left(10-10^{2} \mathrm{~nm}\right)$ that provide a large pore surface area for CBM storage, and macropores/microfractures $\left(>10^{2} \mathrm{~nm}\right)$ that supply the pathway for CBM flow [19-21]. During the CBM production process, the reservoir pressure gradually decreases as the water in the coalbed is drained, and CBM desorbs from the pore surface and diffuses to the cleat/fracture system accompanied by an increase in effective stress and coal matrix shrinkage as gas desorbs [5,
22]. The increase of effective stress may cause the original pores and fractures to partially close, which can further result in a decrease in the porosity and permeability of coals [23], whereas the coal matrix shrinkage effect may lead to the cleat/fracture opening and an increase in permeability $[24,25]$. Therefore, the occurrence and flow characteristics of fluids (CBM and water) in the pore-fracture system of coal reservoirs have a significant implication for understanding the CBM production characteristics and enhancing $\mathrm{CBM}$ recovery.

As shown in the general sketch in Figure 2, we firstly provided an overview of the basic characteristics of fluids in coal reservoirs, including the component characteristics of CBM and the physical properties of fluids in coal reservoirs. Secondly, different characterization methods of a pore-fracture structure were reviewed, and the characteristics and modelling of fluid occurrence and transport in coal reservoirs were expounded in detail. Moreover, the influencing factors of CBM adsorption/desorption and diffusion behaviors and the fluid seepage process were analyzed. Finally, we also studied the implications of fluid occurrence and transport characteristics for CBM production, and proposed three key scientific problems to be solved in future studies. Compared with 


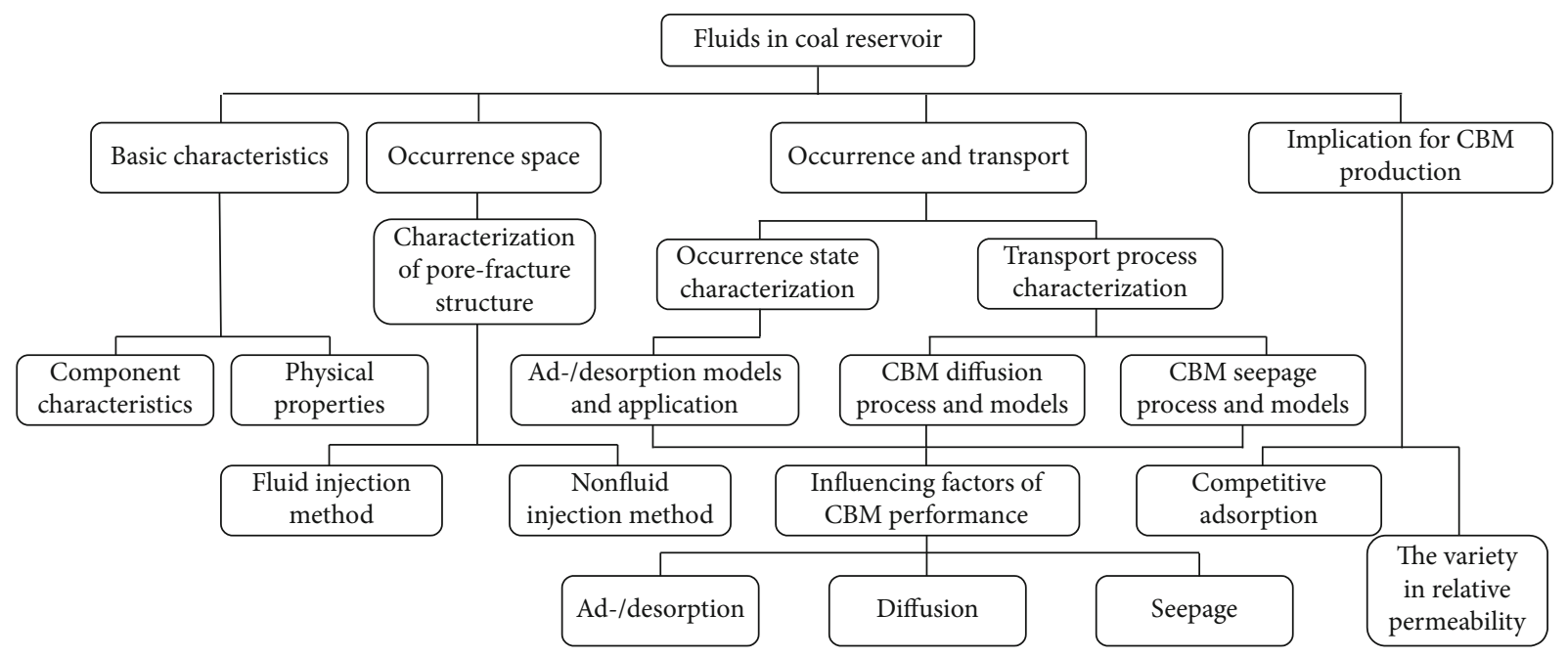

FIGURE 2: The general sketch of fluid performance in coal reservoirs.

previous studies, a comprehensive summary of different fluids in coal reservoirs has been made in this study, including occurrence properties, storage/transport characteristics, and their influencing factors. Meanwhile, the effects of fluid performance on CBM production characteristics have also been thoroughly summarized.

\section{Basic Characteristics of Fluids in Coal Reservoirs}

Fluids occurring in coal reservoirs mainly consist of CBM generated by coalification and water originating from adjacent strata $[16,17,26]$. The physical properties of fluids in coal reservoirs can be characterized by inertia, density, specific volume, compressibility, modulus of elasticity, thermal expansion, viscosity, and the surface tension/capillary phenomenon [27]. Moreover, the chemical properties of fluids mainly consist of their components, the determination and distribution of main ion concentration, and the plane distribution of $\mathrm{pH}$ value and its controlling factors [28]. Due to the special occurrence status and properties of fluids in coal, there is a special fluid-solid coupling state between fluids and the coal matrix.

2.1. Component Characteristics of CBM. The components of CBM mainly consist of hydrocarbon gases $\left(\mathrm{CH}_{4}\right.$ and its congeners) and nonhydrocarbon gases $\left(\mathrm{CO}_{2}, \mathrm{~N}_{2}, \mathrm{H}_{2}, \mathrm{CO}\right.$, $\mathrm{H}_{2} \mathrm{~S}, \mathrm{He}$, and $\mathrm{Ar}$ ). It is known that the main factors controlling the components of CBM are (1) microscopic components of coal, especially the abundance of hydrogen-rich components; (2) the degree of coal metamorphism; and (3) hydrogeological conditions, which affect the components of CBM by transporting the bacterial (biogenic) gas and dissolved gas [29]. For hydrocarbons, the $\mathrm{CH}_{4}$ content is generally greater than $80 \%$, and the content of the other hydrocarbons $\left(\mathrm{C}_{2+}\right)$ is comparatively smaller in CBM. It has been confirmed that the content of hydrocarbons increases with the increase burial depth in the same coal seam [17], whereas heavy hydrocarbons are mostly dis- tributed below the oxidation zone of the coal seam and its content depends on the degree of coal metamorphism (medium - rank coals > low - and high - rank coals) [28]. Moreover, the content of nonhydrocarbon gases is typically less than $20 \%$ of the total CBM content in which the $\mathrm{N}_{2}$ content accounts for about $2 / 3$ and the $\mathrm{CO}_{2}$ content approximately occupies another $1 / 3$ [5]. The $\mathrm{N}_{2}$ molecule is small and moves quickly, and it is mainly influenced by the weight of overlying strata [17]. In contrast, $\mathrm{CO}_{2}$ is easily soluble and taken away by groundwater, and its content is mainly controlled by groundwater activities [30]. Similarly, the content of $\mathrm{N}_{2}$ and $\mathrm{CO}_{2}$ is also influenced by the burial depth of the coal seam and the degree of coal metamorphism [17]. Generally speaking, the content of $\mathrm{N}_{2}$ and $\mathrm{CO}_{2}$ in $\mathrm{CBM}$ is higher when the burial depth of the coal seam is shallower or the degree of coal metamorphism is higher.

As the coalification deepens, biogenic gas and thermogenic gas are successively generated in coals, and the content of biogenic gas is much lower than that of thermogenic gas, as shown in Figure 3. For the same basin, the CBM in a shallow coal seam may be mainly the biogenic gas, whereas the CBM in a deep coal seam is dominated by the thermogenic gas [29]. The differences in generation time, formation temperature and pressure, the parent material, composition, and generation mechanism (presence of bacterial activity) of biogenic gas are quite different from those of thermogenic gas [31]. Biogenic gas is produced by $\mathrm{CO}_{2}$ reduction and organic acid fermentation, and its $\delta^{13} \mathrm{C}_{1}$ value is usually low $(-55 \%$ o $-90 \%$ ) because of the enrichment effect of organisms on ${ }^{12} \mathrm{C}$. In general, the biogenic gas generated by $\mathrm{CO}_{2}$ reduction has a light carbon isotope and is rich in deuterium, whereas the biogenic gas generated by the organic acid fermentation shows a heavier carbon isotope and consumes deuterium [5]. It is worth noting that the $\delta^{13} \mathrm{C}_{1}$ value of biogenic gas produced by $\mathrm{CO}_{2}$ reduction is related to the $\delta^{13} \mathrm{C}_{1}$ value of the $\mathrm{CO}_{2}$ matrix and formation water. Compared to biogenic gas, thermogenic gas demonstrates the following characteristics: (1) heavy hydrocarbons are generally found in high/medium volatile bituminous coals and other 


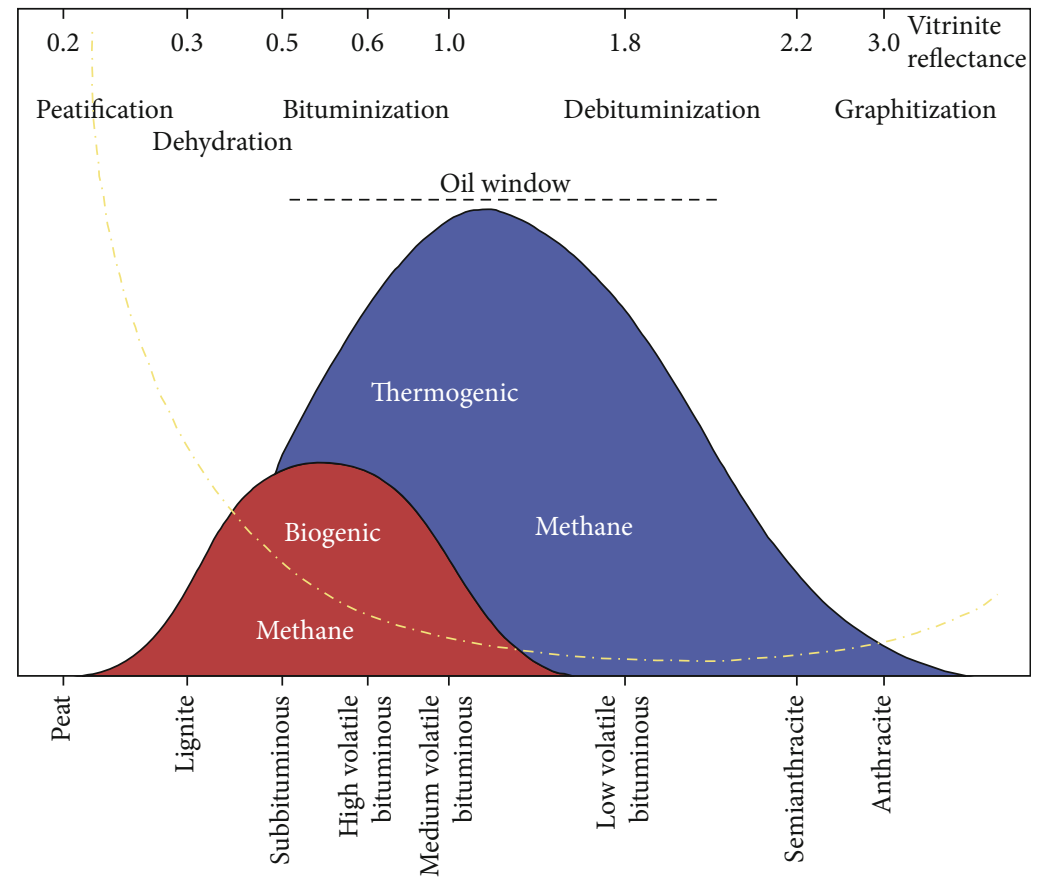

FIGURE 3: Schematic showing the generation characteristics of biogenic and thermogenic gas, and their relationship with coal rank, moisture content, and vitrinite reflectance (modified from Moore [5]).

TABLE 1: The occurrence states and proportion of CBM in coal reservoirs.

\begin{tabular}{lcc}
\hline Occurrence location & Occurrence states & Proportion (\%) \\
\hline Within water-soluble fractures, macropores, and block spaces & Free, water-soluble & $8 \sim 12(1 \sim 3)$ \\
Fractures, macropores, and internal surfaces of blocks & Adsorbed & $1 \sim 5$ \\
Microfractures and micropores & Adsorbed & $75 \sim 80$ \\
\hline
\end{tabular}

Note: medium rank coal, with a buried depth of 800-1200 m.

higher-rank coals; (2) the ${ }^{12} \mathrm{C}-{ }^{12} \mathrm{C}$ bond in the gas molecule breaks more frequently than the ${ }^{12} \mathrm{C}-{ }^{13} \mathrm{C}$ bond as the degree of coalification increases, which causes the enrichment of heavy isotope ${ }^{13} \mathrm{C}$ in $\mathrm{CH}_{4}$ and $\mathrm{C}_{2} \mathrm{H}_{6}$ during the generation of thermogenic gas; and (3) thermogenic gas is comparatively rich in deuterium with the increase of coalification [31].

2.2. Physical Properties of $C B M$ and Water. As shown in Table 1, the occurrence of CBM in coal reservoirs is mainly comprised of the free state, the adsorbed state, and the water-soluble state [26]. The proportion of CBM with different occurrence states depends on the pore-fracture structure, reservoir temperature and pressure, the defects of the coal macromolecular structure, and the adsorption capacity: (1) The proportion of the free-state CBM generally accounts for about $8 \%$ to $12 \%$ under the condition of reservoir pressure and temperature. However, its proportion will gradually increase when the reservoir pressure is reduced by drainage during the CBM production process. (2) The adsorbed-state CBM refers to a general term for CBM adsorbed in fractures, microcracks, and micropore surfaces of coal reservoirs, which accounts for $80 \%$ of the total amount of CBM. There is a constant motion and exchange between adsorbed and free CBM (dynamic equilibrium status) under conditions of reservoir temperature and pressure. (3) The proportion of the dissolved-state CBM is approximately $3 \%$, and the solubility of CBM increases with an increase of pressure [32]. Moreover, the solubility of CBM decreases with an increase of salinity. The solubility of CBM decreases with an increase in temperature when the temperature is $\angle 80^{\circ} \mathrm{C}$, whereas the solubility of $\mathrm{CBM}$ increases with an increase in temperature when the temperature is $>80^{\circ} \mathrm{C}$ [33]. Therefore, the dissolved gas may significantly increase in the coalbed water under high temperature and pressure or if saturated with $\mathrm{CO}_{2}$.

The main sources of coalbed water are the primary sedimentary water in the peat bog, the converted water in the coal-forming process, the infiltration water, and the water introduced by tectonic movement [32]. During the coalification process, a series of physical and chemical reactions happen to coal, such as carburetion, dehydration, aerogenesis, and the reduction of porosity. Meanwhile, CBM is firstly gathered in the pore-fracture system of coal, and then water is gradually displaced between coal particles with the increase of gas pressure in pores, which results in CBM occupying micropores and coalbed water existing 
in larger pores. An interesting phenomenon is that partial coalbed water has not been dislodged and occurred in micropores with an adsorbed state, forming the coexistence of gas and water [34].

\section{Characterization of Fluid Performance in CBM Reservoirs}

Due to the unique and complex pore-fracture structure of coals, the occurrence and transport process of fluids demonstrate the multiphase and multiscale characteristics in coal [27]. Therefore, it requires diversified methods and appropriate instruments to investigate fluid performance in the porefracture structure of coals.

3.1. Characterization of Pore-Fracture Structure. For over decades, characterization techniques of the pore-fracture structure have evolved from the observation of orientation/spacing to the understanding of spacing, size, orientation, connectivity, and porosity for both pores and fractures/cleats $[35,36]$. The quantitative characterization and quantitative analysis techniques of the pore-fracture structure have been gradually developed as well as widely used [37], which are divided into two types: the fluid injection method and the nonfluid injection method (Figure 4). The fluid injection method mainly uses liquids (e.g., $\mathrm{H}_{2} \mathrm{O}$ and $\mathrm{Hg}$ ) and adsorptive gases (e.g., $\mathrm{CO}_{2}$ and $\mathrm{N}_{2}$ ) to inject powder/core coal samples under different pressure conditions, and while it records the corresponding injection volume or adsorption amount data. Generally, $\mathrm{CO}_{2}$ adsorption, low-temperature $\mathrm{N}_{2}$ adsorption, and mercury intrusion porosimetry (MIP) methods are combined to quantitatively characterize the micro-nano-sized pore-fracture structure of coal in which the pore diameter distribution, pore volume, specific surface area, and pore connectivity of coal samples can be calculated by different mathematical methods, such as the Brunauer, Emmett, and Teller method (B.E.T. method) [38]; the Barrett, Joyner, and Halenda method (BJH method) [39]; and the Washburn equation [40]. Moreover, the heterogeneity of the pore-fracture at different scales can also be quantitatively described by the fractal dimension, which is calculated from the pore volume or specific surface area data by using different mathematical models [41]. Recently, nuclear magnetic resonance (NMR), as an accurate and nondestructive technique, has been rapidly developed and widely used to quantitatively characterize the full-size pore-fracture structure of coal [42]. Yao et al. [42-44] firstly used the low-field NMR (LFNMR) method and the transverse relaxation time $\left(T_{2}\right)$ cutoff-value-based model to study the pore type, pore structure, porosity, and permeability of coals, and meanwhile, they compared the results of LFNMR with other traditional methods in revealing the characteristics of the pore-fracture structure (Figure 5). It is found that the distribution of NMR $T_{2}$ is closely related to the pore structure and coal rank of coal, and the porosity of coals decreases with an increase in coal rank [45]. Meanwhile, the variation of porefracture heterogeneity caused by the effect of stress can also be evaluated based on the $T_{2}$ spectrum [46].
Due to the limitation of the experimental principle and method, fluid injection methods are mostly used to characterize open pores in coal and may change the original porefracture structure because of the damage in a coal sample [47]. On this basis, a variety of nondestructive and efficient nonfluid injection methods, such as transmission electron microscopy (TEM), scanning electron microscopy (SEM), atomic force microscopy (AFM), focused ion beam scanning electron microscopy (FIB-SEM), and microfocus computed tomography $(\mu$-CT), have been gradually applied to more accurately and quantitatively characterize the pore-fracture network of coals. Hereinto, TEM, SEM, and AFM techniques are usually used to analyze the size, shape, connectivity, and morphological characteristics of a pore-fracture in twodimensional (2D) surface (Figure 6) [48-50]. In recent years, it has become a hot topic to obtain the quantitative data of pore-fracture structures from 2D SEM images on the basis of the qualitative analysis of pore-fracture morphology in coal. Moreover, based on the continuous scanning technology and the three-dimensional (3D) reconstruction method, FIB-SEM and $\mu$-CT techniques can effectively reveal the continuous changes and the strong heterogeneity of a porefracture structure in 3D space (Figure 7) [51,52]. Meanwhile, CT scanning can obtain the aperture, direction, and spacing distribution of cleavage [53], determine the pore size, distinguish between organic and mineral components combined with other methods (between-class variance maximisation) [54], and further characterize the occurrence of mineral components in coals [55].

In general, the research progress and development trends of the quantitative characterization of the pore-fracture of coal are mainly concentrated on three aspects: (1) the systematic and advanced quantitative evaluation of a pore-fracture structure based on a variety of characterization techniques; (2) the improvement of the accuracy of characterization methods in quantitative characterization of a pore-fracture structure by introducing the knowledge of other disciplines; (3) the establishment of a more advanced, quantitative, and practical characterization system for pore-fracture structures.

\subsection{Fluid Occurrence Characteristics and Modelling}

\subsubsection{Characterization of Fluids with Different Occurrence}

States. There are three different occurrence states of CBM (free state, adsorbed state, and dissolved state) in coals in which the adsorbed gas and the free gas are influenced by numerous factors and demonstrate a uniform dynamic equilibrium process through adsorption and desorption processes (Figure 8) [26]. CBM adsorbed on the internal surface area of coal pores includes three models: monolayer (Type I), multilayer (Type II), and pore filling (Type III). In contrast, water adsorbed on the internal surface shows two models: monolayer (Type I) and multilayer (Type II) (Figure 9) [56]. It has been confirmed that the coal matrix may swell and deform when gas is adsorbed, and shrink when gas is desorbed [24]. Thus, the $\mathrm{CH}_{4} / \mathrm{CO}_{2}$ adsorption and desorption processes can significantly affect the volume change of micropores and macropores in coal, resulting in coal matrix expansion/contraction and coal permeability variation, and 


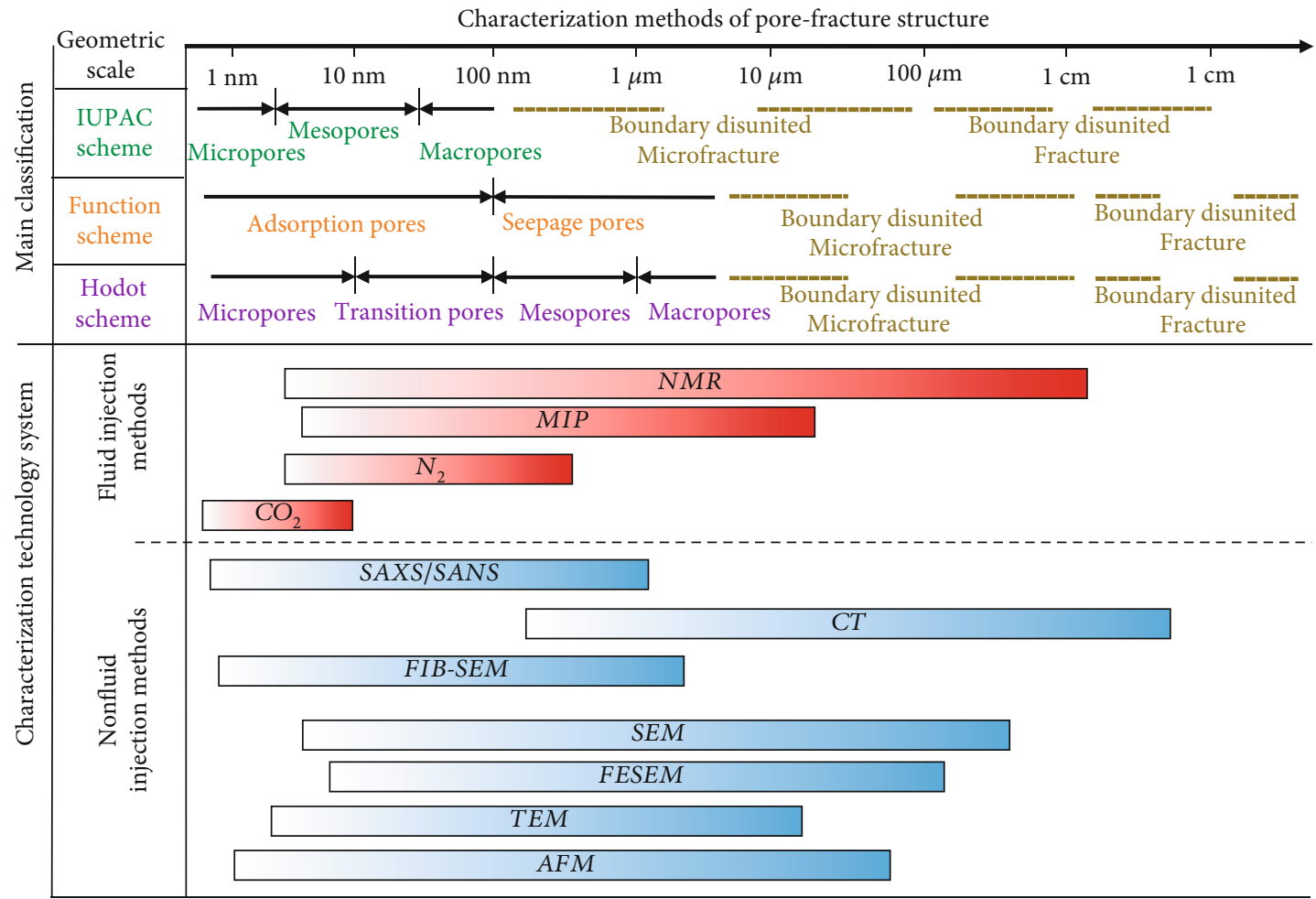

Isothermal adsorption
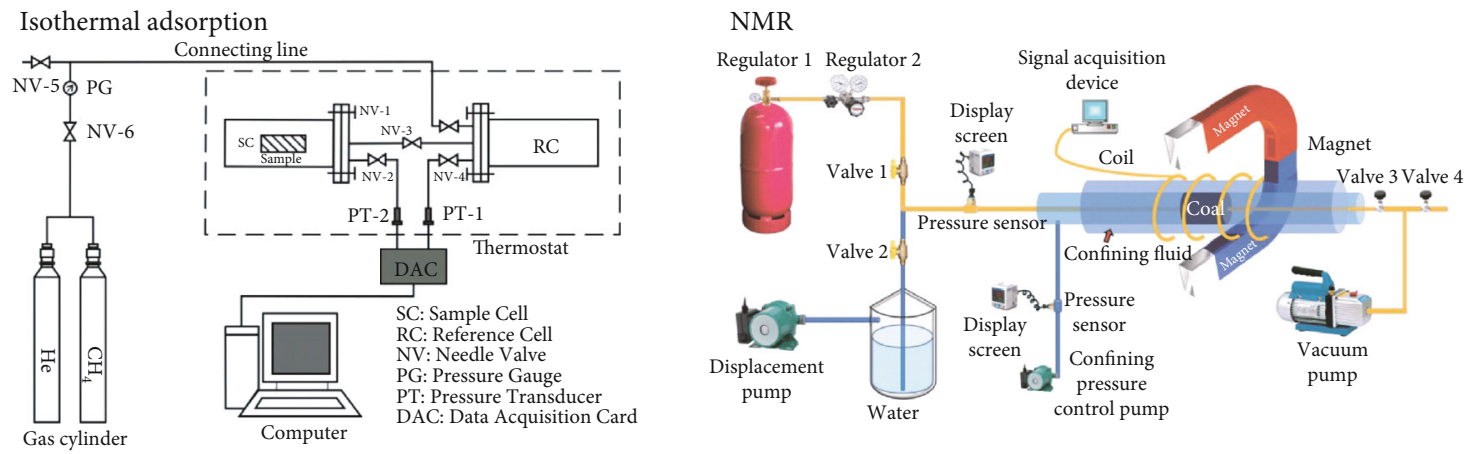

SANS

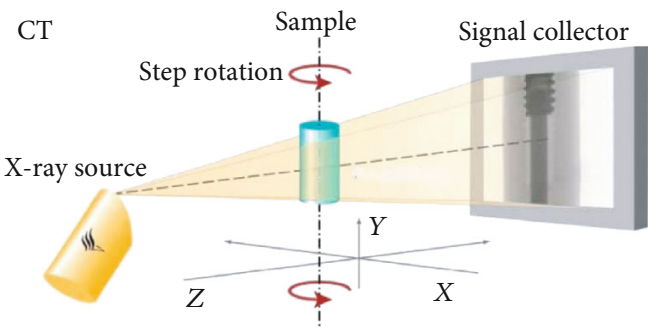

FIGURE 4: Qualitative and quantitative characterization methods of the pore-fracture structure in coal reservoirs with different scales (modified from Yu et al. [37]).

further controlling the gas transport process in coal [57]. There is an adsorption competition between $\mathrm{CH}_{4}$ and $\mathrm{CO}_{2}$, which may be affected by coal composition, macromolecular structure, pore-fracture structure, and reservoir temperature and pressure conditions [58]. Moreover, free gas will be compressed under reservoir conditions, which has a large deviation from ideal conditions. Therefore, the calculation of free gas content in coal should also consider the influence of the compression factor under the ideal gas state. Generally, the free gas content can be calculated by Mariotte's law, as follows [59]:

$$
V_{\mathrm{g}}=\frac{V P T_{0}}{P_{0} T Z},
$$

where $V_{g}$ is the free gas volume in the standard state; $Z$ is the gas compression factor. 

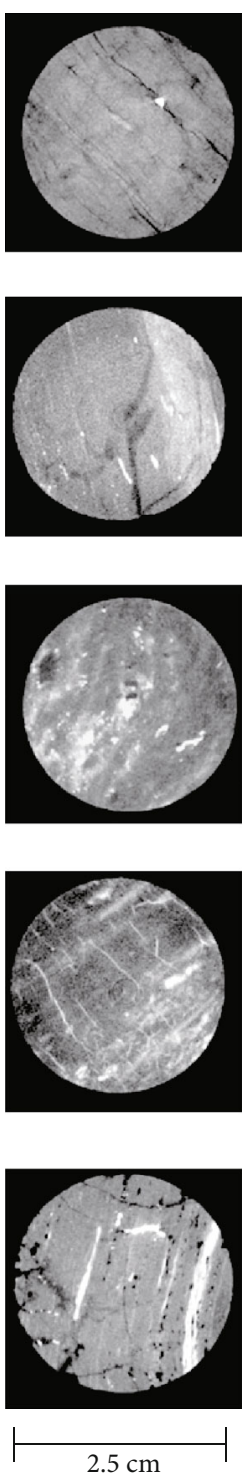

(a)
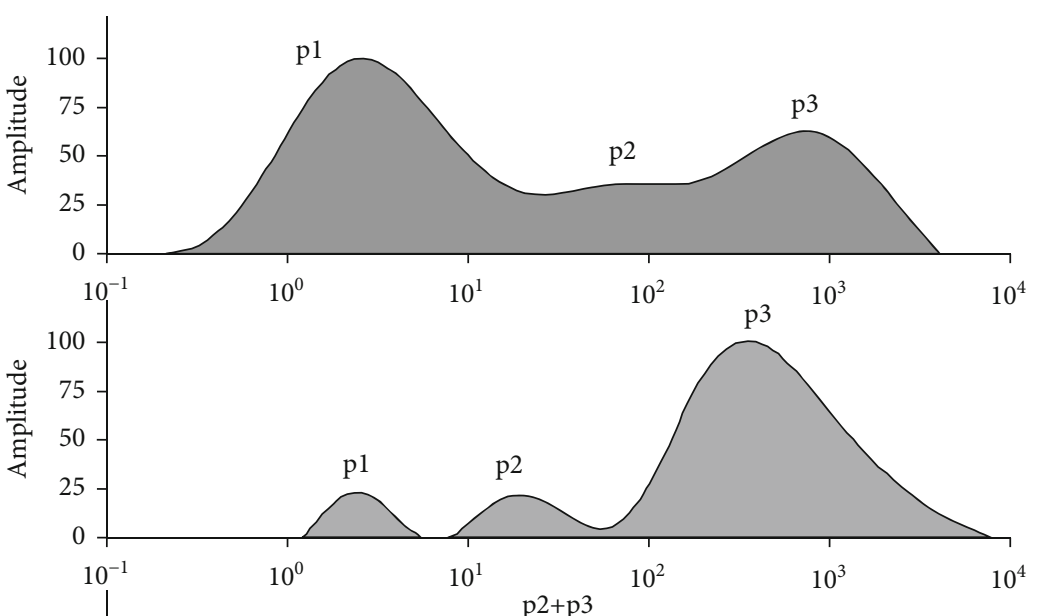

WL7:

$R_{0}=1.01 \%$

$K=3.09 \mathrm{mD}$

$\phi=5.2 \%$

STJ1-10:

$R_{\mathrm{o}}=1.56 \%$

$K=0.067 \mathrm{mD}$

$\phi=2.3 \%$

SH3:

$R_{\mathrm{o}}=2.42 \%$

$K=0.009 \mathrm{mD}$

$\phi=3.12 \%$

G2:

$R_{\mathrm{o}}=2.7 \%$

$K=14.9 \mathrm{mD}$

$\phi=9 \%$

(c)

$T_{2}(\mathrm{~ms})$

(b)

FIGURE 5: CT scanning images and NMR $T_{2}$ distribution showing the pore-fracture characteristics and pore size distribution of differently ranked coals (modified from Yao et al. [42]).

For dissolved gas, the solubility experiment of $\mathrm{CH}_{4}$ in coalbed water shows that (1) the solubility of $\mathrm{CH}_{4}$ in mineralized coalbed water is greater than that in deionized water, which is more obvious with the higher reservoir pressure [60]; (2) for the same coal seam, the solubility of $\mathrm{CH}_{4}$ in coalbed water samples increases with increasing reservoir pressure [32]; and (3) the effect of salinity on $\mathrm{CH}_{4}$ solubility is obvious when the temperature and pressure are low, whereas $\mathrm{CH}_{4}$ solubility is obviously weakened as the temperature and pressure increase $[26,32]$.

The traditional methods for determining gas adsorption/desorption behavior mainly consist of the manometric method [61], the volumetric method [62], and the gravimetric method [63]. The manometric method and the volumetric method both measure the gas adsorption amount by record- ing the adsorption volume corresponding to the pressure, while the gravimetric method obtains the gas adsorption amount through a high-precision balance [28]. The adsorption and desorption hysteresis usually occurs in $\mathrm{CH}_{4}, \mathrm{CO}_{2}$, and $\mathrm{N}_{2}$ or multicomponent gas isotherms by using the volumetric method [64]. Recently, a NMR-based method has been developed to determine the gas/water adsorption/desorption process in coals by utilizing the correlation between the hydrogen strength and $\mathrm{CH}_{4} / \mathrm{H}_{2} \mathrm{O}$ volume (Figure 10) [44, $65,66]$. The advantage of this NMR-based method is that the gas/water adsorption process can be detected in real time [44]. However, it is noted that the calculated values of the Langmuir volumes from the NMR method are usually lower than those from the volumetric method, which is related to the slight change of temperature, the undetected 

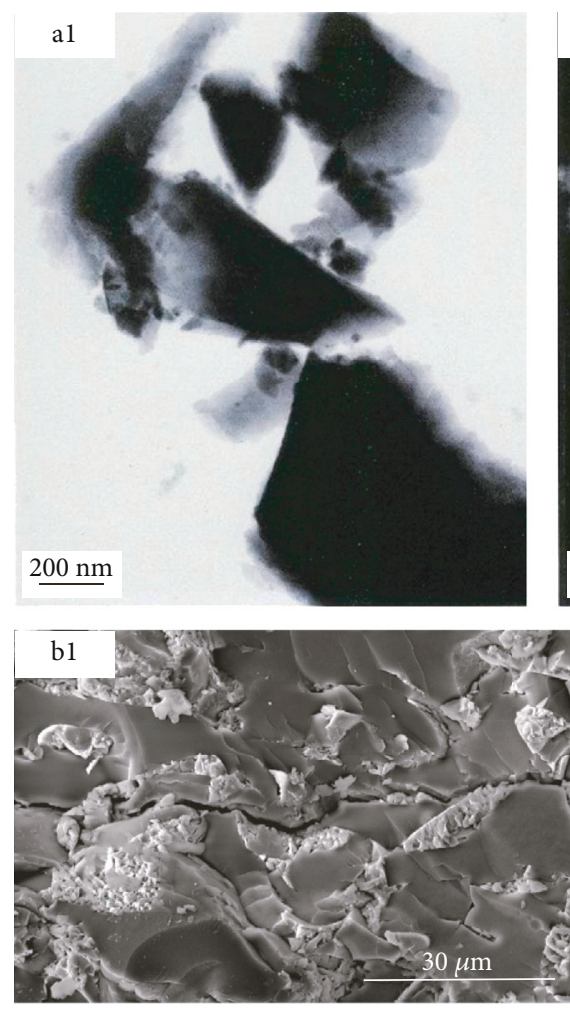
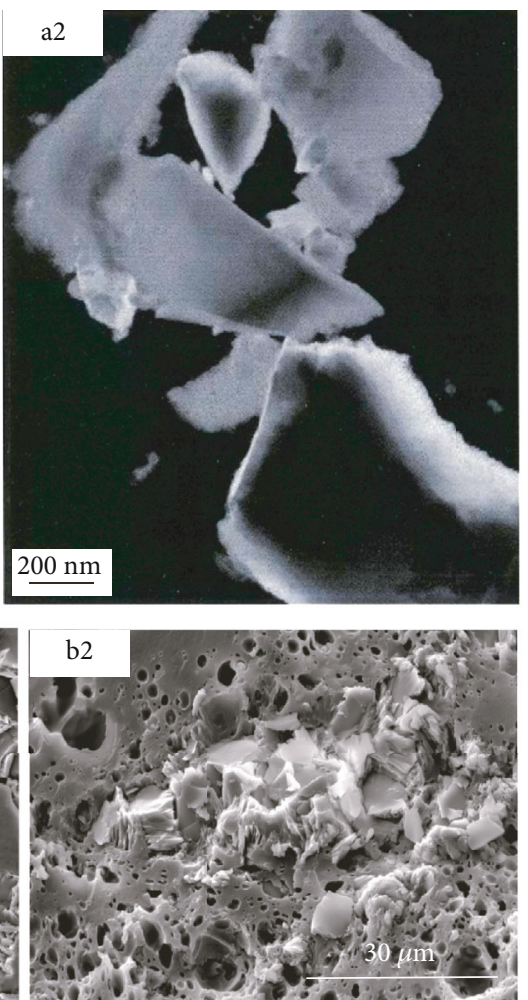
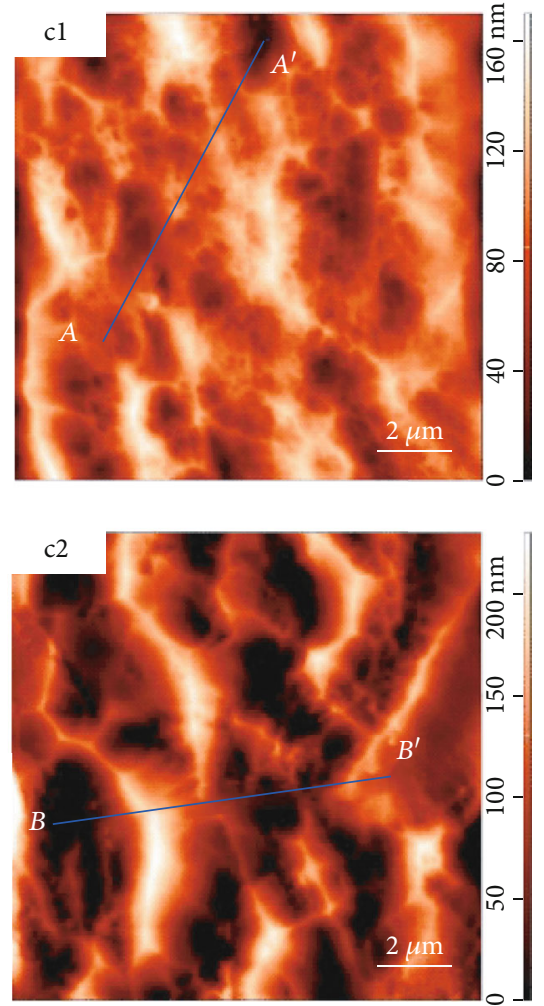

FIGURE 6: TEM images of anthracite grains (a1, a2), SEM images of differently ranked coals (b1, b2), and 2D AFM images of different coal samples (c1, c2) (modified from Kwiecińska et al. [48], Liu et al. [49] and Zhao et al. [50]).

$\mathrm{CH}_{4}$ with relaxation less than $0.1 \mathrm{~ms}$, and more desorbed behavior under the magnetic field. In addition, mathematical simulation and molecular methods have also been established to explore the adsorption/desorption behavior of fluids in coals $[67,68]$.

\subsubsection{CBM Adsorption/Desorption Models and Application.} Table 2 shows the classic CBM adsorption/desorption models, which are widely used to characterize the CBM adsorption/desorption behavior and amount. Based on the monolayer adsorption theory, the Langmuir equation assumes that gas is adsorbed on a solid surface as a single molecule and the thickness of adsorbed gas is one molecular layer [69]. The B.E.T. equation is based on the Langmuir single-layer adsorption model, and its theory points out that the gas adsorbed on the pore surface is a multimolecular layer adsorption phenomenon in which the first layer is composed of the gas molecules adsorbed on the surface under the Van der Waals force, and the other layers mainly depend on the interaction force between gas molecules $[38,70]$. In general, the B.E.T. equation is often used to study water-coal interaction and low-pressure coal-gas interaction. The adsorption potential model is mainly applied to discuss the gas adsorption of microporous solid surfaces, which is based on the theory that the gas adsorption process is not adsorbed on the pore surface of coal, but on the aggregation of gas molecules under the force field [71]. For a microporous structure, the residual force field on the surface may generate a superposition of force fields because the spacing of the pore wall is very small, and a superimposed force field area may be formed in the micropores, which results in a stronger gravitational field in the micropores for gas molecules. On this basis, a variety of classic adsorption isotherm equations have been established, such as the Dubinin-Astakhov (D-A) equation [72] and the Dubinin-Radushkevich (D-R) equation [73]. The D-A equation can well fit most of the gas adsorption data though its theoretical basis remains incomplete and unknown [74]. The D-R equation is a special case of the $\mathrm{D}$-A equation and assumes that the pore distribution of coal is the Gaussian distribution, which has good applicability of studying gas adsorption in a uniform microporous system with a narrow pore size distribution [73, 75]. According to the change of interfacial tension before and after gas adsorption, the gas adsorption amount can be calculated by the Gibbs adsorption formula, and meanwhile, the state information of gas molecules adsorbed on the interface can be obtained [76]. The basic theory of this formula is to use the classic thermodynamic theory to study the adsorption equilibrium process, and consider the adsorbed gas as a $2 \mathrm{D}$ microscopic fluid to study its adsorption process. Moreover, the gas adsorption isotherm can be expressed as an exponential equation (the Freundlich equation) in which two important constants are related to temperature and coal pore distribution [72].

Of all these commonly used gas adsorption models, the Langmuir equation is the most widely used and its parameters have clear physical meanings. However, there could also be some problems when the Langmuir equation is applied in 


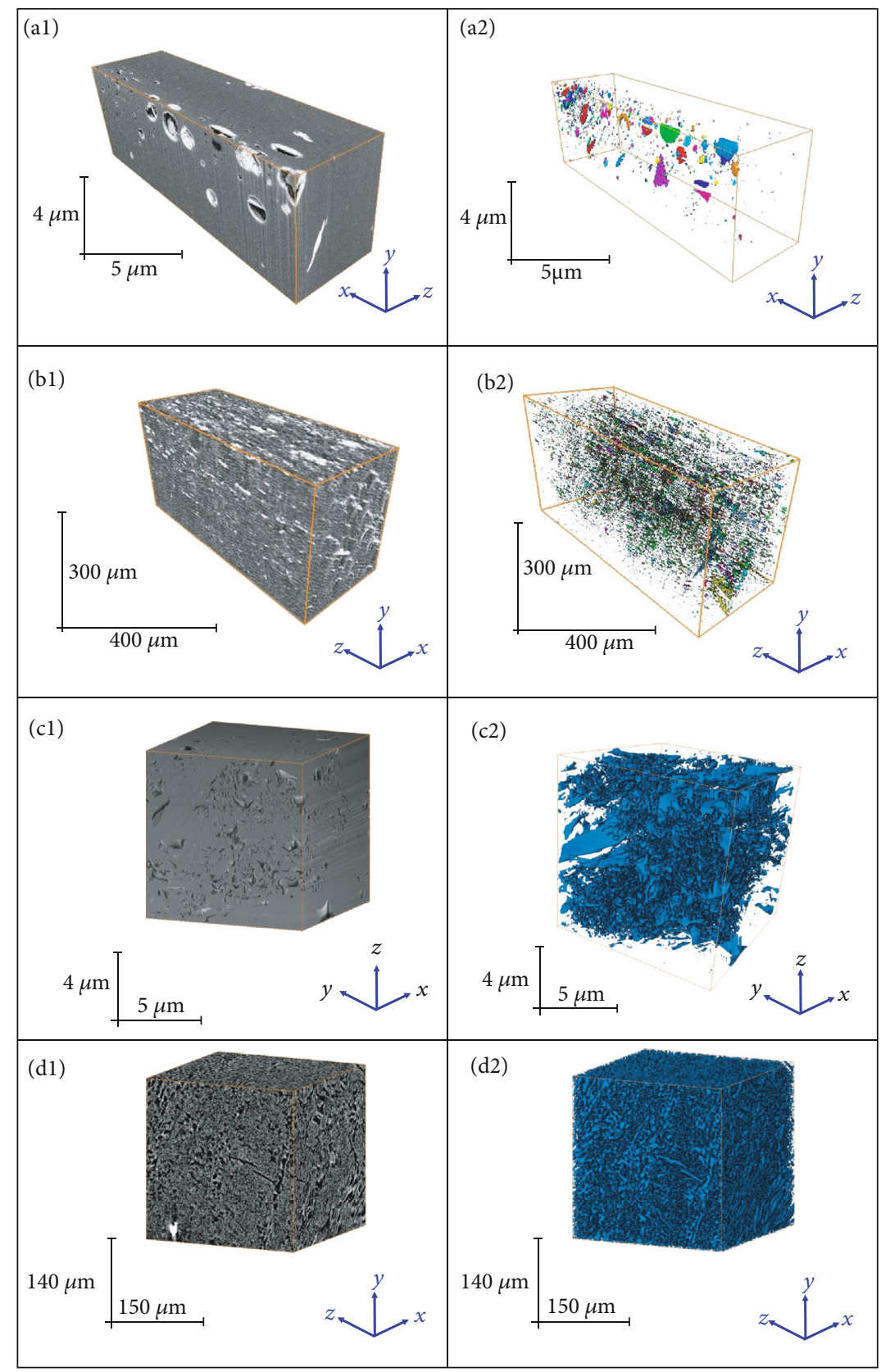

Figure 7: 3D reconstruction images and the extraction of pore-fracture networks: (a1, a2) FIB-SEM data of the BC sample; (b1, b2) X-ray $\mu$-CT data of the BC sample; (c1, c2) FIB-SEM data of the LHG sample; $(\mathrm{d} 1, \mathrm{~d} 2)$ X-ray $\mu$-CT data of the LHG sample (modified from Li et al. [51, 52]).

coals, particularly since it is not suitable for fitting the isothermal adsorption experimental data of water-bearing coal under high pressure conditions [77]. Clarkson and Bustin $[75,78]$ have used four different adsorption models to describe the $\mathrm{CH}_{4}$ adsorption process of coal and found that the accuracy order of simulation models is as follows: D A equation $>$ D - R equation $>$ B.E.T.equation $>$ Langmuir equation. For the characterization of gas desorption behavior, Barrer's model suggested that the cumulative gas desorption amount is proportional to the square root of time under a constant pressure system [27]. In addition, Winter and Janas's model proposed that the gas desorption speed with time can be expressed by a power function [67], whereas Airey's model established an empirical formula of gas desorption based on Darcy's law [79].

\subsection{Fluid Transport Process and Modelling}

3.3.1. CBM Diffusion Behaviors and Models. During the process of drainage and depressurization in CBM reservoirs, the adsorbed CBM is initially desorbed from the pore surface in the coal matrix, and then it diffuses into the fracture network caused by the concentration difference [80]. Generally, there are three modes of gas diffusion in coal: the Fick diffusion, 


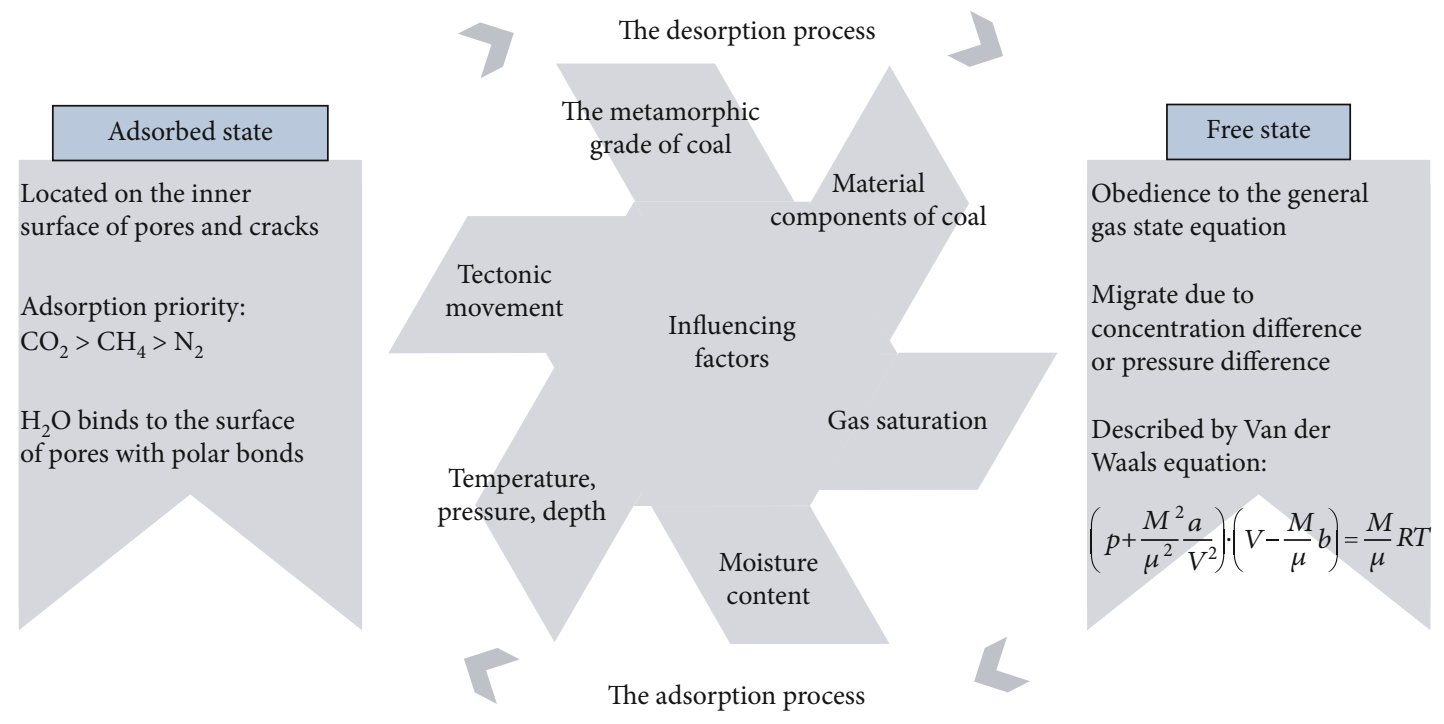

Figure 8: Dynamic equilibrium state and mutual transition process between adsorbed gas and free gas in coal reservoirs.

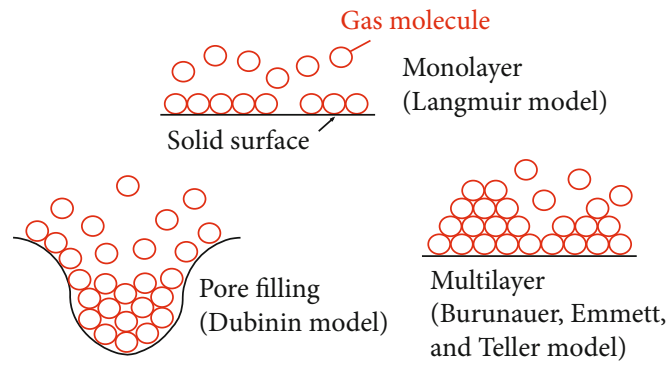

(a)

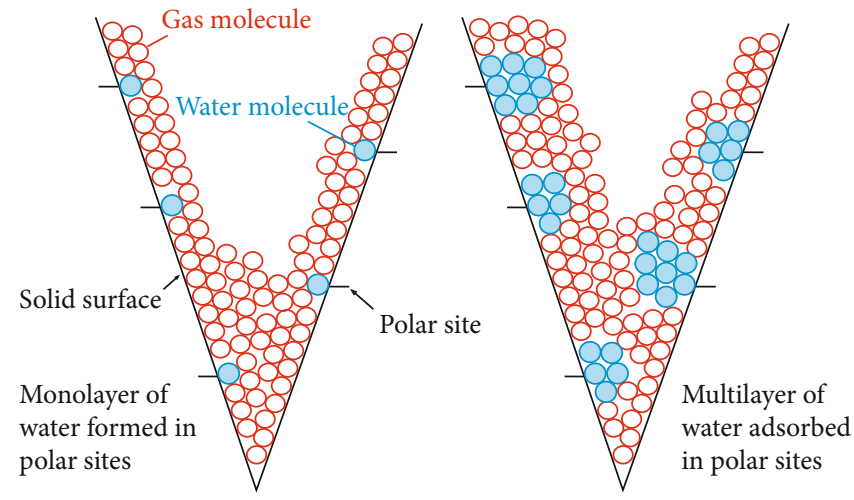

(b)

FIGURE 9: Simplified diagrams of a gas adsorption model (a) and a water molecule adsorption model (b) (modified from Day et al. [56]).

the Knudsen diffusion, and the transitional diffusion (Figure 11). Moreover, gas transport in pores is also controlled by the surface diffusion or the configurational diffusion [81]. The specific mode of gas diffusion in CBM reservoirs can be determined by the Knudsen number $\left(K_{\mathrm{n}}=\lambda / d\right)$, which represents the ratio of the gas molecular mean free path length $(\lambda)$ to the pore diameter $(d)$ of coal [35]. When $K_{n} \leq 0.1$, the gas diffusion in coal pores still follows Fick's law (the Fick diffusion) because the pore diameter is much larger than the mean free path of the gas molecule and a collision mainly occurs between free gas molecules; meanwhile, the collision between gas molecules and the capillary wall is relatively small (Figure $11(\mathrm{a})$ ). When $K_{\mathrm{n}} \geq 10$, the gas diffusion no longer follows Fick's law and tends to the Knudsen diffusion because the mean free path length of the gas molecule is larger than the pore diameter and the collision between gas molecules and the capillary wall primarily happens in coal pores (Figure 11(b)). Moreover, when 0.1 $\leq K_{\mathrm{n}} \leq 10$, the gas diffusion in coal pores is a transitional dif- fusion between the Fick diffusion and the Knudsen diffusion as a result of the pore diameter being close to the mean free path of gas molecules (Figure 11(c)). During this diffusion process, both the collision between free gas molecules and the collision between gas molecules and the capillary wall are equally important. Therefore, CBM diffusion characteristics are mainly governed by the pore structure and the heterogeneity of its coals $[80,82]$.

At present, there are several models to describe the gas diffusion process in coals, as shown in Table 3. Based on Fick's second law for spherically symmetric flow, the unipore model is established by assuming that the gas concentration on the pore surface of coal matrix is constant $[78,83]$. It simplifies the pore structure of coal into a homogenous structure and supposes that the diffusion coefficient is independent of gas concentration. However, due to the strong heterogeneity of the pore structure in the coal matrix, the unipore model has been proven to have certain limitations in some dull coals or low-medium-rank coals [82]. Consequently, Ruckenstein 


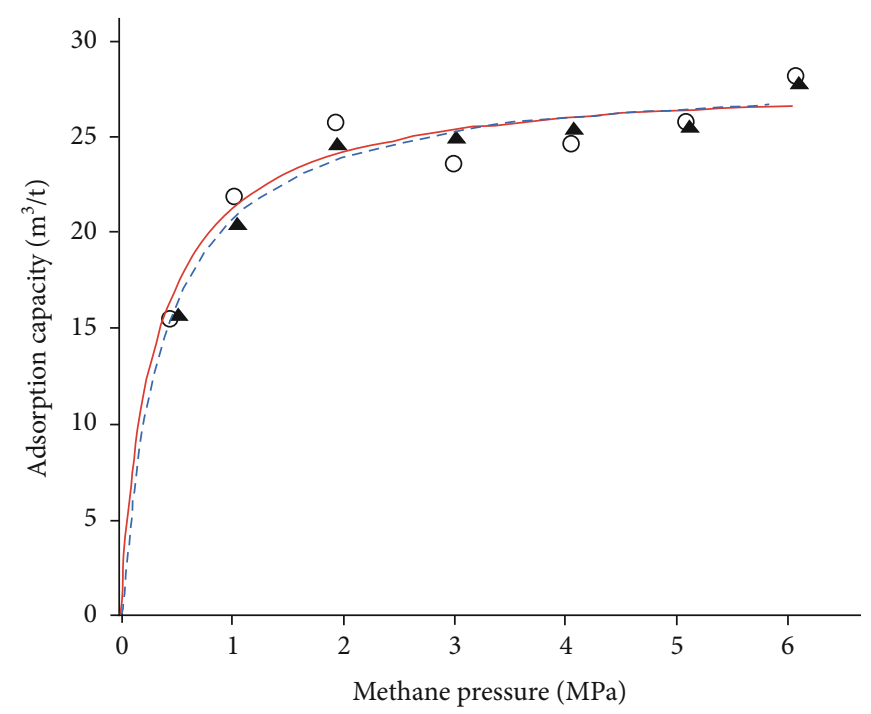

- Data of volumetric method

O Data of NMR method

- - Fit of volumetric method

_ Fit of NMR method

(a)

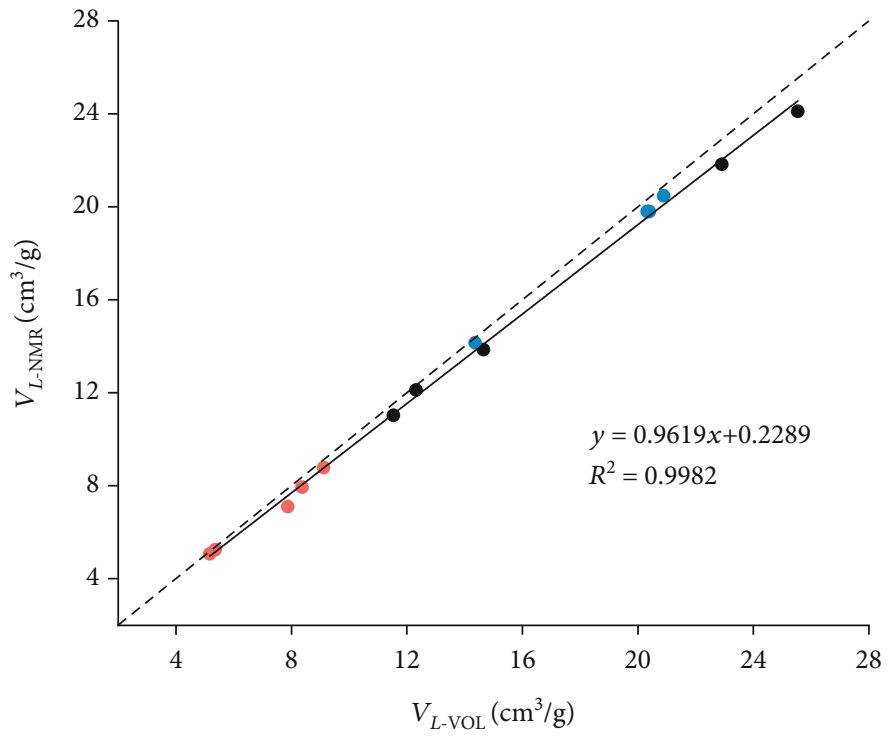

- Low-rank coal

- Medium-rank coal

- High-rank coal

(b)

Figure 10: Continued. 


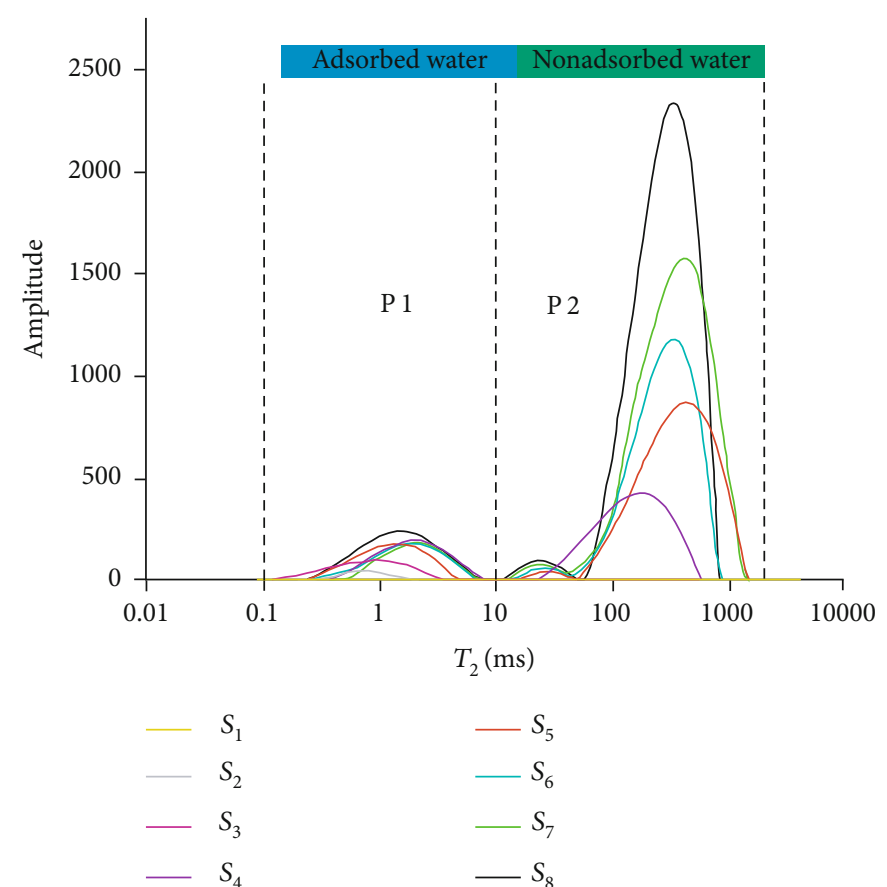

(c)
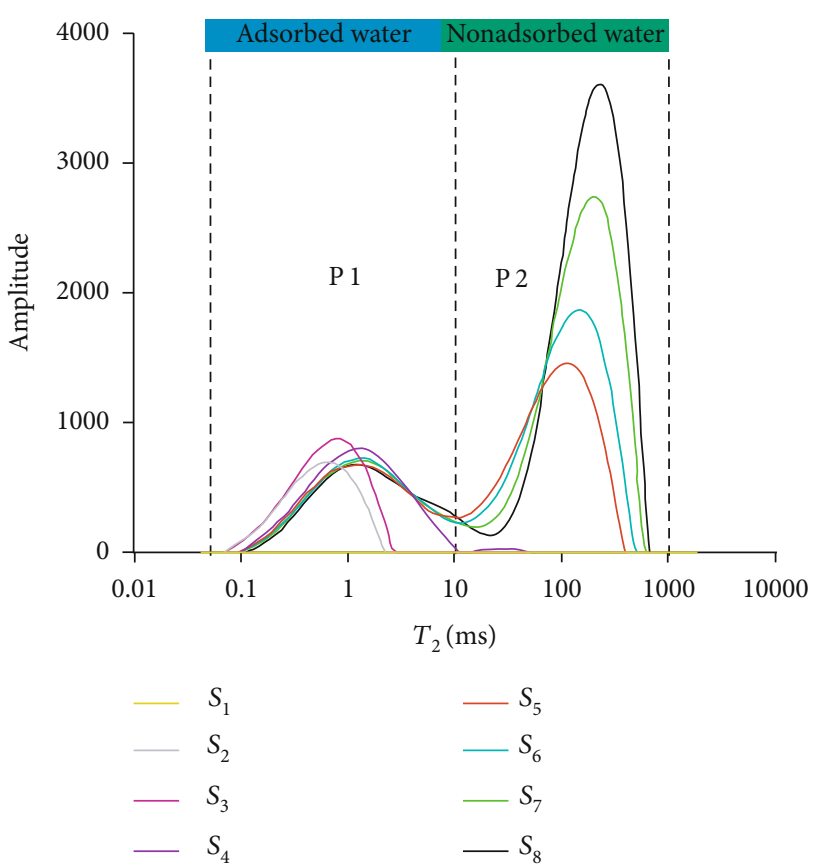

(d)

FIGURE 10: $\mathrm{CH}_{4}$ isothermal adsorption curves measured using the volumetric method and the NMR method (a), the cross plot of the Langmuir volume from the volumetric method and the NMR method (b), and $T_{2}$ spectra distribution of anthracite coal (c) and high volatile bituminous coal (d) after diffused water and added water treatments (modified from Yao et al. [44], Zheng et al. [65], and Wang et al. [66]).

TABLE 2: CBM adsorption/desorption models and mathematical expressions.

\begin{tabular}{|c|c|c|}
\hline & Name of the model & Mathematical expressions of the model \\
\hline \multirow{8}{*}{ CBM adsorption } & The Langmuir equation [69] & $x=a b p / 1+b p$ \\
\hline & The B.E.T. equation [38] & $V=\left(V_{m} p C /\left(p_{s}-p\right)\left[1-\left(p / p_{s}\right)+C\left(p / p_{s}\right)\right]\right) \times 100 \%$ \\
\hline & The adsorption potential theory and model [71] & $V_{a}=f(\varepsilon)=f\left(R T \ln p_{s}\left(P_{s} / p\right)\right)$ \\
\hline & & $w=w_{0} \exp \left[-(A / E)^{n}\right]$ \\
\hline & The Dubinin-Astakhov (D-A) equation [72] & $A=R T \ln \left(P_{\mathrm{s}} / P\right)$ \\
\hline & The Dubinin-Radushkevich (D-R) equation [73] & $\log W=\log W_{0}-b(\varepsilon / \beta)^{2}$ \\
\hline & The Gibbs adsorption formula [76] & $A(\partial \pi / \partial p)_{r}=n(R T / p)$ \\
\hline & The Freundlich equation [72] & $w=f^{p 1 / b}$ \\
\hline \multirow{3}{*}{ CBM desorption } & The Barrer desorption model [27] & $Q_{t} / Q_{\infty}=(2 s / V) \sqrt{D t / \pi}$ \\
\hline & The Winter and Janas desorption model [67] & $Q_{t}=\left(V_{1} / 1-K_{t}\right) t^{1-k}$ \\
\hline & The Airey desorption model [79] & $Q_{t}=Q_{\infty}\left[1-e^{-\left(t / t_{0}\right)^{n}}\right]$ \\
\hline
\end{tabular}

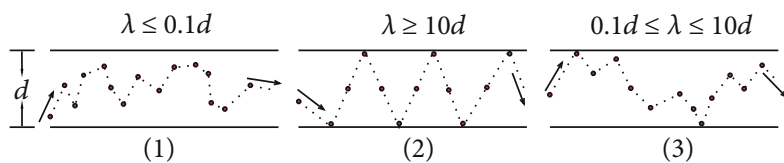

$$
\text { (1) }
$$$$
\text { (2) }
$$$$
\text { (3) }
$$

- Single gas molecule

Direction of gas molecule movement

FIgure 11: Three different modes of the CBM diffusion process: (a) Fick's diffusion; (b) Knudsen's diffusion; (c) transitional diffusion. et al. [84] and Clarkson and Bustin [78] proposed a bidisperse model to describe the gas diffusion behavior of CBM reservoirs developed with a bimodal pore structure, and they divided the gas diffusion process into a fast macropore diffusion stage and an extremely slow micropore diffusion stage (Figure 12). Based on experimental analysis and mathematical derivation, Pan et al. [85] proposed an overall diffusion formula to calculate the proportions of the macropore diffusion stage and the micropore diffusion stage in bituminous coals. Moreover, a new multiporous diffusion model was 
TABLE 3: CBM diffusion models and mathematical expressions.

\begin{tabular}{lc}
\hline & Mathematical expressions of the model \\
\hline The unipore model [83] & $M_{t} / M_{\infty}=1-6 / \pi^{2} \sum_{n=1}^{\infty}\left(1 / n^{2}\right) \exp \left(-D_{e} n^{2} \pi^{2} t\right)$ \\
$M_{a} / M_{a \infty}=1-6 / \pi^{2} \sum_{n=1}^{\infty}\left(1 / n^{2}\right) \exp \left(-D_{a} n^{2} \pi^{2} t / R_{a}^{2}\right)$ \\
$M_{i} / M_{i \infty}=1-6 / \pi^{2} \sum_{n=1}^{\infty}\left(1 / n^{2}\right) \exp \left(-D_{i} n^{2} \pi^{2} t / R_{i}^{2}\right)$ \\
The bidisperse model [78, 82,84,85] \\
$\begin{array}{c}M_{t} / M_{t \infty}=M_{a}+M_{i} / M_{a \infty}+M_{i \infty}=\beta\left(M_{a} / M_{a \infty}\right)+(1-\beta)\left(M_{i} / M_{i \infty}\right) \\
\text { The multiparous model [86] }\end{array} M_{\mathrm{t}} / M_{\infty}=\sum_{\varphi=1}^{n}\left(M_{\varphi} / M_{\varphi \infty}\right)=\partial_{1}\left(M_{1} / M_{1 \infty}\right)+\partial_{2}\left(M_{2} / M_{2 \infty}\right)+\cdots+\left(1-\partial_{1}-\partial_{2}-\cdots-\partial_{\varphi}\right)\left(M_{\varphi} / M_{\varphi \infty}\right)$ \\
\hline
\end{tabular}

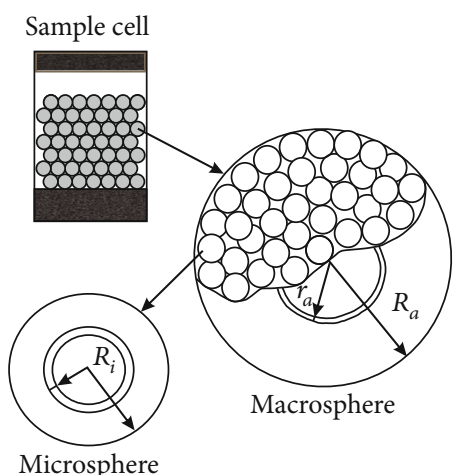

Figure 12: Conceptual model of the bidisperse pore structure in coal reservoirs (modified from Clarkson and Bustin [78]).

established by Li et al. [86], which provides better fitting results than the bidisperse model for low-rank coals, especially for the initial diffusion stage. However, due to the limitation of interpreting the interactions of multicomponent gas molecules, the above formulas derived from Fick's second law cannot well describe the multicomponent gas diffusion behaviors in coals $[87,88]$. In comparison, the MaxwellStefan diffusion theory is superior in characterizing the diffusion process of mixed gaseous molecules in coals [89].

3.3.2. CBM Seepage Process and Models. The permeability of coal directly determines the CBM production process and recovery, which is closely related to the in situ stress, porefracture structure, and reservoir pressure $[13,37]$. It has been confirmed that CBM mainly exhibits a slow laminar flow in fractures with a width of $0.1-10 \mu \mathrm{m}$ (in the case of a low flow rate, the streamline flow is linear and does not mix with the surrounding fluid), a violent laminar flow in fractures with a width of $1.0-100 \mu \mathrm{m}$, and a turbulent flow (composed of a series of various scale random vortices) in fractures with a width greater than $100 \mu \mathrm{m}$ [49]. The CBM laminar flow in coal fractures is driven by the pressure difference, which can be regarded as a linear seepage flow and follows Darcy's law [90]:

$$
\vec{V}=\frac{[K]}{\mu} \nabla P,
$$

where $\vec{V}$ is the CBM seepage velocity, $[K]$ is the permeability tensor, $\nabla$ is the Hamiltonian, $P$ is the fluid pressure, $\mu$ is the fluid viscosity.

Taking the aspects of coal matrix shrinkage effect, gas slippage effect, and effective stress into consideration, different permeability models have been established to predict the permeability of CBM reservoirs (Table 4) [91]. Through analyzing the permeability variation and gas flow mechanisms of coals by these models, the CBM seepage process in coals can be characterized by the following aspects: (1) CBM seepage in underground coal is generally under the control of high reservoir pressure, and both the CBM compressibility and coal matrix compressibility should not be neglected [57, 92]; (2) due to the complex shape and distribution of pore-fractures in coals, the impacts of capillary force and intermolecular force should also be considered to analyze the permeability $[40,93]$; (3) the CBM seepage process occurs synchronously with the desorption and diffusion in coals, and CBM desorption may cause the spontaneous adjustment of coal (coal matrix shrinkage), which further results in the opening of the original fractures and the increase of permeability [57, 94, 95].

3.3.3. Two-Phase Flow Characteristics of CBM and Water. The production of CBM from a well usually goes through the following three stages after drainage and depressurization: (1) the unidirectional flow stage-wellbore pressure is greater than the critical desorption pressure and only water flows in a single phase; (2) the unsaturated flow stage-water flows with discontinuous CBM; and (3) the two-phase flow stage-CBM continuously flows with water [49]. In general, the multiphase flow occurs during both the primary and enhanced CBM recovery processes under reservoir conditions [96]. As water continues to be discharged, the reservoir pressure in the wellbore gradually decreases and CBM begins to desorb from coal when the flowing bottom pressure is less than the critical desorption pressure, resulting in the decreases of water-phase permeability and the increases of gas-phase permeability [88]. Thus, relative permeability is one of the most important parameters affecting the CBM production from reservoirs [97]. For porous media, the effective permeability of each flow phase is always less than the absolute permeability, and the sum of the effective permeabilities of all flow phases is also less than or equal to the absolute permeability [98]. Because the effective permeability of each flow phase varies with the saturation, the relative permeability curve can be used to determine the effective 
TABLE 4: Permeability prediction models and mathematical expressions of coal reservoirs.

\begin{tabular}{|c|c|}
\hline The author of the model & Mathematical expressions of the model \\
\hline Gray (1987) [139] & $\sigma_{\mathrm{h}}{ }^{e}-{\sigma_{\mathrm{h} 0}}^{e}=-(V / 1-V)\left(p-p_{0}\right)+(E / 1-V)\left(\Delta \varepsilon_{s} / \Delta p_{s}\right) \Delta p_{s}$ \\
\hline Seidle et al. (1992) [140] & $k / k_{0}=\exp \left[-3 C_{f}\left(\sigma-\sigma_{0}\right)\right]$ \\
\hline Seidle et al. (1992) [140] & $\Delta k($ slippage effect $)=k-k_{0}=k_{0}\left(1+\left(b_{\mathrm{Me}} / P_{m}\right)\right)-k_{0}=k_{0}\left(b_{\mathrm{Me}} / P_{m}\right)$ \\
\hline Seidle and Huitt (1995) [25] & $\phi=\phi_{0}+\phi_{0}\left(1+\left(2 / \phi_{0}\right)\right) \varepsilon_{1}\left[B p_{0} / 1+B p_{0}-B p / 1+B p\right]$ \\
\hline Harpalani and Chen (1995) [141] & $k_{\text {new }} / k_{\text {old }}=\left(1+\left(2 l_{\mathrm{m}}^{*} \Delta p / \phi_{0}\right)\right)^{3} / 1-l_{\mathrm{m}}^{*} \Delta p$ \\
\hline Levine (1996) [94] & $\begin{array}{c}k=\left(1.013 \times 10^{9}\right) b_{\text {new }}^{3} / 12 a \\
\text { where } b / a \text { is the cleavage density }\end{array}$ \\
\hline Palmer and Mansoori (1998) [22] & $\begin{array}{c}\phi / \phi_{0}=1+\left(C_{\mathrm{m}} / \phi_{0}\right)\left(p-p_{0}\right)+\left(\varepsilon_{1} / \phi_{0}\right)(K / M-1)\left(p / p_{\mathrm{s}}+p-p_{0} / p_{\mathrm{s}}+p_{0}\right) \\
k / k_{0}=\left(\phi / \phi_{0}\right)^{3}\end{array}$ \\
\hline Gilman and Beckie (2000) [142] & $\begin{array}{c}\Delta \sigma e_{x}^{\theta}=-(V / 1-V) \Delta p+(E / 1-V) \partial_{s} \Delta S \\
k / k_{0}=\exp \left(-3 \Delta \sigma e_{x}^{\theta} / E_{F}\right)\end{array}$ \\
\hline Shi and Durucan (2005) [35] & $\sigma-\sigma_{0}=-(V / 1-V)\left(p-p_{0}\right)+(E / 3(1-V)) \varepsilon_{1}\left(p / p+p_{\varepsilon}-p / p_{0}+p_{\varepsilon}\right)$ \\
\hline Cui and Bustin $(2005,2007)[124,143]$ & $\sigma-\sigma_{0}=-(2(1-2 V) / 3(1-V))\left[\left(p-p_{0}\right)+K\left(\varepsilon_{s}-\varepsilon_{s 0}\right)\right]$ \\
\hline Robertson and Christiansen (2006) [144] & $k / k_{0}=e^{3\left\{C_{f}\left(p-p_{0}\right)+\left(3 / \phi_{0}\right)[1-2 V / E]\left(p-p_{0}\right)-\left(\varepsilon_{\max } P_{L} / P_{L}+P_{0}\right) \ln \left(P_{L}+P / P_{L}+P_{0}\right)\right\}}$ \\
\hline Liu and Rutqvist (2010) [95] & $\begin{array}{c}\Delta \sigma=-(V / 1-V) \Delta P+\left(E\left(\Delta \varepsilon_{s}-\Delta \varepsilon_{f}\right) / 1-V\right) \\
\Delta \varepsilon_{f}=1 / 2 \phi_{0}\left(1-e^{-C_{t} \Delta \sigma}\right)\end{array}$ \\
\hline \multirow{3}{*}{ Moghaddam and Jamiolahmady (2016) [127] } & $k_{\text {non-slip }}=k_{\text {non-slip }}^{0}[\exp (\alpha \times \Delta P)]$ \\
\hline & $R_{\mathrm{c}}=R_{\mathrm{c}}^{0}[\exp (\beta \times \Delta P)]$ \\
\hline & $k_{\text {app }}=k_{\text {non-slip }}\left[1+4 C_{1}\left(\lambda / R_{\mathrm{c}}\right)-8 C_{2}\left(\lambda / R_{\mathrm{c}}\right)^{2}\right]$ \\
\hline \multirow{2}{*}{ Fan and Liu (2019) [93] } & $\mathrm{b}_{m}=-\left(12 \mu_{\mathrm{vis}} L(t) Q(t) / W \Delta P\right)$ \\
\hline & $k_{m}=b_{m}^{2} / 12$ \\
\hline
\end{tabular}

permeability of each flow phase for all possible saturation conditions in the reservoir. However, the shape of the relative permeability curve can be affected by the dynamic changes and operating characteristics of CBM reservoirs, which indicates that a series of factors, including nonstatic absolute permeability and porosity during depletion, multilayer effects, and gravity segregation and transient flow, can control the curve shape [98]. Figure 13 shows the changes of the absolute permeability of coal (mainly an exponentially increasing or exponentially decreasing trend), which can also cause a dramatic change in the concavity of the gas and water relative permeability curves (highly nonlinear concave up in Figures 13(a) and 13(b) or highly nonlinear concave down in Figures 13(c) and 13(d)). This means that the changes of absolute permeability and transient flow have a significant impact on the derived relative permeability curves, and meanwhile, the set of derived relative permeability curves are not universal.

\section{Factors Influencing the Fluid Performance in CBM Reservoir}

4.1. Influencing Factors of CBM Adsorption/Desorption Behavior. The influencing factors of CBM adsorption/de- sorption behavior can be divided into two categories: internal factors (such as coal metamorphism, petrographic constituents, macroscopic types, and pore structure of coals) [99] and external factors (such as pressure, temperature, gas type, moisture content, and geophysical and electromagnetic fields) $[26,28]$.

4.1.1. Coal Type. Coal type mainly refers to the physical properties, such as coal rank, maceral composition, minerals, fixed carbon, ash, and volatile matter [100]. It been confirmed that the degree of coal metamorphism is the main controlling factor that controls the gas adsorption/desorption capacity of coals [71]. Bustin and Clarkson [17] proposed that coal rank generally has no universal effect on the gas adsorption of coals, whereas the gas adsorption capacity may be significantly enhanced as the coal rank increases from medium to high volatile bituminous coal (Figure 14(a)) [101]. Some researchers have found that the methane adsorption capacity of coals presents a "U-shaped" correlation with the increase of the fixed carbon content in which the minimum value appears in the stage of high volatile bituminous coal (Figure 14(b)) [102]. Moreover, the gas adsorption capacity of coals is positively correlated with pore surface area, but negatively correlated with ash and mineral content (Figures 14(c) and 


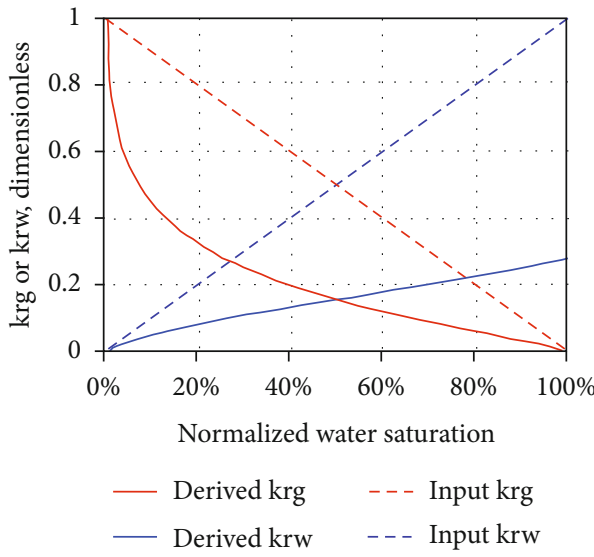

(a)

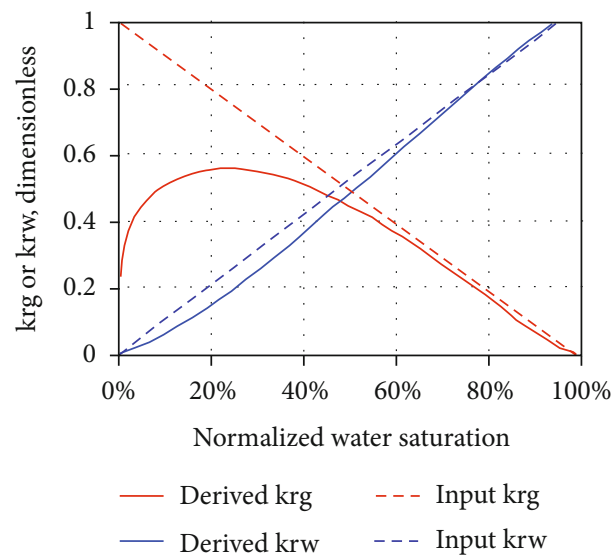

(c)

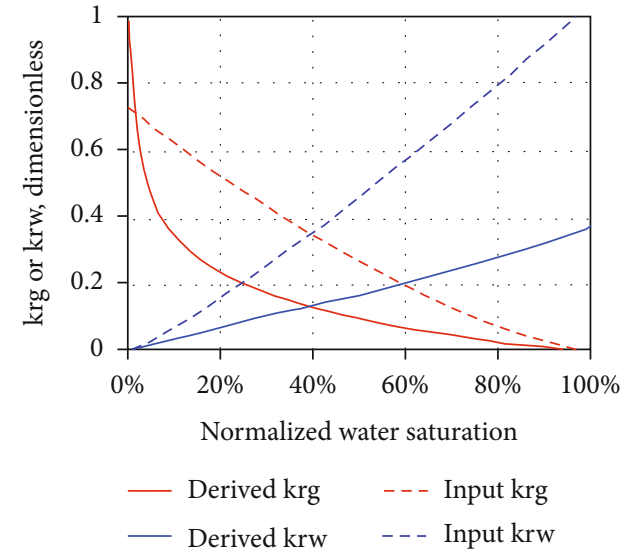

(b)

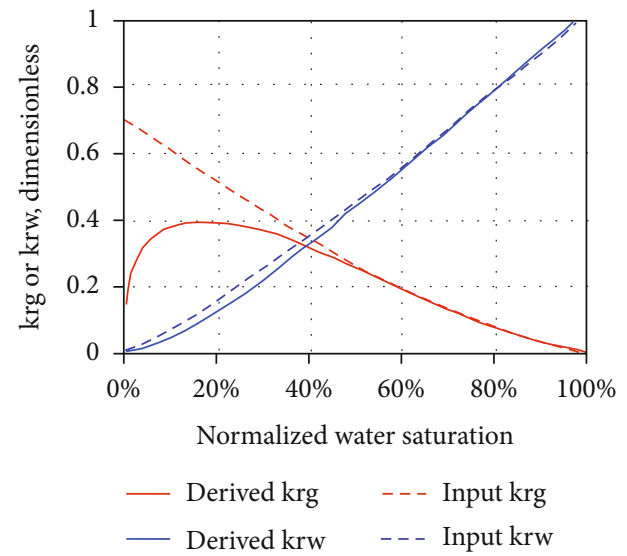

(d)

FIGURE 13: Comparison of derived and input relative permeability curves (modified from Clarkson et al. [98]).

14(d)) [103]. For maceral composition, vitrinite has the strongest adsorption capacity, followed by inertinite and exinite [99, 104]. Therefore, there is no simple functional relationship between coal type and gas adsorption capacity because of the complex components of coal and their different effects on gas adsorption.

4.1.2. Coal Deformation and Pore Structure. According to whether it has experienced the force of tectonic stresses, coal reservoirs can be divided into primary coals and tectonically deformed coals (TDCs) [37]. For TDCs, the primary structure is destroyed, and the pore structure is changed as well. The porosity and specific surface area obviously increase with the increase in the degree of coal deformation, which results in the larger Langmuir volume and lower Langmuir pressure of TDCs (Figures 15(a) and 15(b)) [105, 106]. Meanwhile, the deformation also changes the intramolecular and macromolecular structure of the coal matrix, which further causes the stronger affinity between the coal surface and molecular $\mathrm{CH}_{4}$ [26]. The variation of gas adsorption capacity is mainly related to the pore structure (especially micropores) of coals, whereas the initial fast desorption process is strongly influenced by the mesopores and macropores, and the slow desorption process is dominated by the micropores [99].
4.1.3. Temperature and Pressure. Because the heterogeneity of coal reservoirs is very strong, the variation of gas adsorption/desorption behavior with temperature is relatively complex in different coals. Crosdale et al. [107] found that the absolute difference between all isotherms of subbituminous coals is small when the temperature ranges from $26^{\circ} \mathrm{C}$ to $32^{\circ} \mathrm{C}$ (Figures $16(\mathrm{a})$ and $16(\mathrm{~b})$ ). However, many studies have demonstrated that the gas adsorption capacity generally decreases with the increase of temperature (Figures 16(c)-16(f)) [108, 109]. It has been noted that the gas adsorption rate is positively correlated with the temperature [110]. For a single-component gas, the adsorption capacity always increases with the increase of gas pressure (Figures 17(a)-17(c)). For a multicomponent gas, the total amount of adsorbed gas in the gaseous mixture at a fixed pressure also gradually increases as the proportion of readily adsorbable gas in the gaseous mixture increases, whereas it increases in varying degrees because SG anthracitic coal has a more absorbing substrate than the other two coals (Figures 17(d)-17(f)) [111].

4.1.4. Moisture Content. The effect of moisture content on gas adsorption capacity is clearly observed in Figure 18(a), indicating that the amount of adsorbed carbon dioxide of dry coals is significantly higher than that of wet coals. The reason 


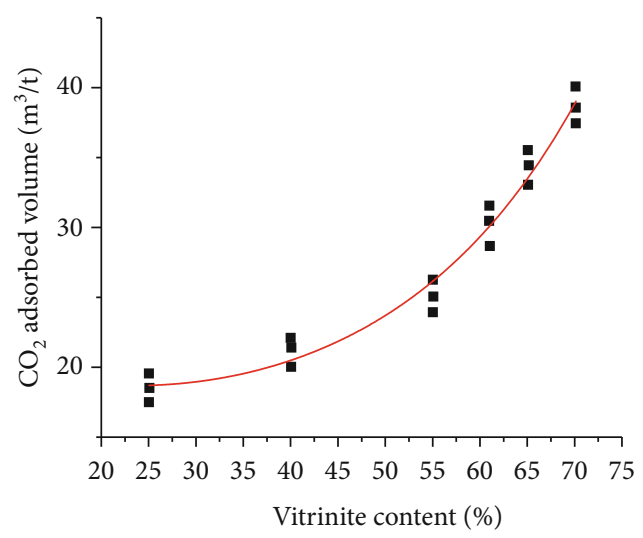

(a)

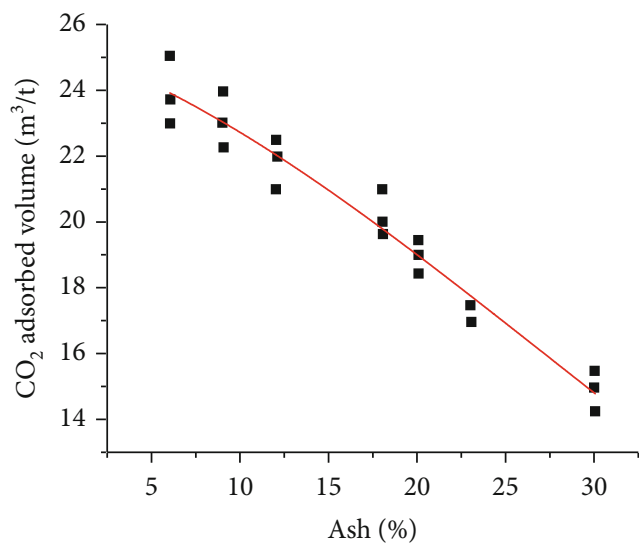

(c)

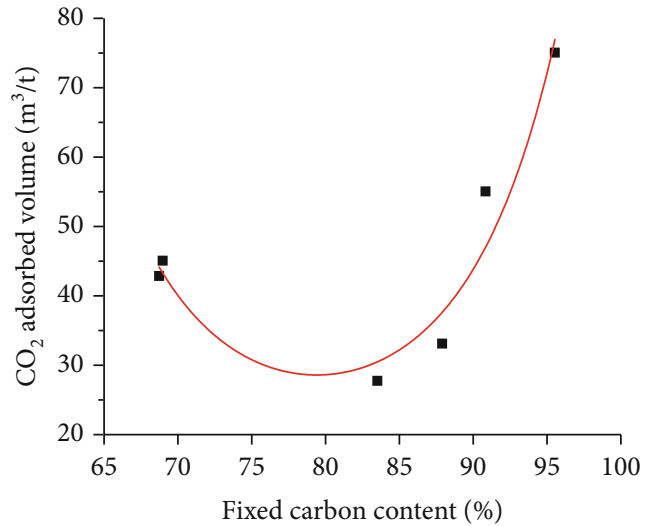

(b)

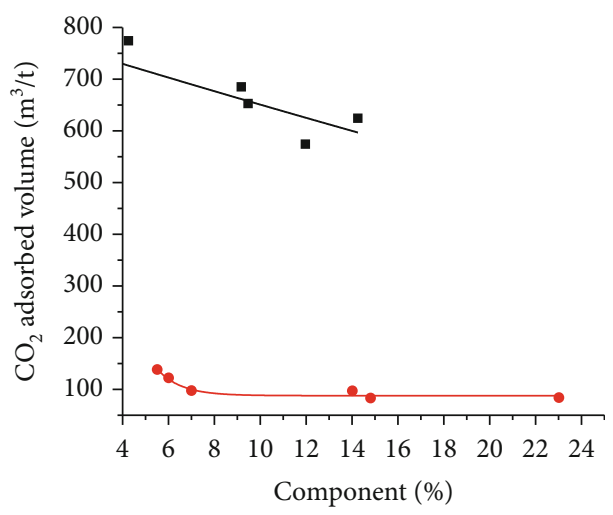

- Mineral matter

- Liptinite

(d)

FIgURE 14: Relationships between $\mathrm{CO}_{2}$ adsorption capacity and maceral composition and coal composition, and the variation of Langmuir parameters with vitrinite reflectance of tectonic/intact coals (e, f) (modified from Bustin and Clarkson [17], Levy et al. [102], and Faiz et al. [103]).
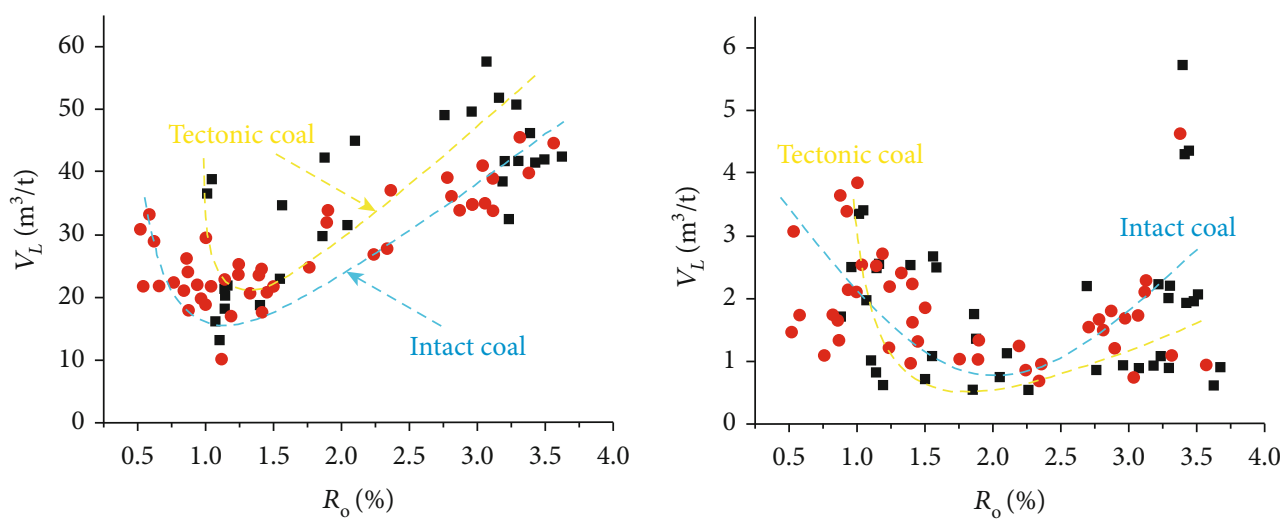

- Tectonic coal

- Intact coal

FIGURE 15: Relationships between the variation of Langmuir parameters with vitrinite reflectance of tectonic/intact coals (modified from Cheng and Pan [106]). 

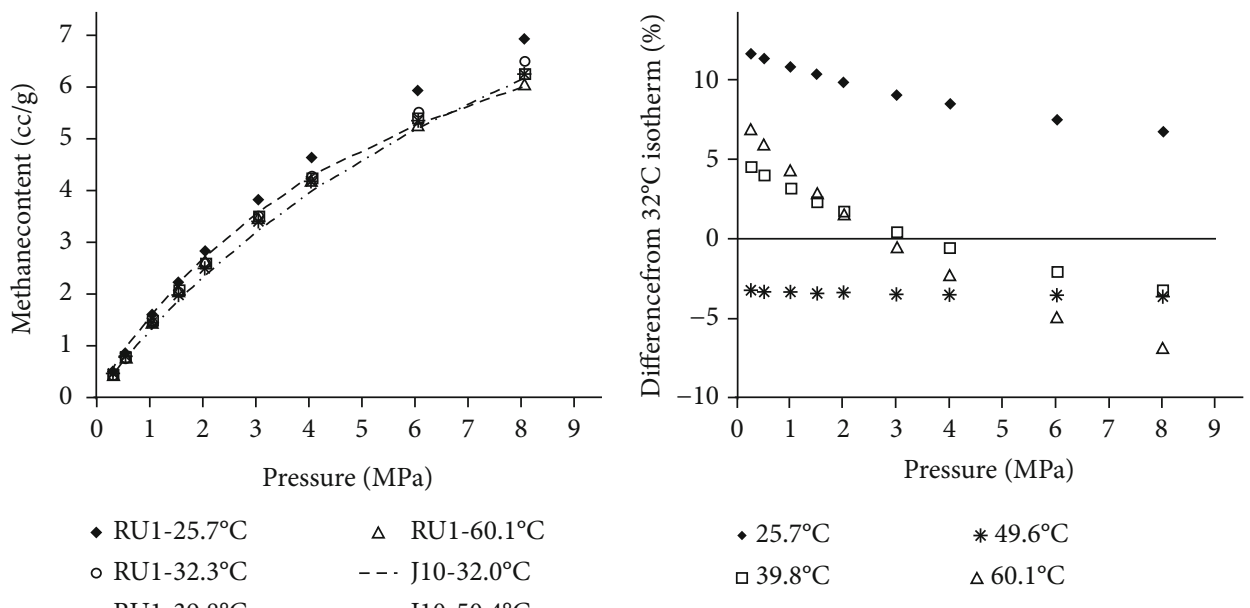

\begin{abstract}
- RU1-25.7 ${ }^{\circ} \mathrm{C}$
○ RU1 $-32.3^{\circ} \mathrm{C}$

口 RU1 $139.8^{\circ} \mathrm{C}$

* RU1 $1-49.6^{\circ} \mathrm{C}$

$\Delta$ RU $1-60.1^{\circ} \mathrm{C}$

- - J $\mathrm{J} 10-32.0^{\circ} \mathrm{C}$

$-\cdot-\mathrm{J} 10-50.4^{\circ} \mathrm{C}$
\end{abstract}

(a)

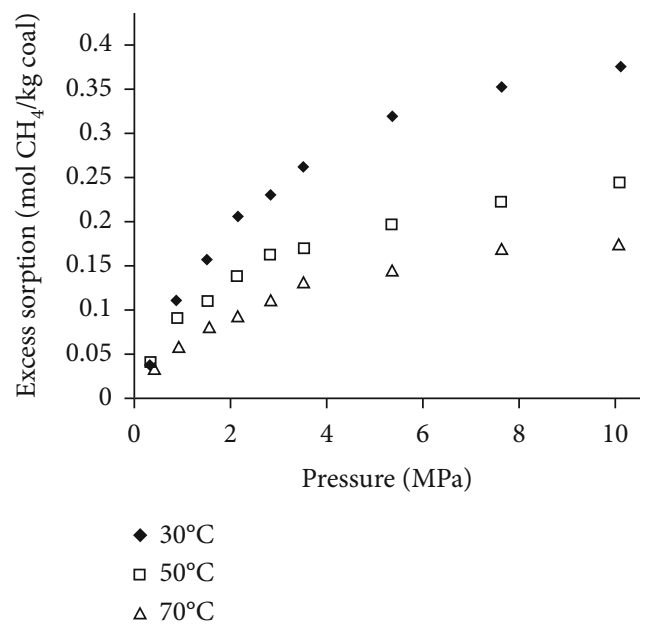

(c)

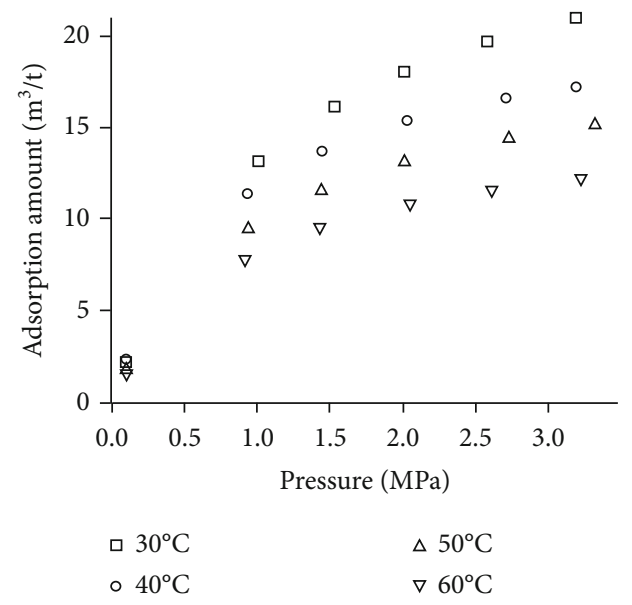

(e)

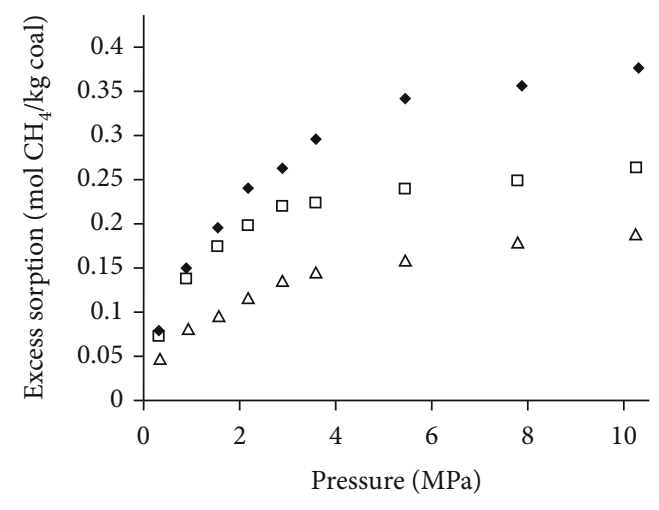

- $30^{\circ} \mathrm{C}$

$50^{\circ} \mathrm{C}$

$\triangle 70^{\circ} \mathrm{C}$

(d)

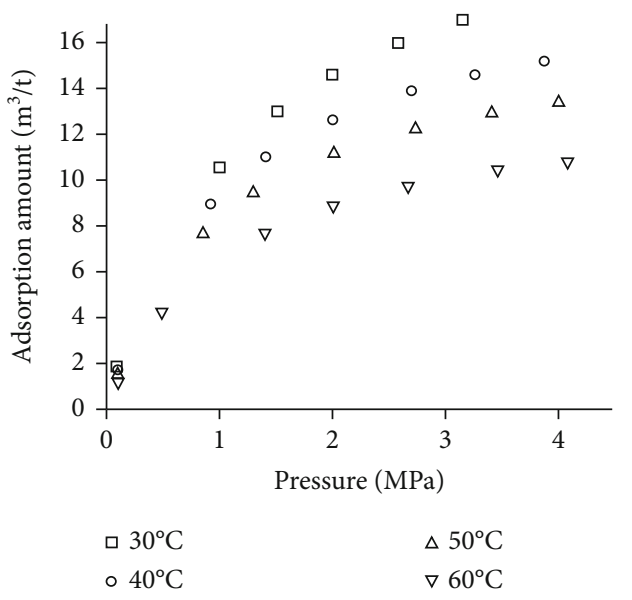

(f)

FIGURE 16: Variations of gas adsorption behavior with temperature in coal reservoirs: (a) methane adsorption isotherms for the $96 \%$ RH (equilibrium moist) samples at a variety of temperatures; (b) percent difference from the $32^{\circ} \mathrm{C}$ (bed temperature) isotherm for the various temperatures of the RU1 samples in (a); (c) adsorption isotherms of the weak-brittle deformed coal at different temperatures; (d) adsorption isotherms of the strong-brittle deformed coal at different temperatures; (e, f) adsorption curves at different temperatures for samples (modified from Crosdale et al. [107], Pan et al. [108], and Liu et al. [109]). 


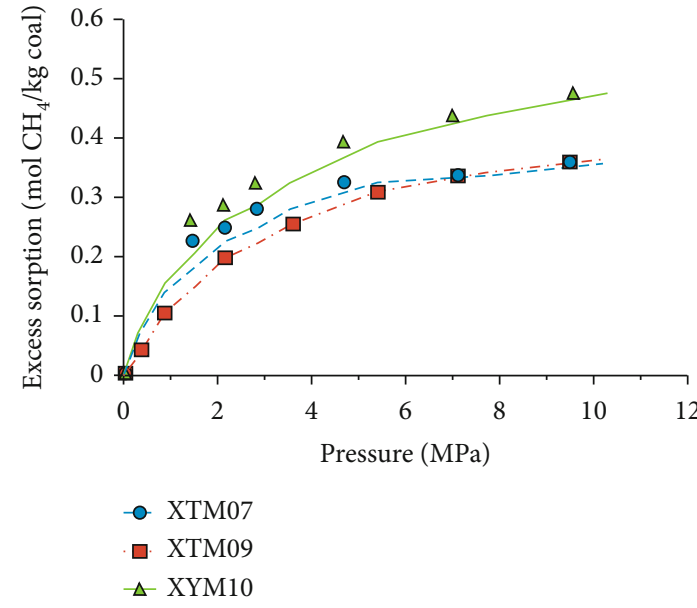

(a)

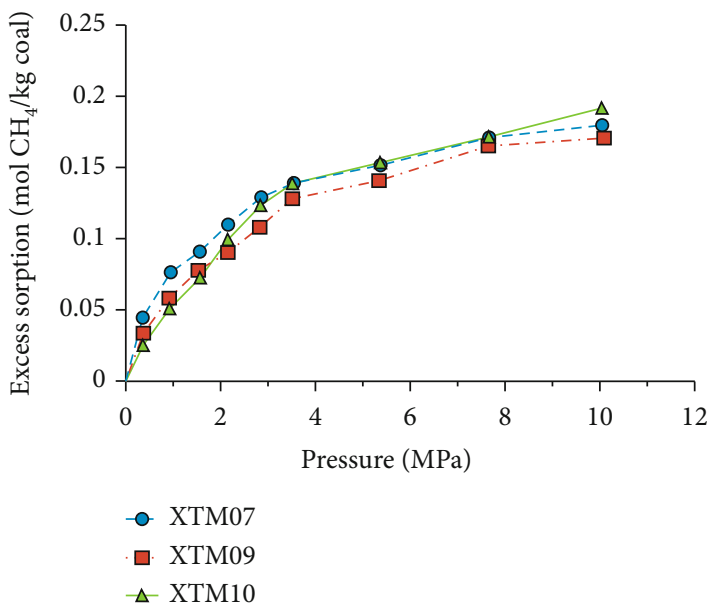

(c)

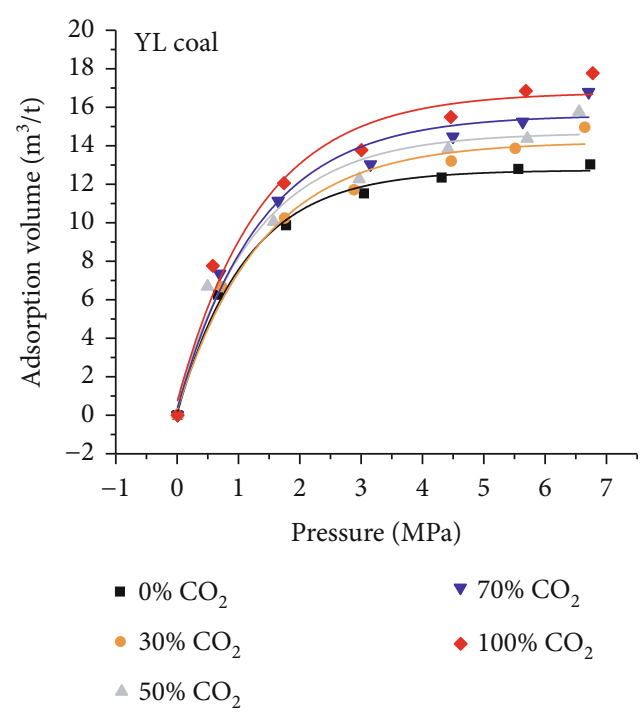

(e)

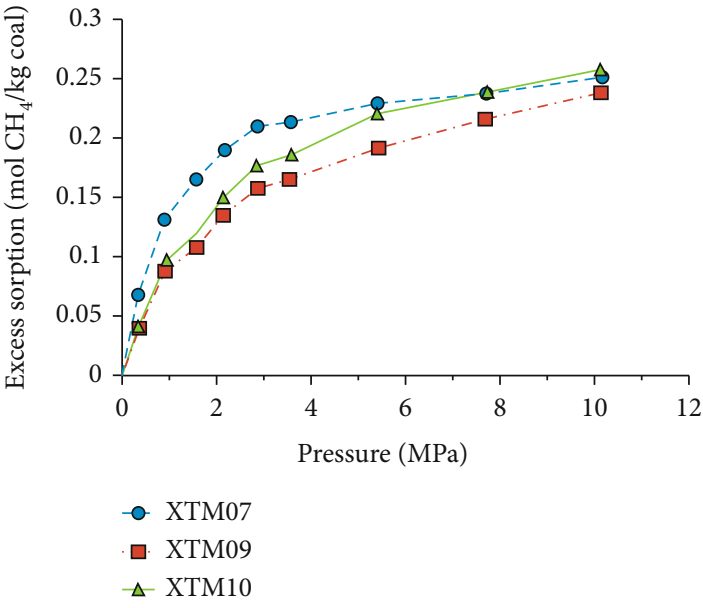

(b)

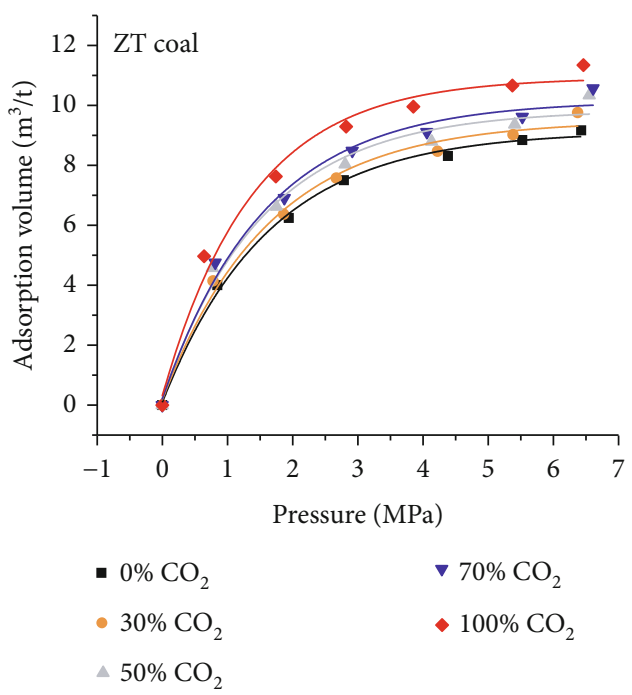

(d)

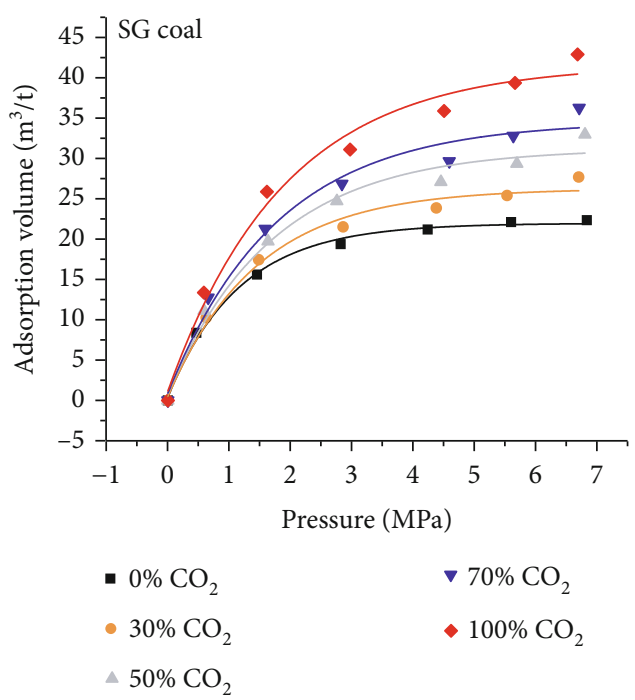

(f)

FIGURE 17: Variations of gas adsorption behavior with pressure in coal reservoirs: $(\mathrm{a}-\mathrm{c})$ adsorption isotherms of tectonically deformed coals at different temperatures; (d-f) isothermal adsorption curves of coals with different adsorbed gases (modified from Pan et al. [108] and Cai et al. [111]). 


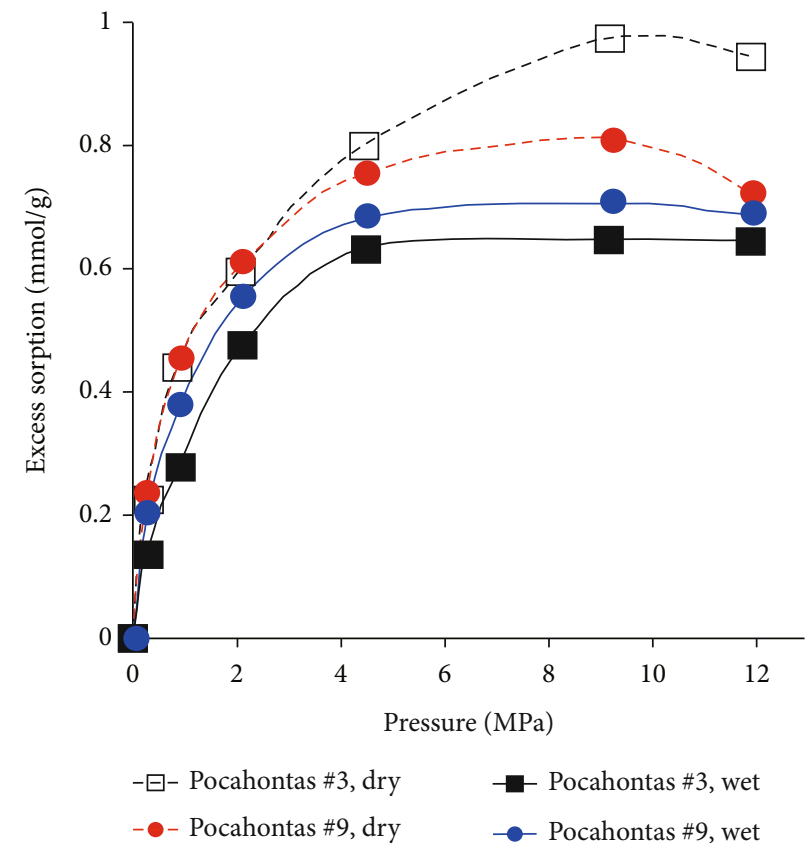

(a)

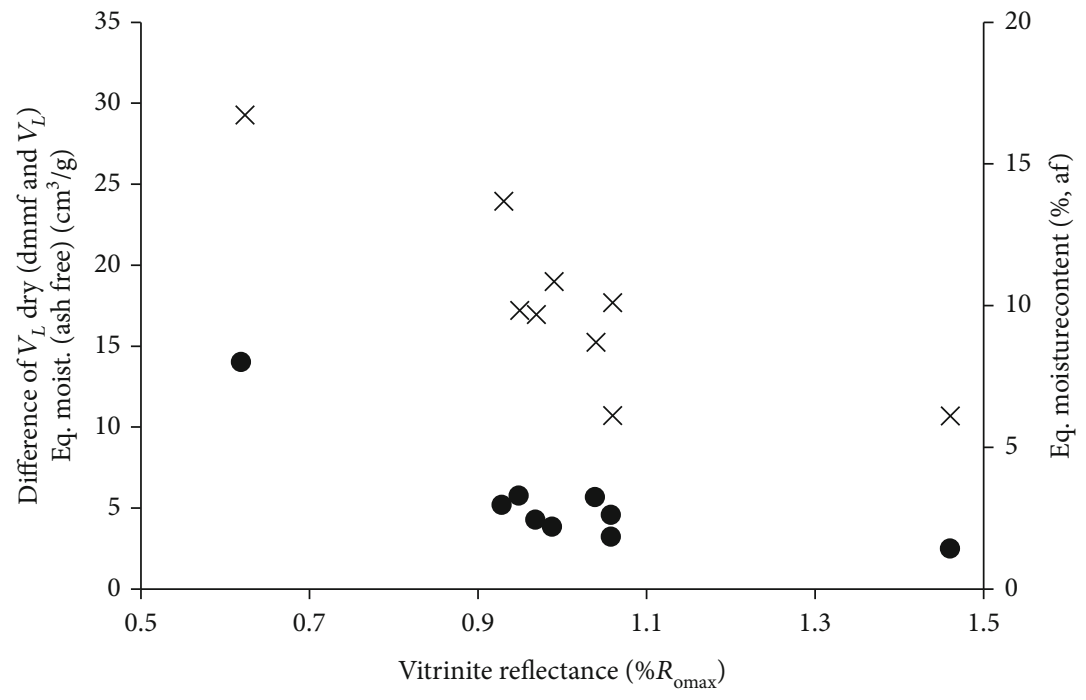

- Difference $\left(V_{L}\right.$ dry coal - $V_{L}$ equilibrium moist coal)

$\times$ Equilibrium moisture (\%, ash-free)

(b)

FIGURE 18: Variations of gas adsorption behavior with moisture in coal reservoirs: (a) $\mathrm{CO}_{2}$ excess sorption isotherms (dry basis) on wet and dry Appalachian coals; (b) difference of $V_{L}$ between dry coal and equilibrium moist coal (modified from Romanov et al. [6] and Laxminarayana and Crosdale [112]).

for this phenomenon is that the surface of the coal matrix can firstly adsorb $\mathrm{H}_{2} \mathrm{O}$ molecules with a strong polarity, which results in the reduction of the adsorption space of adsorbed gas in the coal matrix. Moreover, moisture can cause the secondary hydrocarbon blockage of micropores [112]. Because the low-rank coals have a stronger affinity to moisture, their maximum amount of adsorbed gas is significantly reduced (Figure 18(b)). As coal rank increases, the equilibrium moisture content of coals significantly decreases, resulting in the increase of gas adsorption capacity and the smaller difference of gas adsorption capacity between dry and wet coals [112]. Moreover, the sorption capacity and stability of $\mathrm{CO}_{2}$ show a decreased trend with the structural change of wet coal under high gas pressure [113].

\subsection{Influencing Factors of CBM Diffusion}

4.2.1. Pore Structure. The pore structure is closely related to the coal rank and tectonic movement, where mesopore and macropore volumes and the specific surface areas (SSA) 

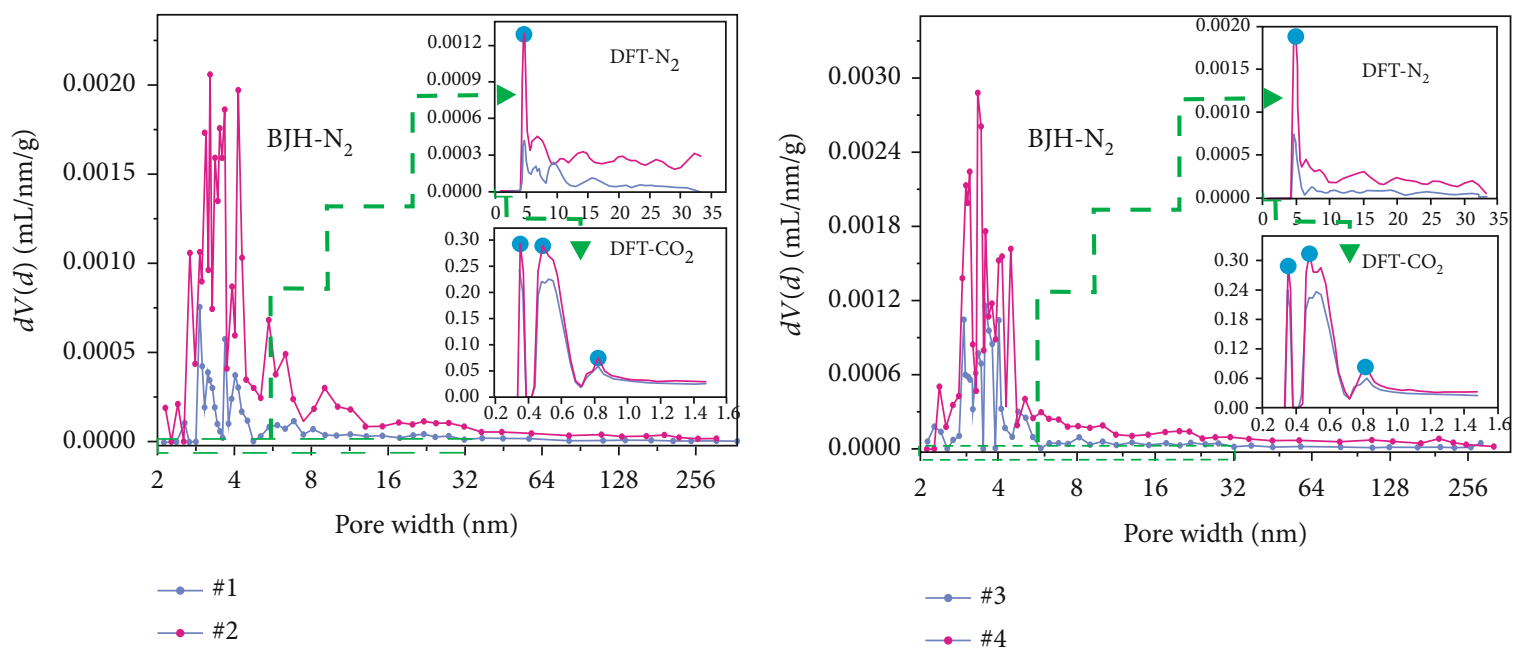

(a)
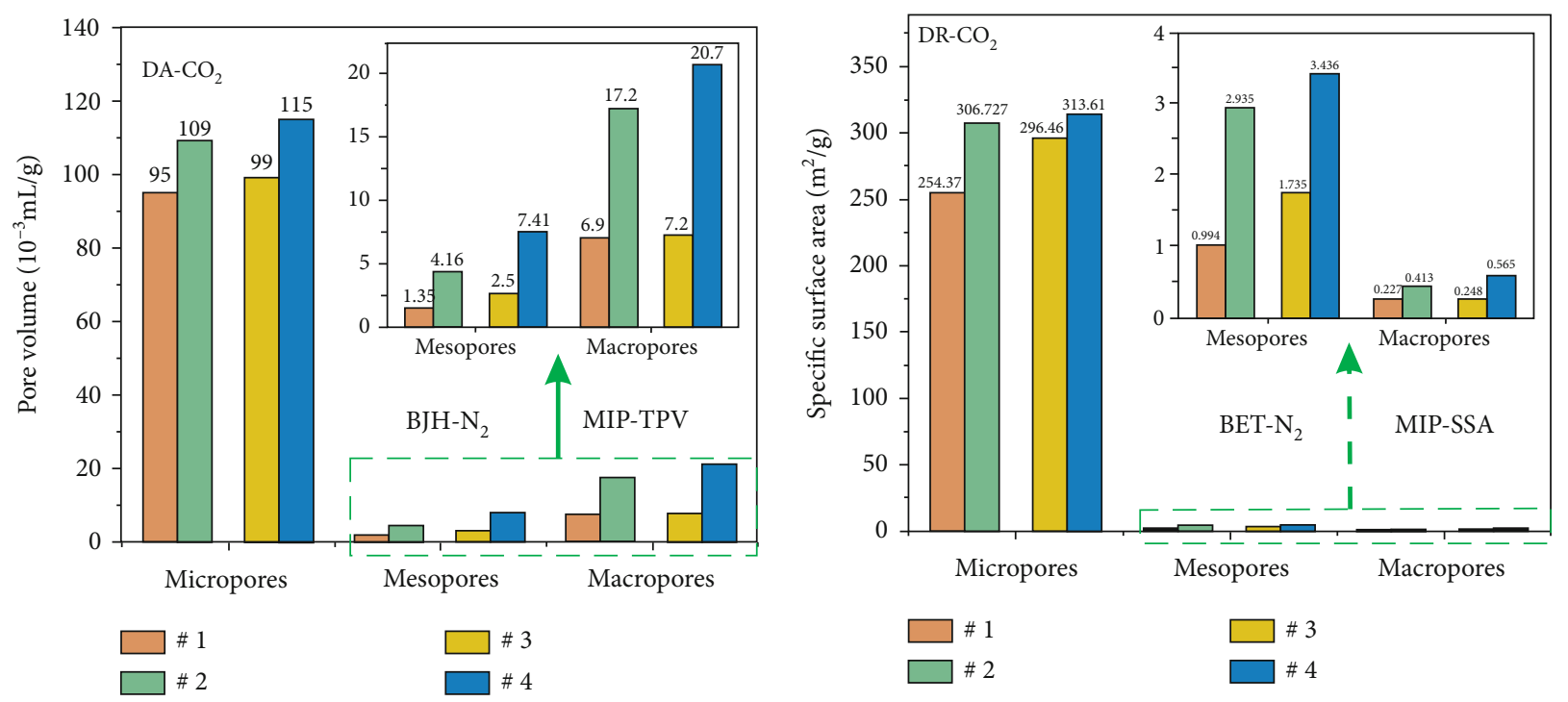

(c)

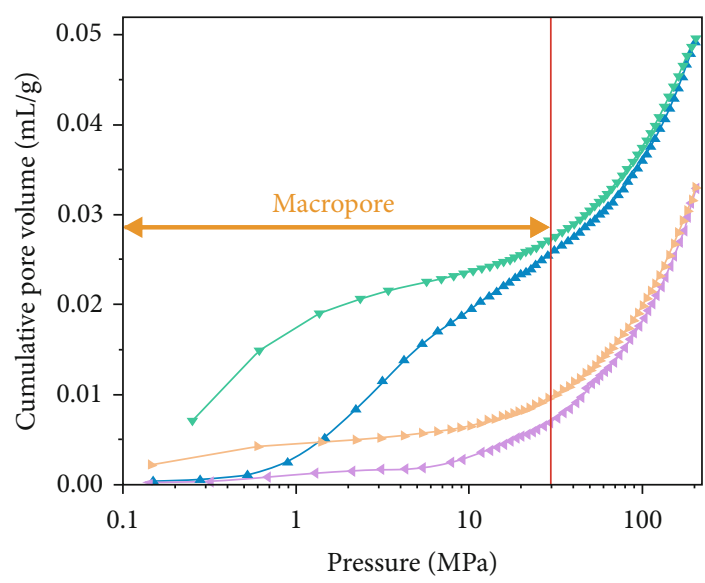

$$
\leftarrow \text { «1, injection } \rightarrow \text { \#2, injection }
$$

(e)
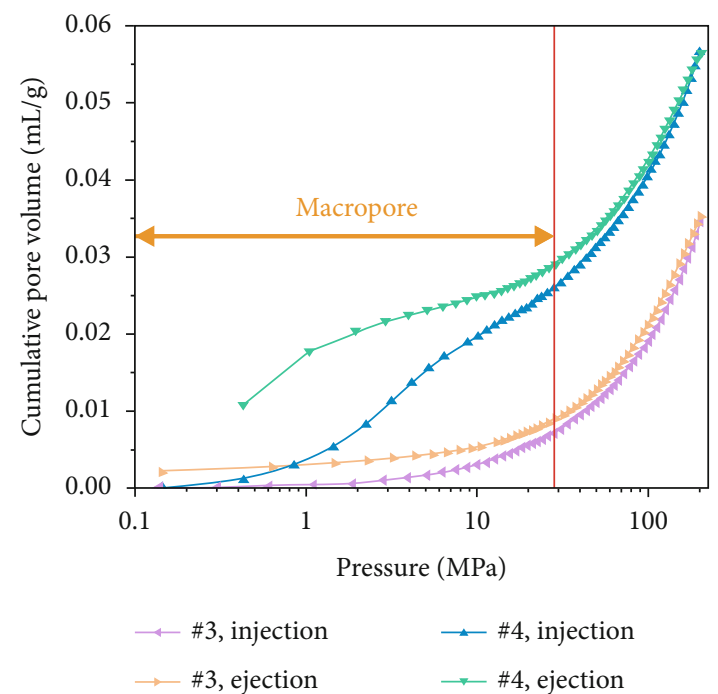

(f)

Figure 19: Continued. 


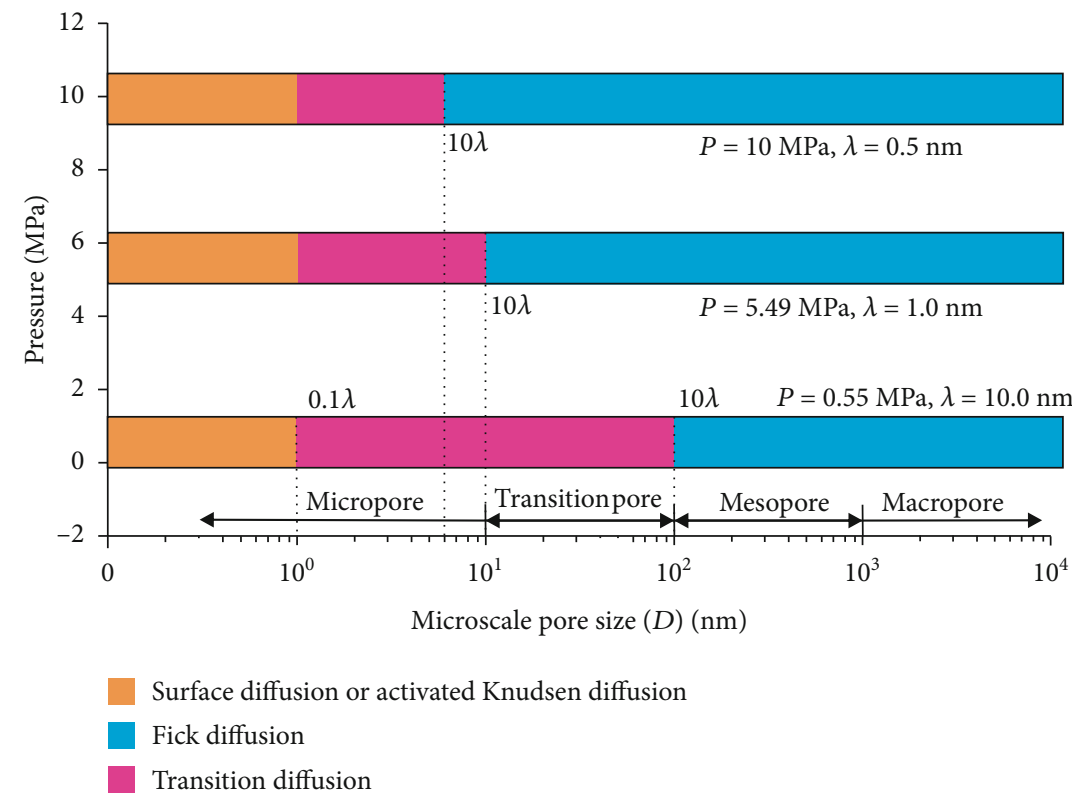

(g)

FIgURE 19: Characterization of the pore-fracture structure in different coals: $(\mathrm{a}, \mathrm{b})$ pore size distribution of coals from the gas adsorption/desorption method; ( $c, d$ ) pore volume and SSA of coals; (, $\mathrm{f}$ ) pore size distribution of coals from the MIP method; ( $\mathrm{g}$ ) relationship between the gas diffusion mechanism and pore size (modified from Du et al. [81] and Wang et al. [115]).

and porosity of coal reservoirs increase after having experienced tectonic damage $[114,115]$. Based on $\mathrm{N}_{2} / \mathrm{CO}_{2}$ adsorption and MIP measurements, Wang et al. [115] found that the pore structure of tectonic coal is more developed than that of intact coal (Figures 19(a) and 19(b)), and meanwhile, it shows higher values of pore volume and SSA (Figures 19(c) and 19(d)) and better connectivity (Figures 19(e) and 19(f)). There are different gas diffusion patterns in coals developed with different PSDs in which more micropores can cause a high proportion of transitional diffusion, whereas more mesopores (100-1000 nm) and macropores (1000$10,000 \mathrm{~nm}$ ) can result in a high proportion of Fick's diffusion in coals $[78,81]$. Moreover, the mean free path of molecular gas generally increases with the decrease of gas pressure, which leads to the decrease of the proportion of the Fick diffusion in multiscale pores of coals (Figure 19(g)).

4.2.2. Gas Components and Moisture Content. Knowledge of CBM belongs to the multicomponent mixed gas, which mainly consists of $\mathrm{CH}_{4}, \mathrm{C}_{2+}, \mathrm{CO}_{2}, \mathrm{~N}_{2}$, and partially inert gases. Firstly, the concentration differences of different gas components can inevitably lead to different diffusion rates of CBM in coals [85]. Moreover, the adsorption kinetics of different gas molecules on the pore surface are different in coals, which may also cause different diffusion behaviors [116]. Clarkson and Bustin [78] found that $\mathrm{CO}_{2}$ diffusivity is generally higher than that of $\mathrm{CH}_{4}$ and $\mathrm{N}_{2}$. Based on the smallest relative molecular size and kinetic diameter, the diffusion coefficients of three gases in coals decrease with the order of $\mathrm{CO}_{2}>\mathrm{N}_{2}>\mathrm{CH}_{4}$ (Figures 19(a) and 19(b)) [116]. $\mathrm{Li}$ et al. [86] found that the gas diffusion rate of wet coal is slower than that of dry coal, and this is because the moisture adsorbs to the pore surface and further occupies the pore space. Moreover, partial minerals in coal can swell through adsorbing moisture, which may block the path of pores and result in the decrease of the gas diffusion rate [117]. As shown in Figures 20(c)-20(h), the $\mathrm{CH}_{4}$ macropore and micropore diffusivities decrease with the increase of pressure, whereas the mesopore diffusivities increase with the increase of pressure, which may result from the different performance of gas diffusion in different pore structures [86]. Moreover, the $\mathrm{CH}_{4}$ diffusion coefficient is more easily affected by moisture than that of $\mathrm{CO}_{2}$ [85]. It has been noted that gas diffusion generally occurs in both the gas phase and liquid phase in watersaturated coals, indicating that the effective diffusion rate mainly depends on the saturation and distribution of water in the coal matrix [118].

4.2.3. Temperature and Pressure. Previous research [61, 78, $110,119]$ has shown that the diffusivity of $\mathrm{CO}_{2}$ in coal is greater than that of $\mathrm{CH}_{4}$ and $\mathrm{N}_{2}$ because of their different kinetic diameters, and gas diffusivities generally increase with the increase of pressure and temperature (Table 5). On one hand, the molecular gas becomes more active and diffuses more easily with the increase of temperature. On the other hand, the molecular gas desorbs more easily from the pore surface and then accumulates in the coal matrix with the increase of temperature, resulting in the increase of the gas diffusion rate [85]. As shown in Figure 21(a), a strong positive correlation exists between the gas pressure and the diffusion coefficients of differently ranked coals with the increase of gas pressure, which is influenced by different diffusion mechanisms under different pressures [120, 121]. However, Clarkson and Bustin [78] found that gas diffusivities 

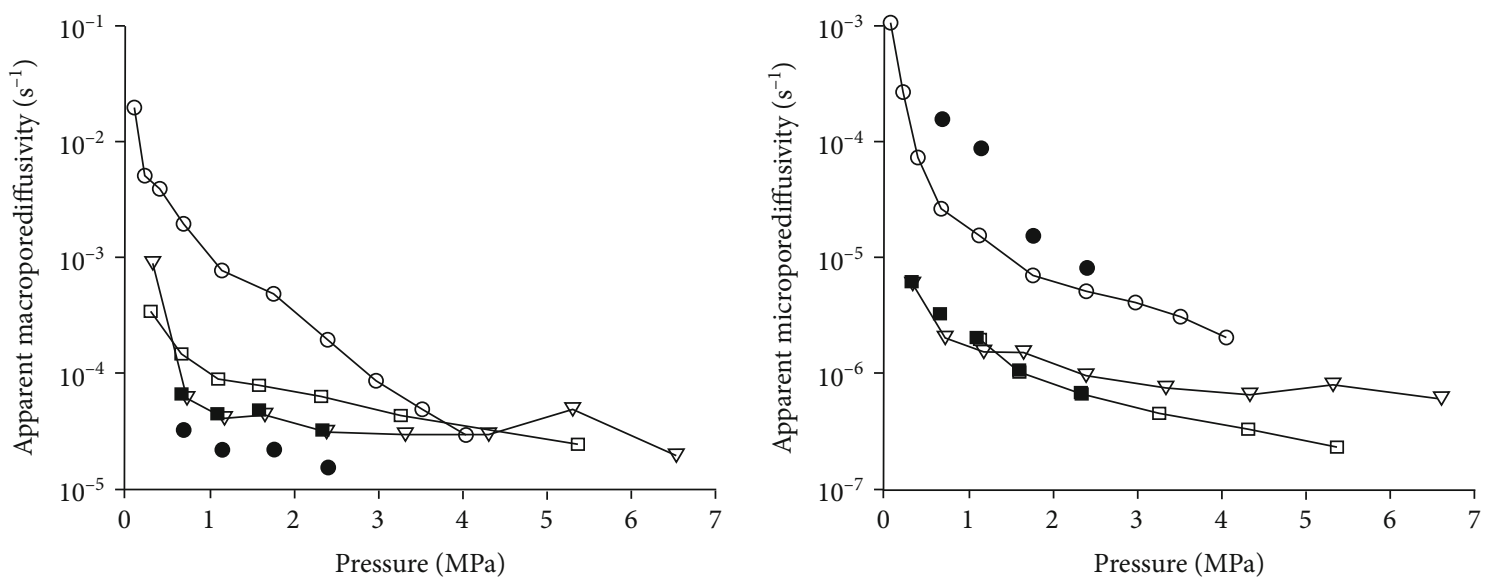

- 0 Carbon dioxide

- Methane

- 0 Carbon dioxide

$\nabla$ Nitrogen

- Methane

$\nabla$ Nitrogen

(a)
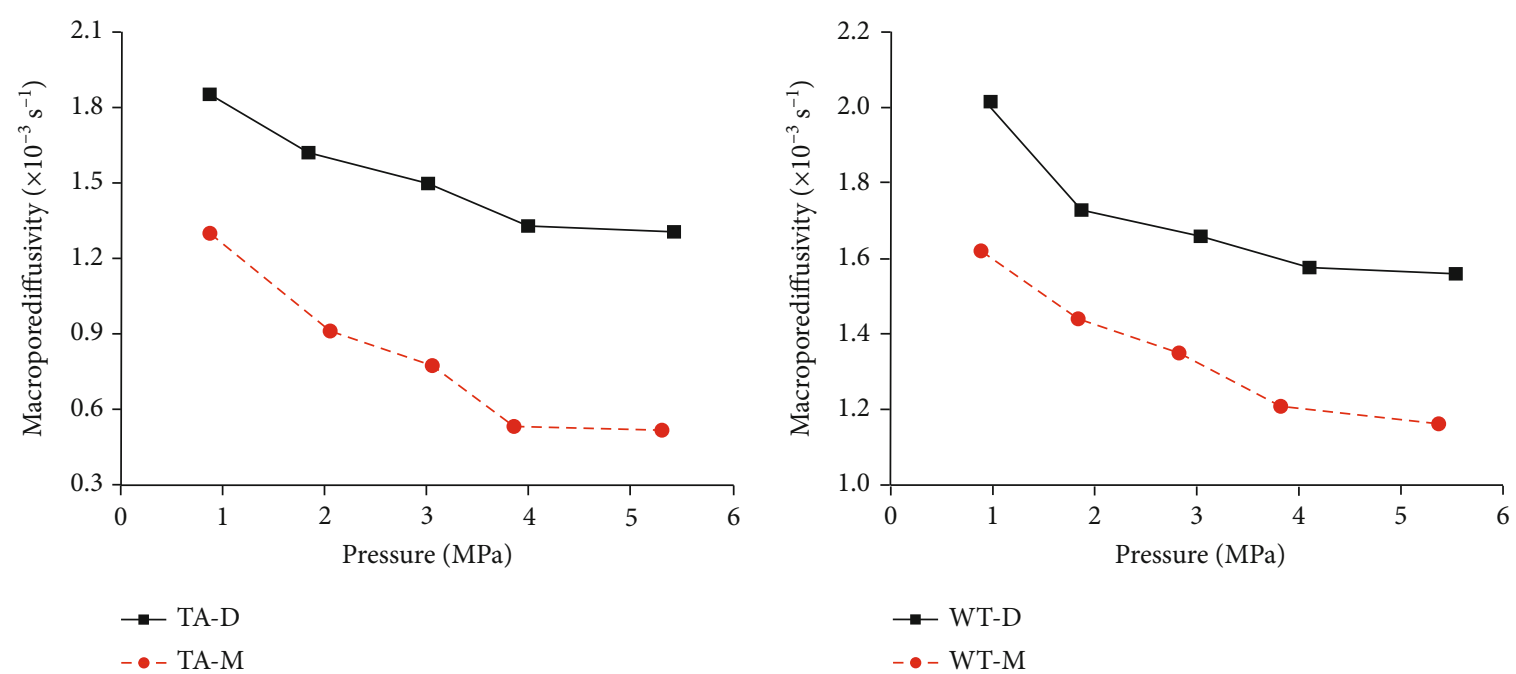

(c)
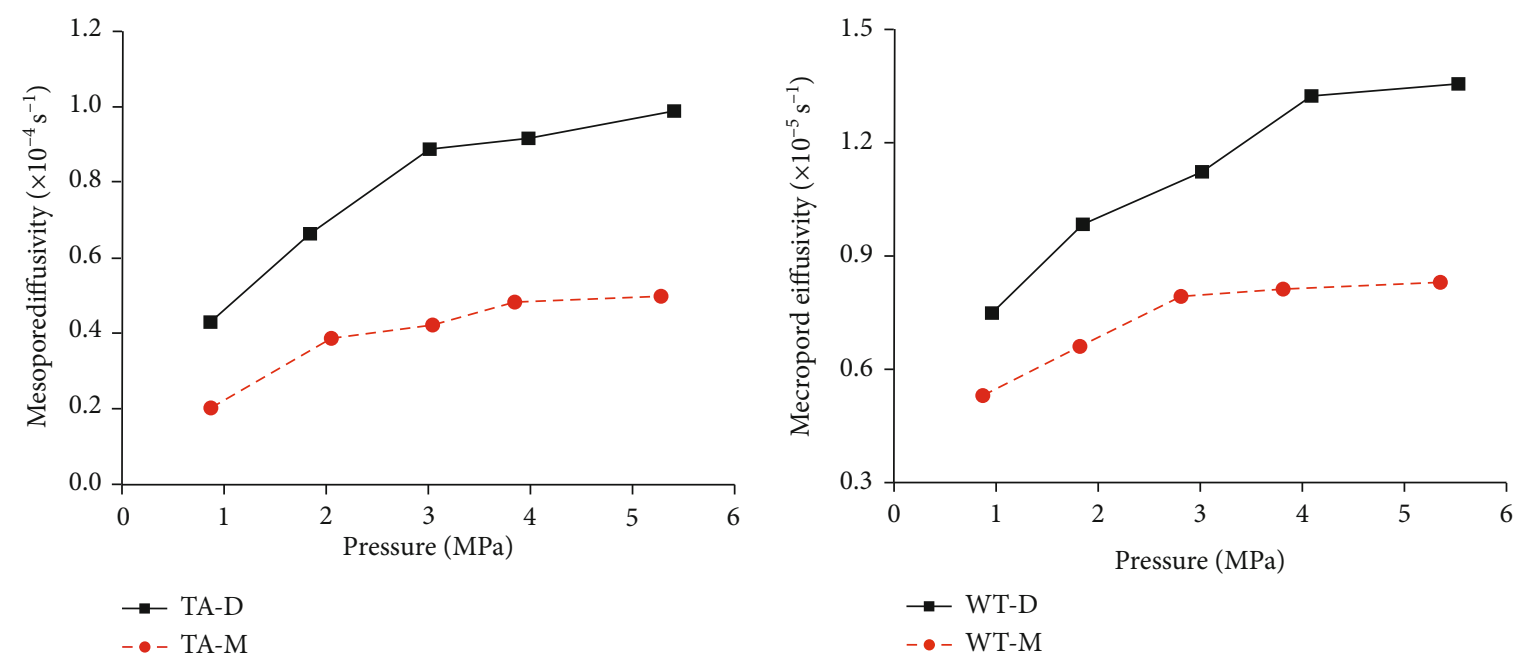

(e)

Figure 20: Continued. 


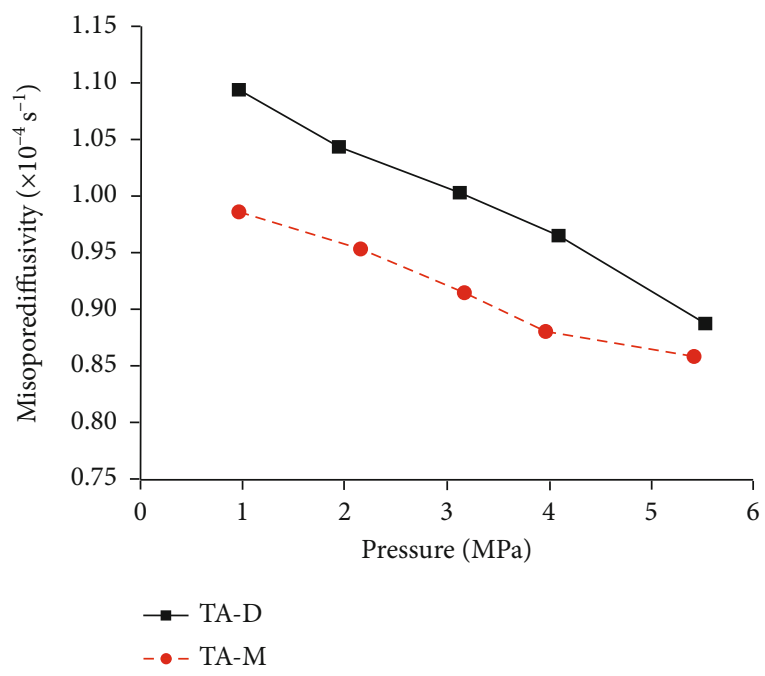

(g)

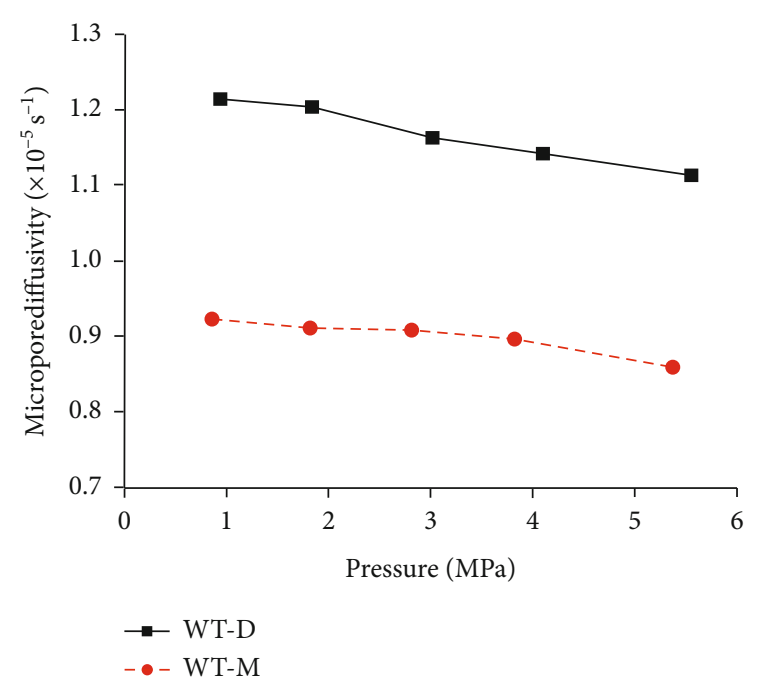

(h)

FIGURE 20: Relationships between gas diffusion diffusivities and pressure/moisture (modified from Li et al. [86] and Cui et al. [116]).

TABle 5: $\mathrm{CH}_{4}$ diffusivity under different temperatures and pressures (data from Cai et al. [120]).

\begin{tabular}{|c|c|c|c|c|c|c|}
\hline \multirow{2}{*}{ Gas species } & \multirow{2}{*}{ Temperature } & \multicolumn{2}{|c|}{ Pressure (MPa) } & \multirow{2}{*}{$\beta$} & \multirow{2}{*}{$D_{\mathrm{i}} / R_{i}^{2}\left(S^{-1}\right)$} & \multirow{2}{*}{$D_{a} / R_{a}^{2}\left(S^{-1}\right)$} \\
\hline & & From & To & & & \\
\hline \multirow{6}{*}{$\mathrm{CH}_{4}$} & \multirow{3}{*}{20} & 0.00 & 1.03 & 0.70 & $9.26 \times 10^{-7}$ & $9.16 \times 10^{-6}$ \\
\hline & & 1.03 & 2.75 & 0.70 & $9.88 \times 10^{-7}$ & $1.00 \times 10^{-6}$ \\
\hline & & 2.75 & 3.80 & 0.70 & $1.68 \times 10^{-6}$ & $7.35 \times 10^{-5}$ \\
\hline & \multirow{3}{*}{50} & 0.00 & 1.60 & 0.56 & $6.83 \times 10^{-6}$ & $1.94 \times 10^{-3}$ \\
\hline & & 1.60 & 2.95 & 0.56 & $8.98 \times 10^{-6}$ & $2.54 \times 10^{-3}$ \\
\hline & & 2.95 & 3.95 & 0.56 & $1.50 \times 10^{-5}$ & $2.10 \times 10^{-3}$ \\
\hline
\end{tabular}

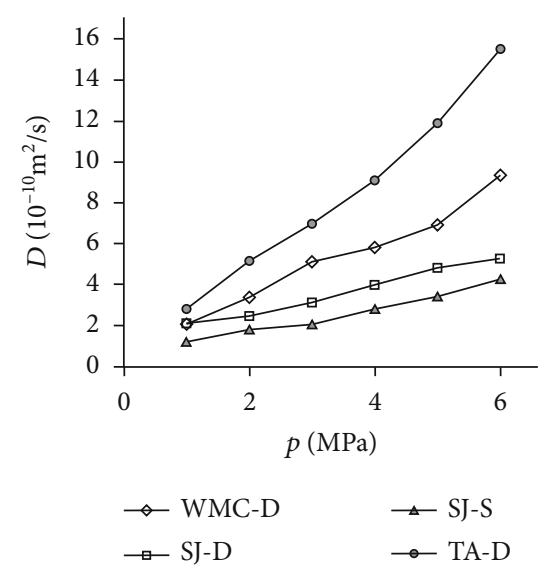

(a)

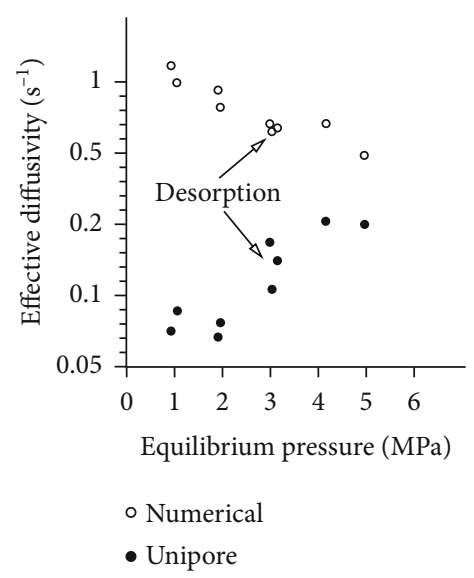

(b)

Figure 21: Variation of effective diffusion coefficients with different gas pressures (modified from Clarkson and Bustin [78] and Xu et al. [121]).

calculated from their numerical model decrease as gas pressure increases, whereas gas diffusivities calculated from the unipore model also increase as the gas pressure increases (Figure 21(b)). The negative trend between gas diffusivities and pressure may be dominated by different mechanisms of gas diffusion in coals, whereas the positive trend between gas diffusivities and pressure may be due to the nonlinearity of gas isotherms.

4.3. Influencing Factors of the CBM Seepage Process. The CBM seepage process is mainly dominated by the physical properties of coals, fracture development, in situ stress/effective 


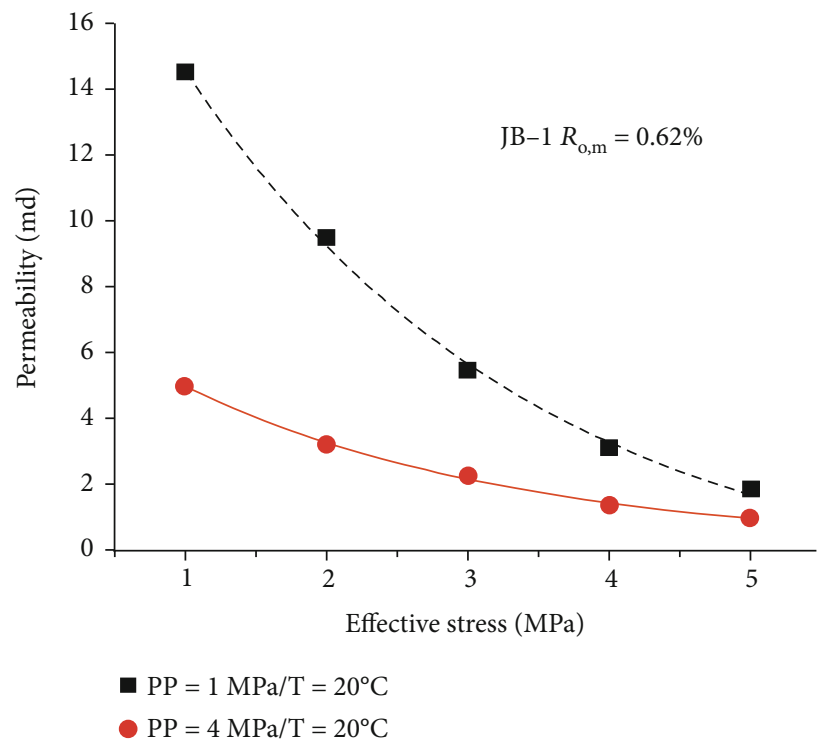

(a)

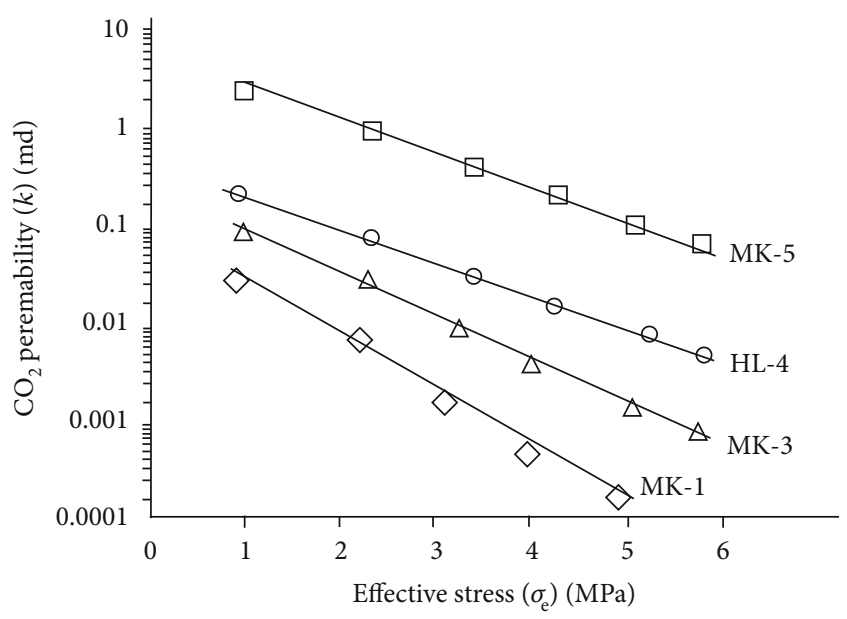

(c)

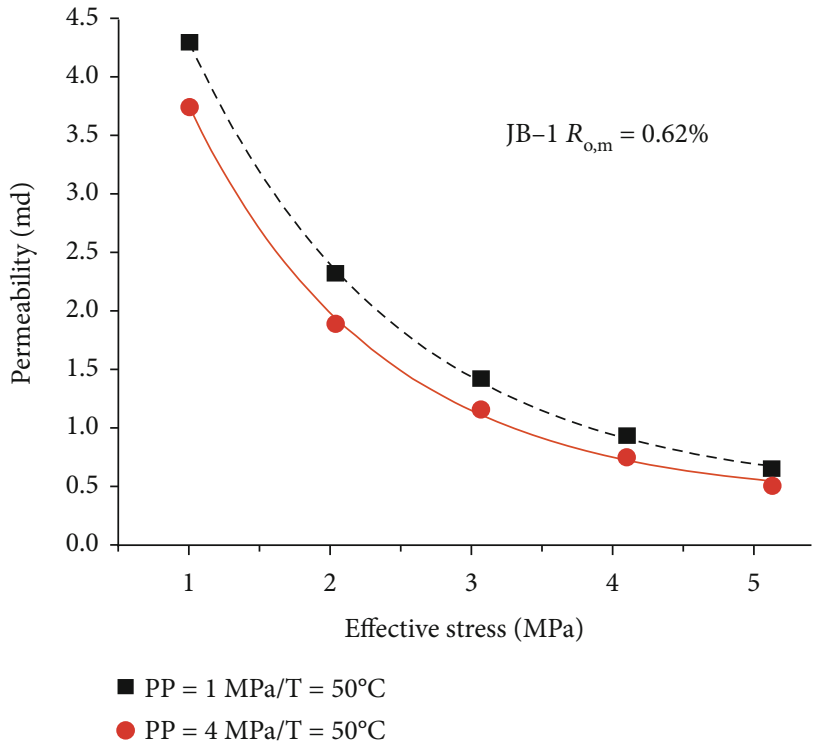

(b)

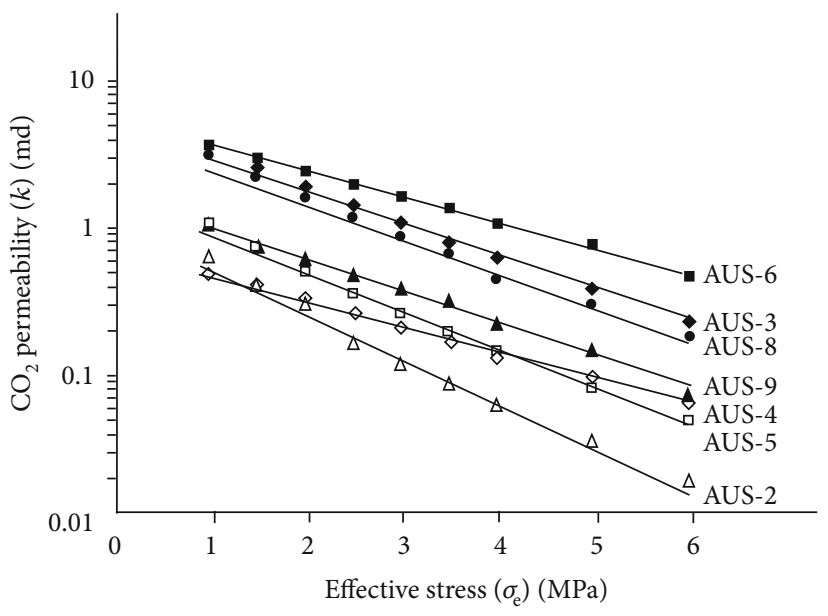

(d)

FIgURE 22: Relationship between coal permeability and effective stress (modified from Cai et al. [120] and Mckee et al. [125]).

stress, matrix shrinkage effect, and gas slippage effect [91, 122]. Generally, the extensive development of fractures is beneficial to the permeability of coal [90]. As the in situ stress increases, the permeability of coal shows a decreased tendency (a power exponential relationship with the in situ minimum principal stress) because natural fractures/cracks may be compressed or even closed [91, 123]. However, the dynamic change of coal permeability mainly depends on the effective stress, gas slippage effect, and coal matrix shrinkage effect during the drainage and depressurization process.

4.3.1. Effective Stress Effect. Compared with the conventional oil/gas reservoirs, coal reservoirs have obvious elastoplastic deformation characteristics and stress sensitivity in which the increase of effective stress can compress or close the fractures/cracks and further decrease the absolute permeability of coal. During the CBM production process, the pore pressure decreases and the effective stress increases with the continuous extraction of underground fluids, which causes the compression deformation of the coal matrix and the continuous reduction of pore-fracture space and permeability [124]. As shown in Figure 22, there is an exponential or linear decreasing relationship between permeability and the effective stress $[120,125]$. This trend may be contributed to the compression of pore-fracture space with the increase of effective stress during fluid migration in coals.

4.3.2. Gas Slippage Effect. When the average free path of gas molecules reaches the order of pore size, gas molecules can interact with the surface of the flow path, resulting in the increase of molecular velocity and coal permeability [126]. Taking molecular velocity into consideration, the measured gas permeability $(k)$ can be given by [122]:

$$
k=k_{0}\left(1+\frac{b}{P_{m}}\right)
$$




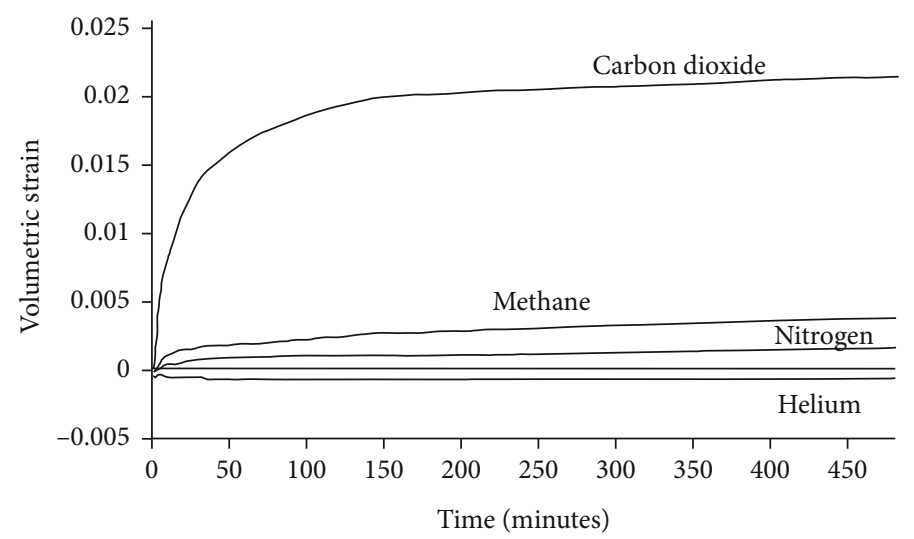

(a)

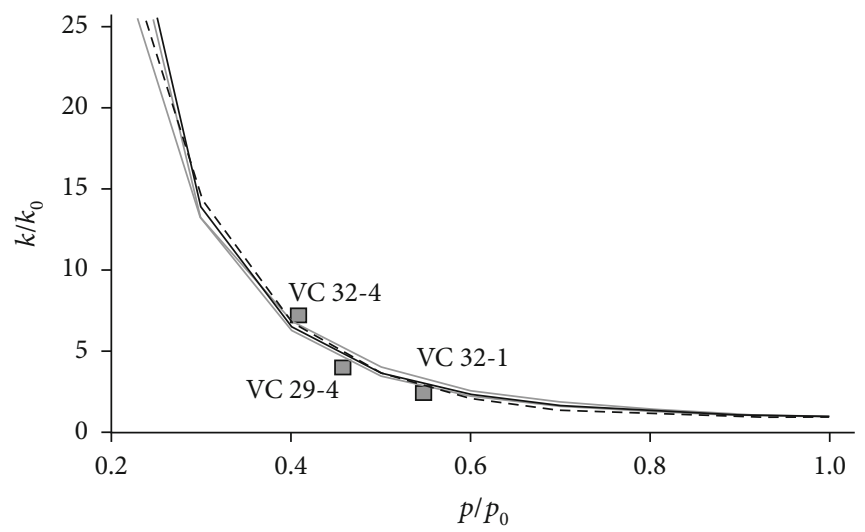

$\square$ Well test

— Present model

- - Mavor and vaughn (VC 32-1)

(b)

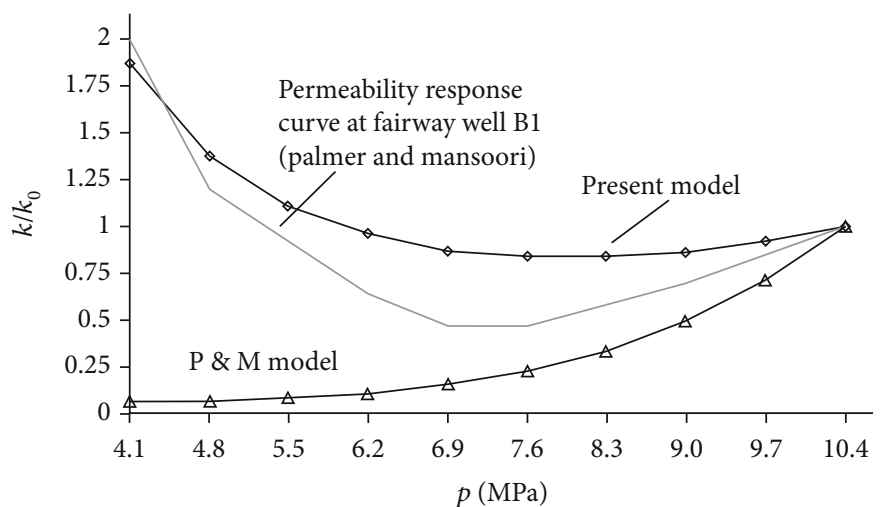

(c)

FIGURE 23: (a) Volumetric strain associated with gas adsorption at $4 \mathrm{MPa}$. (b) Comparison between the simulation results of the permeability model and well test data. (c) Permeability response curves of different permeability models. (Modified from St George and Barakat [23] and Shi and Durucan [128]).

where $k_{0}$ is the absolute permeability, $P_{m}$ is the mean gas pressure, $b$ is the "Klinkenberg coefficient," as follows:

$$
b=\frac{16 c \mu}{w} \sqrt{\frac{2 R T}{\pi M}}
$$

where $c$ is a constant (typically taken as 0.9 ), $\mu$ is the fluid viscosity, $M$ is the fluid molecular weight, $w$ is the flow path width, $R$ is the universal gas constant, and $T$ is the absolute temperature.

As shown in equation (4), the Klinkenberg coefficient is not only related to the physical properties of molecular gas, but it is also related to the pore-fracture structure and 


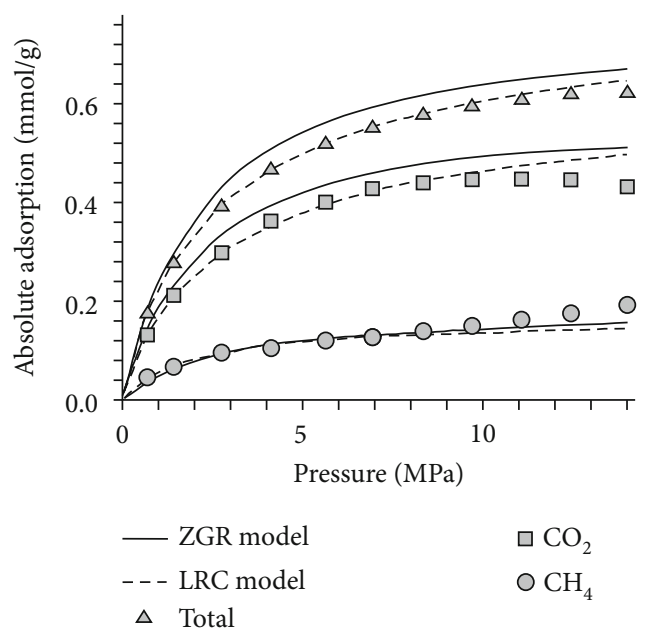

(a)

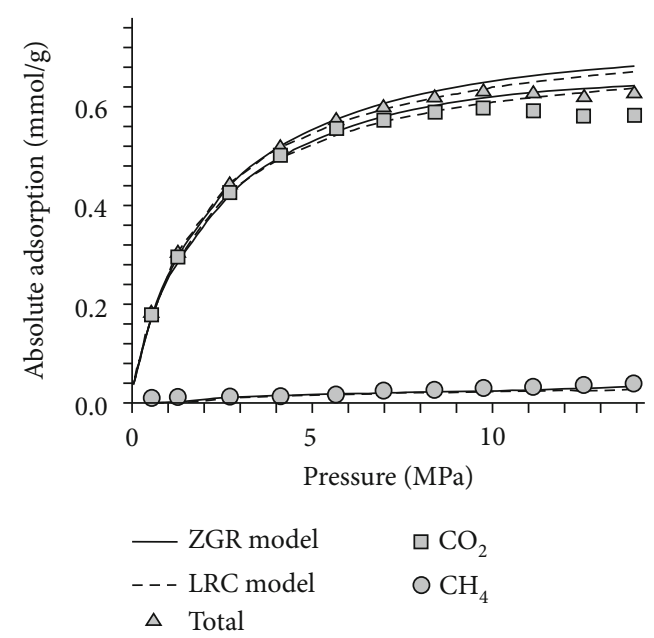

(b)

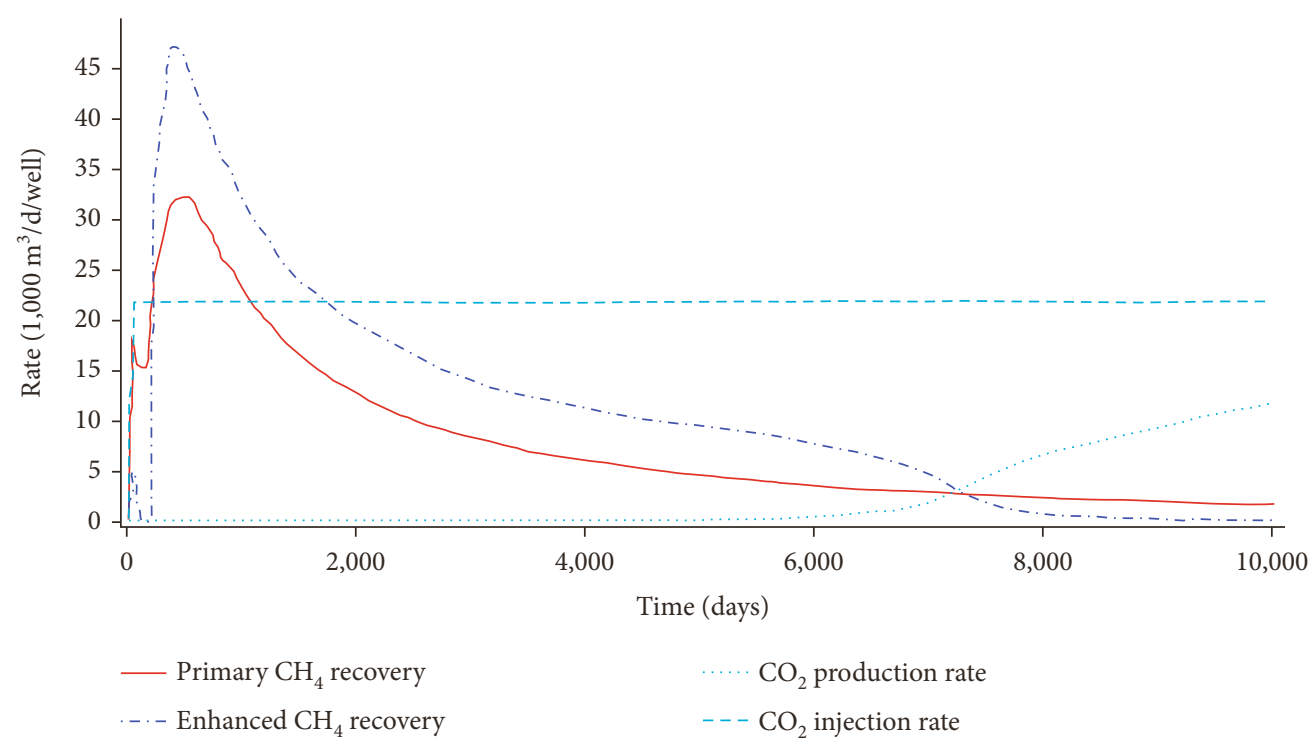

(c)

Figure 24: (a) Absolute adsorption of $40 / 60$ mole\% mixture: $\mathrm{CH}_{4} / \mathrm{CO}_{2}$ feed mixture on a wet Tiffany mixed-coal sample at $327.6 \mathrm{~K}$. (b) Absolute adsorption of 20/80 mole $\%$ mixture: $\mathrm{N}_{2} / \mathrm{CO}_{2}$ feed mixture on a wet Tiffany mixed-coal sample at $327.6 \mathrm{~K}$. (c) Predicted rates for primary gas recovery and the $\mathrm{CO}_{2}$ injection scenario. (Modified from Fitzgerald et al. [62] and Sander et al. [135]).

temperature. The Klinkenberg coefficient has no standard value and cannot be measured directly. The Klinkenberg coefficient of helium $\left(b_{\mathrm{He}}\right)$ and methane $\left(b_{\mathrm{Me}}\right)$ can be derived as follows [122]:

$$
\begin{gathered}
b_{\mathrm{He}}=\frac{16 c \mu_{\mathrm{He}}}{w} \sqrt{\frac{2 R T}{\pi M_{\mathrm{He}}}}, \\
b_{\mathrm{Me}}=\frac{16 c \mu_{\mathrm{Me}}}{w} \sqrt{\frac{2 R T}{\pi M_{\mathrm{Me}}}} .
\end{gathered}
$$

Thus, equation (6) can also be written as follows:

$$
b_{\mathrm{Me}}=\frac{\mu_{\mathrm{Me}}}{\mu_{\mathrm{He}}} \sqrt{\frac{M_{\mathrm{He}}}{M_{\mathrm{Me}}}} b_{\mathrm{He}} .
$$

The change of coal permeability $(\Delta k)$ caused by the gas slippage effect can be expressed as follows:

$$
\Delta k(\text { slippage effect })=k-k_{0}=k_{0}\left(1+\frac{b_{\mathrm{Me}}}{P_{\mathrm{m}}}\right)-k_{0}=k_{0} \frac{b_{\mathrm{Me}}}{P_{\mathrm{m}}} .
$$

Under the conditions of low gas pressure and gas density, the gas slippage effect becomes more obvious in the smaller path. As fluids are extracted from the coal reservoir, the gas slippage effect generally causes an increase in the apparent permeability and presents a positive effect on the CBM seepage in coals [127]. Moreover, the characteristics of the gas-water two-phase flow can be accurately predicted by considering the dynamic gas slippage factor. 


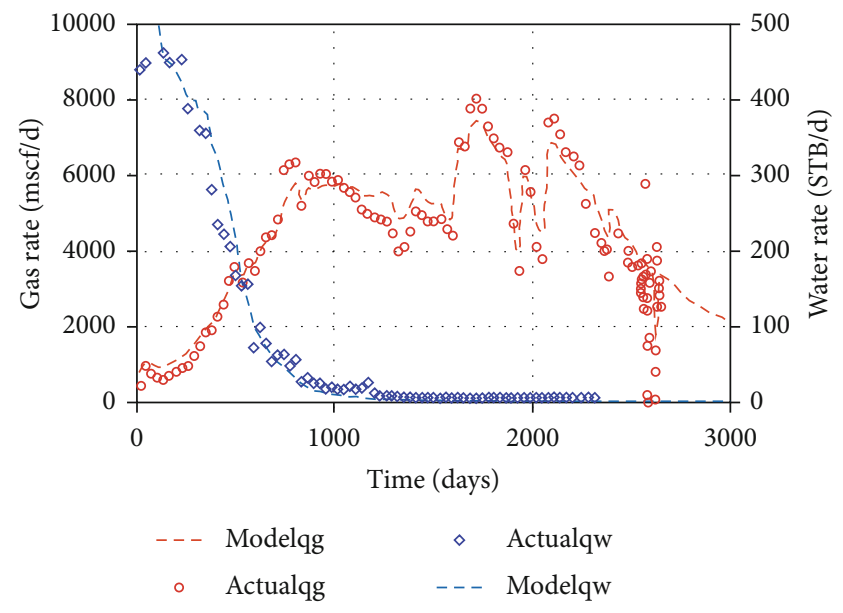

(a)

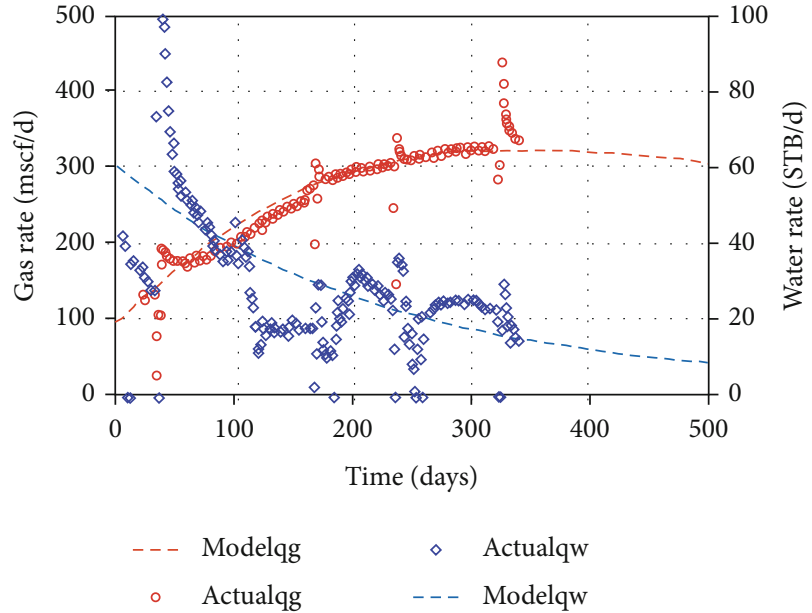

(b)

FIGURE 25: Match of simulation results and the gas/water production data: (a) exponentially increasing absolute permeability model; (b) constant absolute permeability model (modified from Clarkson et al. [98]).

4.3.3. Coal Matrix Shrinkage Effect. The phenomenon of coal matrix shrinkage generally occurs when the adsorbed gas desorbs from the coal matrix and the shrinkage degree can be accurately measured by an experiment (Figure 23(a)). The coal matrix shrinkage can lead to the decrease of horizontal stress and effective stress, and the increase of fracture width and permeability. Based on equation (8), the $\Delta k$ caused by the coal matrix shrinkage effect can be written as follows:

$$
\begin{aligned}
& \Delta k(\text { shrinkage effect })=k(\text { methane })-k_{0} \\
& -\Delta k(\text { slippage effect })=k(\text { methane })-k_{0}-k_{0} \frac{b_{\mathrm{Me}}}{P_{\mathrm{m}}},
\end{aligned}
$$

where $k$ (methane) is the measured permeability using methane.

Taking the effects of coal matrix shrinkage and different elastic properties into consideration, Shi and Durucan [128] proposed a model to simulate coal permeability (solid thin lines, Figure 23(b)), which is in accordance with the history-matched permeability response curve (thick broken line, Figure 23(b)) and shows better application than the previous model (Figure 23(c)). When the shrinkage degree of the coal matrix is less than the compaction degree by in situ stress, the porosity and permeability of coals may gradually decrease with the continuous production of CBM. Conversely, the porosity and permeability of coals show an increasing trend.

\section{Implication of Fluid Performance for CBM Production}

5.1. Competitive Adsorption of Different Gas Components. As shown in Figure 24(a) and Figure 24(b), the absorption capacity of $\mathrm{CO}_{2}$ is almost three times that of $\mathrm{CH}_{4}$ and 20 times that of $\mathrm{N}_{2}$ in coals under a certain pressure [62]. This phenomenon can be attributed to the following three aspects: (1) the adsorbents with higher atmospheric boiling points are preferentially adsorbed [129]; (2) the diameter of molecular $\mathrm{CO}_{2}$ is smaller than that of molecular $\mathrm{CH}_{4}$ and $\mathrm{N}_{2}$, which can go through the smaller micropores or throat; and (3) the critical temperature of $\mathrm{CO}_{2}\left(31.3^{\circ} \mathrm{C}\right)$ is closer to the reservoir temperature compared to that of $\mathrm{CH}_{4}\left(-81.9^{\circ} \mathrm{C}\right)$ [130]. Based on this property, the process of $\mathrm{CO}_{2}$ injection into coal reservoirs to replace or displace $\mathrm{CH}_{4}$ can improve $\mathrm{CBM}$ recovery [131-133]. As $\mathrm{CO}_{2}$ is injected into the coal seam, pores with different scales have different effects on different gas molecules in which the macropores provide a channel for molecular $\mathrm{CH}_{4}$ migration and the micropores can capture molecular $\mathrm{CO}_{2}$ by providing adsorption sites [134]. Sander et al. [135] found that the CBM production peak value of the primary recovery is increased by $46 \%$ with $\mathrm{CO}_{2}$ injection, and the total CBM production has also been improved during the long-term production process (Figure 24(c)). However, it is worth noting that $\mathrm{CO}_{2}$ is beginning to appear in production wells after 6000 days, which means $\mathrm{CO}_{2}$ may be extracted to the surface again with the decline of $\mathrm{CO}_{2}$ storage capacity in the coal seam.

5.2. Fluid Transport Process in CBM Reservoir. As the coalbed water is pumped out from a CBM well, the original pressure balance of a coal reservoir is broken, and the CBM flow velocity and pressure at any point in the flow field constantly changes with time. The CBM production process generally undergoes three seepage stages: (1) the single-phase water flow stage, (2) the gas-water two-phase flow stage, (3) the single-phase gas flow stage $[136,137]$. By comparing the simulation results of different permeability models and the gas and water production data, Clarkson et al. [98] found that the water relative permeability decreases and the gas relative permeability increases during the CBM production process, and large increases in gas rate after 1500 days are related to 


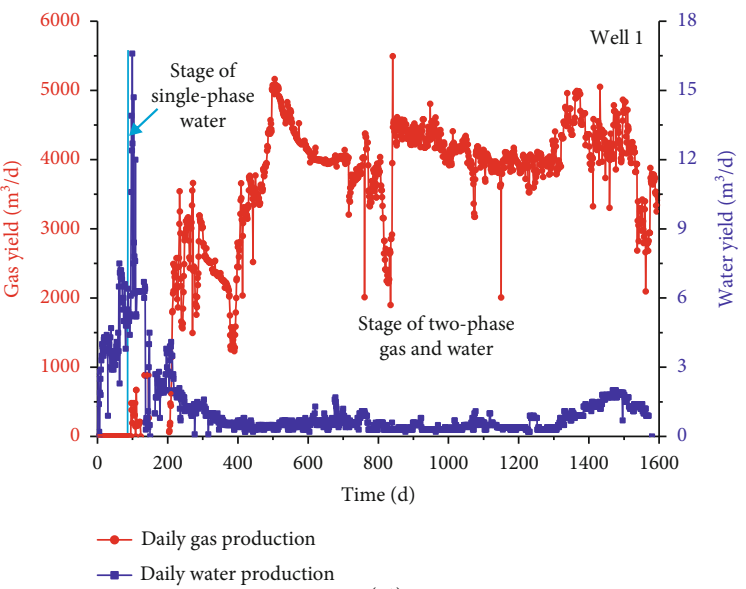

(a1)

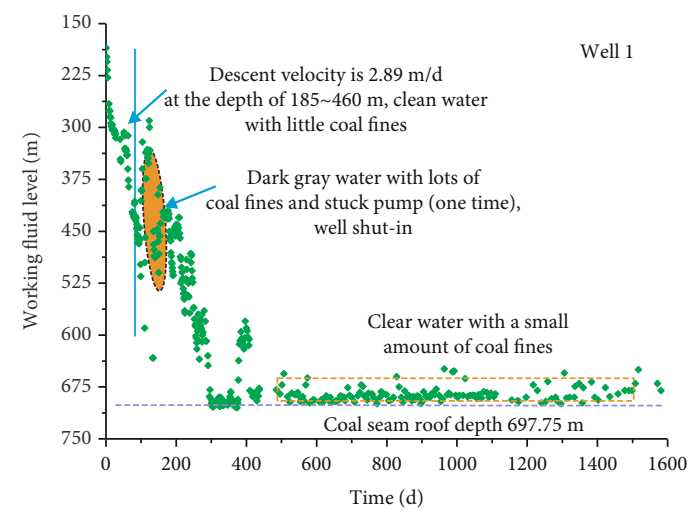

(a2)

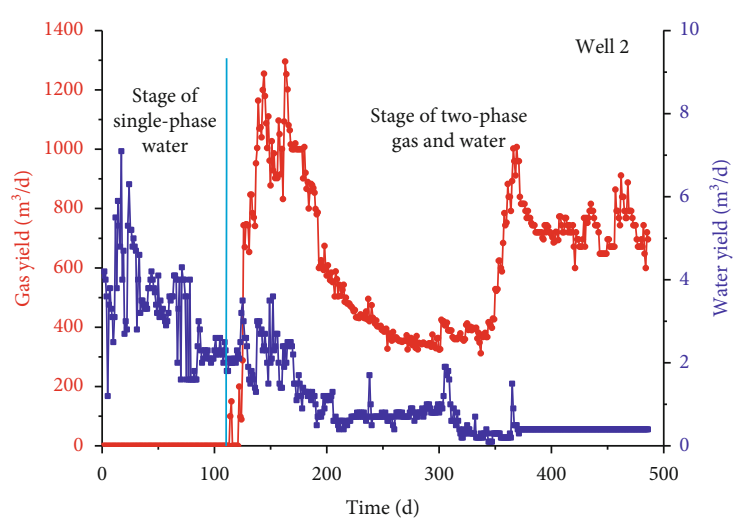

(b1)

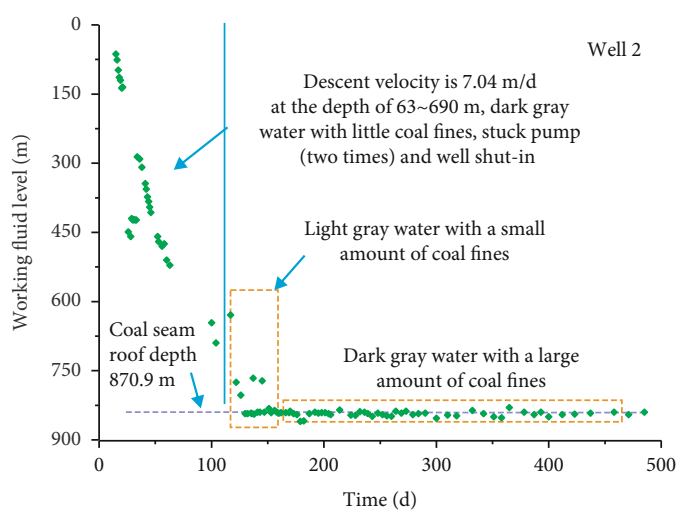

(b2)

Figure 26: Production profiles of Well 1 (a1, a2) and Well 2 (b1, b2) in the Zhengzhuang area of southern Qinshui Basin, China (modified from Liu et al. [49]).

the decrease of backpressure (wellhead compression and line pressure decreases) (Figure 25). Two CBM production wells in the Zhengzhuang area of southern Qinshui Basin are compared. The drainage rate of Well 1 is relatively slow $(2.89 \mathrm{~m} / \mathrm{d})$ in the single-phase water stage, and the CBM production quickly increases to its peak with a higher value $\left(\sim 4000 \mathrm{~m}^{3} / \mathrm{d}\right)$ and shows a long stable production period of $\sim 1200$ days (Figures 26(a1) and 26(a2)). In comparison, the drainage rate of Well 2 is fast $(7.04 \mathrm{~m} / \mathrm{d})$ in the single-phase water stage, and the CBM production decreases rapidly after reaching the peak value $\left(\sim 1200 \mathrm{~m}^{3} / \mathrm{d}\right)$ and has a short stable production period ( $\sim 100$ days) (Figures 26(b1) and 26(b2)). This indicates that the relative low drainage rate can flush coal fines so that it cannot block pore-fractures; thus, it improves CBM production. In comparison, the fast drainage rate can create new coal fines that may block the effective seepage paths and the wellbore area, which is not conducive to CBM production [49]. Therefore, the flow velocity of gas and water in coal reservoirs has a significant influence on the production characteristics of a CBM well [138].

\section{Summary and Conclusions}

The occurrence and transport characteristics of fluids (CBM and water) in a pore-fracture system of coal reservoirs have great significance for understanding the CBM production patterns and enhancing CBM recovery. This paper has reviewed and summarized several important aspects related to the fluid performance in coal reservoirs: (1) the component characteristics of CBM and the physical properties of fluids in coal reservoirs; (2) different characterization methods of the pore-fracture structure and the characteristics and modelling of fluid occurrence and transport in coal reservoirs; (3) the influencing factors of CBM adsorption/desorption and diffusion behaviors and the fluid seepage process; and (4) the implications of fluid occurrence and transport in coal reservoirs for CBM production. Moreover, although different methods have been constructed and used to characterize the fluid performance in coal reservoirs, there are still some key scientific problems to be investigated in future studies: (1) the control mechanism of the microscopic dynamics of fluids on CBM enrichment and storage under complex geological conditions; (2) the need for increasing the CBM desorption/seepage rate in coal reservoirs and clarifying its coupling effect with the evolution of geological structure; and (3) the synergistic effect of multiple spaces (pore-fracture system), multilevel flow fields (diffusion field, seepage field, and laminar flow-turbulence field), and multiphase flow (multiphase gas, water, and coal fines) in coal reservoirs. 


\section{Nomenclature}

$\begin{array}{ll}b: & \text { the "Klinkenberg coefficient" } \\ b_{\mathrm{He}}: & \text { the Klinkenberg coefficient of helium } \\ b_{\mathrm{Me}}: & \text { the Klinkenberg coefficient of helium } \\ k_{0}: & \text { the absolute permeability } \\ k(\text { methane) }: & \text { the measured permeability using methane } \\ {[K]:} & \text { the permeability tensor } \\ M: & \text { the fluid molecular weight } \\ P: & \text { the free gas pressure in the actual state }(\mathrm{MPa}) \\ P_{0}: & \text { the free gas pressure in the standard state } \\ P_{m}: & \text { (MPa) } \\ R: & \text { the mean gas pressure } \\ T: & \text { the free gas temperature in the actual state }(\mathrm{K}) \\ T_{0}: & \text { the free gas temperature in the standard state } \\ V: & \text { the free gas volume in the actual state }\left(\mathrm{m}^{3}\right) \\ V_{\mathrm{g}}: & \text { the free gas volume in the standard state }\left(\mathrm{m}^{3}\right) \\ \vec{V}: & \text { the CBM seepage velocity } \\ w: & \text { the flow path width } \\ Z: & \text { the gas compression factor } \\ \nabla: & \text { the Hamiltonian } \\ \mu: & \text { the fluid viscosity } \\ \mathrm{He}: & \text { helium } \\ M e: & \text { methane } \\ g: & \text { the gas } \\ m: & \text { mean } \\ 0: & \text { Standard state. }\end{array}$

\section{Conflicts of Interest}

The authors declare that they have no conflicts of interest.

\section{Acknowledgments}

This research was funded by the National Natural Science Foundation of China (grant nos. 41830427, 41922016, 41772160, and 41902165).

\section{References}

[1] S. F. Greb, W. A. DiMichele, and R. A. Gastaldo, "Evolution and importance of wetlands in earth history," Special Papers-Geological Society of America, vol. 399, 2006.

[2] D. Lv, Z. Li, D. Wang et al., "Sedimentary model of coal and shale in the Paleogene Lijiaya Formation of the Huangxian Basin: insight from petrological and geochemical characteristics of coal and shale," Energy \& Fuels, vol. 33, no. 11, pp. 10442-10456, 2019.

[3] D. Lv, Y. Song, L. Shi, Z. Wang, P. Cong, and A. T. van Loon, "The complex transgression and regression history of the northern margin of the Palaeogene Tarim Sea (NW China), and implications for potential hydrocarbon occurrences," Marine and Petroleum Geology, vol. 112, article 104041, 2020.

[4] T. Olsen, G. Brenize, and T. Frenzel, "Improvement processes for coalbed natural gas completion and stimulation," in SPE Annual Technical Conference and Exhibition, Society of Petroleum Engineers, 2003.
[5] T. A. Moore, "Coalbed methane: a review," International Journal of Coal Geology, vol. 101, pp. 36-81, 2012.

[6] V. N. Romanov, T. B. Hur, J. J. Fazio, B. H. Howard, and G. A. Irdi, "Comparison of high-pressure $\mathrm{CO}_{2}$ sorption isotherms on Central Appalachian and San Juan Basin coals," International Journal of Coal Geology, vol. 118, pp. 89-94, 2013.

[7] J. C. Pashin, P. E. Clark, M. R. McIntyre-Redden et al., "SECARB $\mathrm{CO}_{2}$ injection test in mature coalbed methane reservoirs of the Black Warrior Basin, Blue Creek Field, Alabama," International Journal of Coal Geology, vol. 144-145, pp. 71-87, 2015.

[8] R. Sander, L. D. Connell, M. Camilleri, and Z. Pan, " $\mathrm{CH}_{4}$, $\mathrm{CO}_{2}, \mathrm{~N}_{2}$ diffusion in Bowen Basin (Australia) coal: relationship between sorption kinetics of coal core and crushed coal particles," Journal of Natural Gas Science and Engineering, vol. 81, article 103468, 2020.

[9] Y. Tang, F. Gu, X. Wu, H. Ye, Y. Yu, and M. Zhong, "Coalbed methane accumulation conditions and enrichment models of Walloon coal measure in the Surat Basin, Australia," Natural Gas Industry B, vol. 5, no. 3, pp. 235-244, 2018.

[10] Z. Li, Evolution of Pore-Fractures of Coal Reservoir and Its Impact on CBM Microcosmic Flow, China University of Geosciences (Beijing), Beijing, 2018.

[11] S. Tao, Z. Pan, S. Tang, and S. Chen, "Current status and geological conditions for the applicability of CBM drilling technologies in China: a review," International Journal of Coal Geology, vol. 202, pp. 95-108, 2019.

[12] S. Tao, D. Tang, H. Xu, L. Gao, and Y. Fang, "Factors controlling high-yield coalbed methane vertical wells in the Fanzhuang Block, Southern Qinshui Basin," International Journal of Coal Geology, vol. 134-135, pp. 38-45, 2014.

[13] Y. Meng, D. Tang, H. Xu, C. Li, L. Li, and S. Meng, "Geological controls and coalbed methane production potential evaluation: a case study in Liulin area, eastern Ordos Basin, China," Journal of Natural Gas Science and Engineering, vol. 21, pp. 95-111, 2014.

[14] S. Tao, Z. Pan, S. Chen, and S. Tang, "Coal seam porosity and fracture heterogeneity of marcolithotypes in the Fanzhuang Block, southern Qinshui Basin, China," Journal of Natural Gas Science and Engineering, vol. 66, pp. 148-158, 2019.

[15] S. Tao, S. Chen, and Z. Pan, "Current status, challenges, and policy suggestions for coalbed methane industry development in China: a review," Energy Science \& Engineering, vol. 7, no. 4, pp. 1059-1074, 2019.

[16] J. R. Levine, Coalification: The Evolution of Coal as Source Rock and Reservoir Rock for Oil and Gas: Chapter 3, AAPG Special Volumes, 1993.

[17] R. Bustin and C. Clarkson, "Geological controls on coalbed methane reservoir capacity and gas content," International Journal of Coal Geology, vol. 38, no. 1-2, pp. 3-26, 1998.

[18] C. Ö. Karacan, "Swelling-induced volumetric strains internal to a stressed coal associated with $\mathrm{CO}_{2}$ sorption," International Journal of Coal Geology, vol. 72, no. 3-4, pp. 209-220, 2007.

[19] Z. Li, D. Liu, Y. Cai, Y. Wang, and J. Teng, "Adsorption pore structure and its fractal characteristics of coals by $\mathrm{N}_{2}$ adsorption/desorption and FESEM image analyses," Fuel, vol. 257, article 116031, 2019.

[20] J. Warren and P. J. Root, "The behavior of naturally fractured reservoirs," Society of Petroleum Engineers Journal, vol. 3, no. 3, pp. 245-255, 1963. 
[21] Y. Cai, D. Liu, Z. Pan, Y. Yao, J. Li, and Y. Qiu, "Pore structure and its impact on $\mathrm{CH}_{4}$ adsorption capacity and flow capability of bituminous and subbituminous coals from Northeast China," Fuel, vol. 103, pp. 258-268, 2013.

[22] I. Palmer and J. Mansoori, "How permeability depends on stress and pore pressure in coalbeds: a new model," in Paper presented at the SPE Annual Technical Conference and Exhibition, pp. 539-544, Denver, Colorado, 1996, Society of Petroleum Engineers.

[23] J. D. St George and M. Barakat, "The change in effective stress associated with shrinkage from gas desorption in coal," International Journal of Coal Geology, vol. 45, no. 2-3, pp. 105113, 2001.

[24] S. Durucan, M. Ahsanb, and J.-Q. Shia, "Matrix shrinkage and swelling characteristics of European coals," Energy Procedia, vol. 1, no. 1, pp. 3055-3062, 2009.

[25] J. R. Seidle and L. Huitt, "Experimental measurement of coal matrix shrinkage due to gas desorption and implications for cleat permeability increases," Paper presented at the International Meeting on Petroleum Engineering, 1995, pp. 575582, Beijing, China, 1995, Society of Petroleum Engineers.

[26] R. M. Flores, Coal and Coalbed Gas: Fueling the Future, Newnes, 2013.

[27] R. M. Barrer, Diffusion in and through Solid [M], Cambridge University Press, 1951.

[28] M. S. A. Perera, P. Ranjith, S. Choi, D. Airey, and P. Weniger, "Estimation of gas adsorption capacity in coal: a review and an analytical study," International Journal of Coal Preparation and Utilization, vol. 32, no. 1, pp. 25-55, 2012.

[29] P. C. Hackley, E. H. Guevara, T. F. Hentz, and R. W. Hook, "Thermal maturity and organic composition of Pennsylvanian coals and carbonaceous shales, north-central Texas: implications for coalbed gas potential," International Journal of Coal Geology, vol. 77, no. 3-4, pp. 294-309, 2009.

[30] Y. Cai, D. Liu, Y. Yao, J. Li, and Y. Qiu, "Geological controls on prediction of coalbed methane of No. 3 coal seam in Southern Qinshui Basin, North China," International Journal of Coal Geology, vol. 88, no. 2-3, pp. 101-112, 2011.

[31] D. D. Rice, "Composition and origins of coalbed gas," Hydrocarbons from coal: AAPG Studies in Geology, vol. 38, no. 1, pp. 159-184, 1993.

[32] P. Humez, B. Mayer, J. Ing et al., "Occurrence and origin of methane in groundwater in Alberta (Canada): gas geochemical and isotopic approaches," Science of the Total Environment, vol. 541, pp. 1253-1268, 2016.

[33] B. R. Stanmore, Y. He, E. T. White, B. Firth, G. O'Brien, and M. O'Brien, "Porosity and water retention in coarse coking coal," Fuel, vol. 76, no. 3, pp. 215-222, 1997.

[34] M. Švábová, Z. Weishauptová, and O. Přibyl, "Water vapour adsorption on coal," Fuel, vol. 90, no. 5, pp. 1892-1899, 2011.

[35] J.-Q. Shi and S. Durucan, "Gas storage and flow in coalbed reservoirs: implementation of a bidisperse pore model for gas diffusion in coal matrix," in Paper presented at the SPE Annual Technical Conference and Exhibition, pp. 169-175, Denver, Colorado, 2003, Society of Petroleum Engineers.

[36] Y. Lu, D. Liu, Y. Cai, Q. Li, and Q. Jia, "Pore-fractures of coalbed methane reservoir restricted by coal facies in Sangjiang-Muling coal-bearing basins, northeast China," Energies, vol. 13, no. 5, p. 1196, 2020.
[37] S. Yu, J. Bo, L. Ming, H. Chenliang, and X. Shaochun, "A review on pore-fractures in tectonically deformed coals," Fuel, vol. 278, article 118248, 2020.

[38] S. Brunauer, P. H. Emmett, and E. Teller, "Adsorption of gases in multimolecular layers," Journal of the American Chemical Society, vol. 60, no. 2, pp. 309-319, 1938.

[39] E. P. Barrett, L. G. Joyner, and P. P. Halenda, "The determination of pore volume and area distributions in porous substances. I. Computations from nitrogen isotherms," Journal of the American Chemical Society, vol. 73, no. 1, pp. 373380, 1951.

[40] E. W. Washburn, “The dynamics of capillary flow," Physical Review, vol. 17, no. 3, pp. 273-283, 1921.

[41] G. Wang, J. Shen, S. Liu, C. Jiang, and X. Qin, "Three-dimensional modeling and analysis of macro-pore structure of coal using combined X-ray CT imaging and fractal theory," International Journal of Rock Mechanics and Mining Sciences, vol. 123, article 104082, 2019.

[42] Y. Yao, D. Liu, Y. Che, D. Tang, S. Tang, and W. Huang, "Petrophysical characterization of coals by low-field nuclear magnetic resonance (NMR)," Fuel, vol. 89, no. 7, pp. 1371-1380, 2010.

[43] Y. Yao and D. Liu, "Comparison of low-field NMR and mercury intrusion porosimetry in characterizing pore size distributions of coals,” Fuel, vol. 95, pp. 152-158, 2012.

[44] Y. Yao, D. Liu, and S. Xie, "Quantitative characterization of methane adsorption on coal using a low-field NMR relaxation method," International Journal of Coal Geology, vol. 131, pp. 32-40, 2014.

[45] S. Chen, D. Tang, S. Tao, X. Ji, and H. Xu, "Fractal analysis of the dynamic variation in pore-fracture systems under the action of stress using a low-field NMR relaxation method: an experimental study of coals from western Guizhou in China," Journal of Petroleum Science and Engineering, vol. 173, pp. 617-629, 2019.

[46] J. Zhang, C. Wei, W. Ju et al., "Stress sensitivity characterization and heterogeneous variation of the pore-fracture system in middle-high rank coals reservoir based on NMR experiments," Fuel, vol. 238, pp. 331-344, 2019.

[47] X. Li, Y. Kang, and M. Haghighi, "Investigation of pore size distributions of coals with different structures by nuclear magnetic resonance (NMR) and mercury intrusion porosimetry (MIP)," Measurement, vol. 116, pp. 122-128, 2018.

[48] B. Kwiecińska, S. Pusz, and B. J. Valentine, "Application of electron microscopy TEM and SEM for analysis of coals, organic-rich shales and carbonaceous matter," International Journal of Coal Geology, vol. 211, article 103203, 2019.

[49] Z. Liu, D. Liu, Y. Cai, and Z. Pan, "The impacts of flow velocity on permeability and porosity of coals by core flooding and nuclear magnetic resonance: implications for coalbed methane production," Journal of Petroleum Science and Engineering, vol. 171, pp. 938-950, 2018.

[50] S. Zhao, Y. Li, Y. Wang, Z. Ma, and X. Huang, "Quantitative study on coal and shale pore structure and surface roughness based on atomic force microscopy and image processing," Fuel, vol. 244, pp. 78-90, 2019.

[51] Z. Li, D. Liu, Y. Cai, P. Ranjith, and Y. Yao, "Multi-scale quantitative characterization of 3-D pore-fracture networks in bituminous and anthracite coals using FIBSEM tomography and X-ray $\mu$-CT," Fuel, vol. 209, pp. $43-53,2017$. 
[52] Q. Li, D. Liu, Y. Cai, B. Zhao, Y. Qiu, and Y. Zhou, "Scalespan pore structure heterogeneity of high volatile bituminous coal and anthracite by FIB-SEM and X-ray $\mu$-CT," Journal of Natural Gas Science and Engineering, vol. 81, article 103443, 2020.

[53] S. Mazumder, K.-H. Wolf, K. Elewaut, and R. Ephraim, "Application of X-ray computed tomography for analyzing cleat spacing and cleat aperture in coal samples," International Journal of Coal Geology, vol. 68, no. 3-4, pp. 205-222, 2006.

[54] Y. Zhao, Y. Sun, S. Liu, Z. Chen, and L. Yuan, "Pore structure characterization of coal by synchrotron radiation nano-CT," Fuel, vol. 215, pp. 102-110, 2018.

[55] A. Golab, C. R. Ward, A. Permana, P. Lennox, and P. Botha, "High-resolution three-dimensional imaging of coal using microfocus X-ray computed tomography, with special reference to modes of mineral occurrence," International Journal of Coal Geology, vol. 113, pp. 97-108, 2013.

[56] S. Day, R. Sakurovs, and S. Weir, "Supercritical gas sorption on moist coals," International Journal of Coal Geology, vol. 74, no. 3-4, pp. 203-214, 2008.

[57] G. Wang, X. Wei, K. Wang, P. Massarotto, and V. Rudolph, "Sorption-induced swelling/shrinkage and permeability of coal under stressed adsorption/desorption conditions," International Journal of Coal Geology, vol. 83, no. 1, pp. 46-54, 2010.

[58] G. Ceglarska-Stefańska and K. Zarębska, "The competitive sorption of $\mathrm{CO}_{2}$ and $\mathrm{CH}_{4}$ with regard to the release of methane from coal," Fuel Processing Technology, vol. 77-78, pp. 423-429, 2002.

[59] R. P. Benedict, Fundamentals of Temperature, Pressure, and Flow Measurements, John Wiley \& Sons, 1984.

[60] S. Tamamura, T. Murakami, A. Ueno et al., "Formation of coalbed methane and water-dissolved gas in Kushiro Coal Mine, Japan, based on isotopic compositions of gas, groundwater, and calcite," International Journal of Coal Geology, vol. 229, article 103577, 2020.

[61] A. Busch, Y. Gensterblum, and B. M. Krooss, "Methane and $\mathrm{CO}_{2}$ sorption and desorption measurements on dry Argonne premium coals: pure components and mixtures," International Journal of Coal Geology, vol. 55, no. 2-4, pp. 205-224, 2003.

[62] J. Fitzgerald, Z. Pan, M. Sudibandriyo, R. L. Robinson, Jr, K. Gasem, and S. Reeves, "Adsorption of methane, nitrogen, carbon dioxide and their mixtures on wet Tiffany coal," Fuel, vol. 84, no. 18, pp. 2351-2363, 2005.

[63] J.-S. Bae and S. K. Bhatia, "High-pressure adsorption of methane and carbon dioxide on coal," Energy \& Fuels, vol. 20, no. 6, pp. 2599-2607, 2006.

[64] R. Anderson, J. Bayer, and L. Hofer, Equilibrium Sorption Studies of Methane on Pittsburgh Seam and Pocahontas No. 3 Seam Coal, ACS Publications, 1966.

[65] S. Zheng, Y. Yao, D. Liu, Y. Cai, and Y. Liu, "Quantitative characterization of multiphase methane in coals using the NMR relaxation method," Journal of Petroleum Science and Engineering, vol. 198, article 108148, 2021.

[66] F. Wang, Y. Yao, Z. Wen, Q. Sun, and X. Yuan, "Effect of water occurrences on methane adsorption capacity of coal: a comparison between bituminous coal and anthracite coal," Fuel, vol. 266, article 117102, 2020.

[67] K. Winter and H. Janas, Gas emission characteristics of coal and methods of determining the desorbable gas content by means of desorbometers [C], XIV International Conference of Coal Mine Safety Research, 1996.

[68] T. Yin, D. Liu, Y. Cai, Z. Liu, and M. Gutierrez, "A new constructed macromolecule-pore structure of anthracite and its related gas adsorption: a molecular simulation study," International Journal of Coal Geology, vol. 220, article 103415, 2020.

[69] I. Langmuir, "The adsorption of gases on plane surfaces of glass, mica and platinum," Journal of the American Chemical Society, vol. 40, no. 9, pp. 1361-1403, 1918.

[70] J. I. Joubert, C. T. Grein, and D. Bienstock, "Sorption of methane in moist coal," Fuel, vol. 52, no. 3, pp. 181-185, 1973.

[71] M. Polanyi, "The potential theory of adsorption," Science, vol. 141, no. 3585, pp. 1010-1013, 1963.

[72] A. Erdem-Şenatalar, M. Tatller, and A. Sirkecioğlu, "The relationship of the geometric factor in the Dubinin-Astakhov isotherm equation with the fractal dimension," Colloids and Surfaces A: Physicochemical and Engineering Aspects, vol. 173, no. 1-3, pp. 51-59, 2000.

[73] T. Meguro, N. Torikai, N. Watanabe, and I. Tomizuka, "Application of the Dubinin-Radushkevich equation to iodine adsorption by activated carbons from aqueous solution," Carbon, vol. 23, no. 2, pp. 137-140, 1985.

[74] S. Chen and R. Yang, "Theoretical basis for the potential theory adsorption isotherms. The Dubinin-Radushkevich and Dubinin-Astakhov equations," Langmuir, vol. 10, no. 11, pp. 4244-4249, 1994.

[75] C. Clarkson and R. Bustin, "The effect of pore structure and gas pressure upon the transport properties of coal: a laboratory and modeling study. 1 . Isotherms and pore volume distributions," Fuel, vol. 78, no. 11, pp. 1333-1344, 1999.

[76] G. W. Scherer, "Use of the Adam-Gibbs equation in the analysis of structural relaxation," Journal of the American Ceramic Society, vol. 67, no. 7, pp. 504-511, 1984.

[77] G. J. Bell and K. C. Rakop, "Hysteresis of methane/coal sorption isotherms," in Paper presented at the SPE Annual Technical Conference and Exhibition, pp. 29-34, New Orleans, Louisiana, 1986, Society of Petroleum Engineers.

[78] C. Clarkson and R. Bustin, "The effect of pore structure and gas pressure upon the transport properties of coal: a laboratory and modeling study. 2. Adsorption rate modeling," Fuel, vol. 78, no. 11, pp. 1345-1362, 1999.

[79] E. Airey, "Gas emission from broken coal. An experimental and theoretical investigation," International Journal of Rock Mechanics and Mining Science and Geomechanics Abstracts, vol. 5, no. 6, pp. 475-494, 1968.

[80] M. Pillalamarry, S. Harpalani, and S. Liu, "Gas diffusion behavior of coal and its impact on production from coalbed methane reservoirs," International Journal of Coal Geology, vol. 86, no. 4, pp. 342-348, 2011.

[81] Z. Du, Q. Huang, J. Guo, F. Gao, and Y. Du, "The occurrence of nano- and micro-scale pores and their controls on the selective migration of gases in the coals of different ranks," Fuel, vol. 264, article 116748, 2020.

[82] D. M. Smith and F. L. Williams, "Diffusional effects in the recovery of methane from coalbeds," Society of Petroleum Engineers Journal, vol. 24, no. 5, pp. 529-535, 1984.

[83] J. Crank, The Mathematics of Diffusion, Oxford University Press, 1979.

[84] E. Ruckenstein, A. Vaidyanathan, and G. Youngquist, "Sorption by solids with bidisperse pore structures," Chemical Engineering Science, vol. 26, no. 9, pp. 1305-1318, 1971. 
[85] Z. Pan, L. D. Connell, M. Camilleri, and L. Connelly, "Effects of matrix moisture on gas diffusion and flow in coal," Fuel, vol. 89, no. 11, pp. 3207-3217, 2010.

[86] Z. Li, D. Liu, Y. Cai, and Y. Shi, "Investigation of methane diffusion in low-rank coals by a multiporous diffusion model," Journal of Natural Gas Science and Engineering, vol. 33, pp. 97-107, 2016.

[87] A. Fick, "On liquid diffusion," Journal of Membrane Science, vol. 100, no. 1, pp. 33-38, 1995.

[88] G. G. Wang, X. Zhang, X. Wei, X. Fu, B. Jiang, and Y. Qin, “A review on transport of coal seam gas and its impact on coalbed methane recovery," Frontiers of Chemical Science and Engineering, vol. 5, no. 2, pp. 139-161, 2011.

[89] R. Krishna and J. Wesselingh, "The Maxwell-Stefan approach to mass transfer," Chemical Engineering Science, vol. 52, no. 6, pp. 861-911, 1997.

[90] S. Whitaker, "Flow in porous media I: a theoretical derivation of Darcy's law," Transport in Porous Media, vol. 1, no. 1, pp. 3-25, 1986.

[91] Z. Pan and L. D. Connell, "Modelling permeability for coal reservoirs: a review of analytical models and testing data," International Journal of Coal Geology, vol. 92, pp. 1-44, 2012.

[92] Y. Jing, A. Rabbani, R. T. Armstrong, J. Wang, and P. Mostaghimi, "A hybrid fracture-micropore network model for multiphysics gas flow in coal," Fuel, vol. 281, article 118687, 2020.

[93] L. Fan and S. Liu, "Fluid-dependent shear slip behaviors of coal fractures and their implications on fracture frictional strength reduction and permeability evolutions," International Journal of Coal Geology, vol. 212, article 103235, 2019.

[94] J. R. Levine, "Model study of the influence of matrix shrinkage on absolute permeability of coal bed reservoirs," Geological Society, London, Special Publications, vol. 109, no. 1, pp. 197-212, 1996.

[95] H.-H. Liu and J. Rutqvist, "A new coal-permeability model: internal swelling stress and fracture-matrix interaction," Transport in Porous Media, vol. 82, no. 1, pp. 157-171, 2010.

[96] J. Zhang, Q. Feng, X. Zhang, S. Wen, and Y. Zhai, "Relative permeability of coal: a review," Transport in Porous Media, vol. 106, no. 3, pp. 563-594, 2015.

[97] S. Harpalani and A. Schraufnagel, "Measurement of parameters impacting methane recovery from coal seams," International Journal of Mining and Geological Engineering, vol. 8, no. 4, pp. 369-384, 1990.

[98] C. R. Clarkson, M. R. Rahmanian, A. Kantzas, and K. Morad, "Relative permeability of CBM reservoirs: controls on curve shape," in Paper presented at the Canadian Unconventional Resources and International Petroleum Conference, Calgary, Alberta, Canada, 2010.

[99] P. J. Crosdale, B. B. Beamish, and M. Valix, "Coalbed methane sorption related to coal composition," International Journal of Coal Geology, vol. 35, no. 1-4, pp. 147-158, 1998.

[100] M. Mukherjee and S. Misra, "A review of experimental research on Enhanced Coal Bed Methane (ECBM) recovery via $\mathrm{CO}_{2}$ sequestration," Earth-Science Reviews, vol. 179, pp. 392-410, 2018.

[101] A. Saghafi, M. Faiz, and D. Roberts, " $\mathrm{CO}_{2}$ storage and gas diffusivity properties of coals from Sydney Basin, Australia," International Journal of Coal Geology, vol. 70, no. 1-3, pp. 240-254, 2007.
[102] J. H. Levy, S. J. Day, and J. S. Killingley, "Methane capacities of Bowen Basin coals related to coal properties," Fuel, vol. 76, no. 9, pp. 813-819, 1997.

[103] M. Faiz, N. Aziz, A. Hutton, and B. Jones, "Porosity and gas sorption capacity of some eastern Australian coals in relation to coal rank and composition," in Coalbed Methane Symposium, vol. 19, p. 21, Townsville, 1992.

[104] M. N. Lamberson and R. M. Bustin, "Coalbed methane characteristics of Gates Formation coals, northeastern British Columbia: effect of maceral composition," AAPG Bulletin, vol. 77, no. 12, pp. 2062-2076, 1993.

[105] Y. Ju, B. Jiang, Q. Hou, Y. Tan, G. Wang, and W. Xiao, "Behavior and mechanism of the adsorption/desorption of tectonically deformed coals," Chinese Science Bulletin, vol. 54, no. 1, pp. 88-94, 2009.

[106] Y. Cheng and Z. Pan, "Reservoir properties of Chinese tectonic coal: a review," Fuel, vol. 260, article 116350, 2020.

[107] P. J. Crosdale, T. A. Moore, and T. E. Mares, "Influence of moisture content and temperature on methane adsorption isotherm analysis for coals from a low-rank, biogenicallysourced gas reservoir," International Journal of Coal Geology, vol. 76, no. 1-2, pp. 166-174, 2008.

[108] J. Pan, Q. Hou, Y. Ju, H. Bai, and Y. Zhao, "Coalbed methane sorption related to coal deformation structures at different temperatures and pressures," Fuel, vol. 102, pp. 760-765, 2012.

[109] H. Liu, J. Mou, and Y. Cheng, "Impact of pore structure on gas adsorption and diffusion dynamics for long-flame coal," Journal of Natural Gas Science and Engineering, vol. 22, pp. 203-213, 2015.

[110] D. Charrière, Z. Pokryszka, and P. Behra, "Effect of pressure and temperature on diffusion of $\mathrm{CO}_{2}$ and $\mathrm{CH}_{4}$ into coal from the Lorraine basin (France)," International Journal of Coal Geology, vol. 81, no. 4, pp. 373-380, 2010.

[111] J. Cai, S. Yang, X. Hu et al., "Risk assessment of dynamic disasters induced by gas injection displacement in coal seams," Process Safety and Environmental Protection, vol. 128, pp. 41-49, 2019.

[112] C. Laxminarayana and P. J. Crosdale, "Controls on methane sorption capacity of Indian coals," AAPG Bulletin, vol. 86, no. 2, pp. 201-212, 2002.

[113] H. J. Kim, Y. Shi, J. He, H.-H. Lee, and C.-H. Lee, “Adsorption characteristics of $\mathrm{CO}_{2}$ and $\mathrm{CH}_{4}$ on dry and wet coal from subcritical to supercritical conditions," Chemical Engineering Journal, vol. 171, no. 1, pp. 45-53, 2011.

[114] Z. Wang, Y. Cheng, L. Wang et al., "Characterization of pore structure and the gas diffusion properties of tectonic and intact coal: implications for lost gas calculation," Process Safety and Environmental Protection, vol. 135, pp. 12-21, 2020.

[115] X. Wang, D. Zhang, E. Su et al., "Pore structure and diffusion characteristics of intact and tectonic coals: implications for selection of $\mathrm{CO}_{2}$ geological sequestration site," Journal of Natural Gas Science and Engineering, vol. 81, article 103388, 2020.

[116] X. Cui, R. M. Bustin, and G. Dipple, "Selective transport of $\mathrm{CO}_{2}, \mathrm{CH}_{4}$, and $\mathrm{N}_{2}$ in coals: insights from modeling of experimental gas adsorption data," Fuel, vol. 83, no. 3, pp. 293-303, 2004.

[117] T. Zhang, G. S. Ellis, S. C. Ruppel, K. Milliken, and R. Yang, "Effect of organic-matter type and thermal maturity on 
methane adsorption in shale-gas systems," Organic Geochemistry, vol. 47, pp. 120-131, 2012.

[118] S. Mazumder, W.-J. Plug, and H. Bruining, "Capillary pressure and wettability behavior of coal-water-carbon dioxide system," in Paper presented at the SPE Annual Technical Conference and Exhibition, Denver, Colorado, 2003Society of Petroleum Engineers.

[119] A. Busch, Y. Gensterblum, B. M. Krooss, and R. Littke, "Methane and carbon dioxide adsorption-diffusion experiments on coal: upscaling and modeling," International Journal of Coal Geology, vol. 60, no. 2-4, pp. 151-168, 2004.

[120] Y. Cai, Z. Pan, D. Liu et al., "Effects of pressure and temperature on gas diffusion and flow for primary and enhanced coalbed methane recovery," Energy Exploration \& Exploitation, vol. 32, no. 4, pp. 601-619, 2014.

[121] H. Xu, D. Tang, J. Zhao, S. Li, and S. Tao, "A new laboratory method for accurate measurement of the methane diffusion coefficient and its influencing factors in the coal matrix," Fuel, vol. 158, pp. 239-247, 2015.

[122] T. Ertekin, G. A. King, and F. C. Schwerer, "Dynamic gas slippage: a unique dual-mechanism approach to the flow of gas in tight formations," SPE Formation Evaluation, vol. 1, no. 1, pp. 43-52, 1986.

[123] S. Durucan and J. Edwards, "The effects of stress and fracturing on permeability of coal," Mining Science and Technology, vol. 3, no. 3, pp. 205-216, 1986.

[124] X. Cui and R. M. Bustin, "Volumetric strain associated with methane desorption and its impact on coalbed gas production from deep coal seams," AAPG Bulletin, vol. 89, no. 9, pp. 1181-1202, 2005.

[125] C. R. McKee, A. C. Bumb, and R. A. Koenig, "Stress-dependent permeability and porosity of coal and other geologic formations," SPE Formation Evaluation, vol. 3, no. 1, pp. 81-91, 1988.

[126] L. Klinkenberg, "The permeability of porous media to liquids and gases," in Paper presented at the Drilling and Production Practice, pp. 200-213, New York, New York, 1941, OnePetro.

[127] R. Nazari Moghaddam and M. Jamiolahmady, "Fluid transport in shale gas reservoirs: simultaneous effects of stress and slippage on matrix permeability," International Journal of Coal Geology, vol. 163, pp. 87-99, 2016.

[128] J. Shi and S. Durucan, "Drawdown induced changes in permeability of coalbeds: a new interpretation of the reservoir response to primary recovery," Transport in Porous Media, vol. 56, no. 1, pp. 1-16, 2004.

[129] S. Harpalani, B. K. Prusty, and P. Dutta, "Methane/ $\mathrm{CO}_{2}$ sorption modeling for coalbed methane production and $\mathrm{CO}_{2}$ sequestration," Energy \& Fuels, vol. 20, no. 4, pp. 15911599, 2006.

[130] R. Sakurovs, S. Day, and S. Weir, "Relationships between the critical properties of gases and their high pressure sorption behavior on coals," Energy \& Fuels, vol. 24, no. 3, pp. 17811787, 2010.

[131] Y. Li, Y. Wang, J. Wang, and Z. Pan, "Variation in permeability during $\mathrm{CO}_{2}-\mathrm{CH}_{4}$ displacement in coal seams: part 1-experimental insights," Fuel, vol. 263, article 116666, 2020.

[132] Y. Li, D.-H. Zhou, W.-H. Wang, T.-X. Jiang, and Z.-J. Xue, "Development of unconventional gas and technologies adopted in China," Energy Geoscience, vol. 1, no. 1-2, pp. 55-68, 2020.
[133] A. A. Bhatti, A. Ismail, A. Raza et al., "Permeability prediction using hydraulic flow units and electrofacies analysis," Energy Geoscience, vol. 1, no. 1-2, pp. 81-91, 2020.

[134] C. Ö. Karacan, "Heterogeneous sorption and swelling in a confined and stressed coal during $\mathrm{CO}_{2}$ injection," Energy \& Fuels, vol. 17, no. 6, pp. 1595-1608, 2003.

[135] R. Sander, W. Allinson, L. Connell, and P. Neal, "Methodology to determine the economics of $\mathrm{CO}_{2}$ storage in coal seams with enhanced coalbed methane recovery," Energy Procedia, vol. 4, pp. 2129-2136, 2011

[136] S. Tao, D. Tang, H. Xu et al., "Fluid velocity sensitivity of coal reservoir and its effect on coalbed methane well productivity: a case of Baode Block, northeastern Ordos Basin, China," Journal of Petroleum Science and Engineering, vol. 152, pp. 229-237, 2017.

[137] L. Zhang, Z. Kou, H. Wang et al., "Performance analysis for a model of a multi-wing hydraulically fractured vertical well in a coalbed methane gas reservoir," Journal of Petroleum Science and Engineering, vol. 166, pp. 104-120, 2018.

[138] F. I. Syed, S. Neghabhan, and A. K. Dahaghi, "Unconventional EOR applications in unconventional hydrocarbon reservoirs-numerical trend analysis," Unconventional Resources, 2020.

[139] I. Gray, "Reservoir engineering in coal seams: part 1-the physical process of gas storage and movement in coal seams," SPE Reservoir Engineering, vol. 2, no. 1, pp. 28-34, 1987.

[140] J. Seidle, M. Jeansonne, and D. Erickson, “Application of matchstick geometry to stress dependent permeability in coals," in Paper presented at the SPE Rocky Mountain Regional Meeting, pp. 433-444, Casper, Wyoming, 1992, Society of Petroleum Engineers.

[141] S. Harpalani and G. Chen, "Estimation of changes in fracture porosity of coal with gas emission," Fuel, vol. 74, no. 10, pp. 1491-1498, 1995.

[142] A. Gilman and R. Beckie, "Flow of coal-bed methane to a gallery," Transport in Porous Media, vol. 41, no. 1, pp. 1-16, 2000.

[143] X. Cui, R. M. Bustin, and L. Chikatamarla, "Adsorptioninduced coal swelling and stress: implications for methane production and acid gas sequestration into coal seams," Journal of Geophysical Research - Solid Earth, vol. 112, no. B10, 2007.

[144] E. P. Robertson and R. L. Christiansen, "A permeability model for coal and other fractured, sorptive-elastic media," in SPE Eastern Regional Meeting,, 2006Society of Petroleum Engineers. 